\title{
REGIONAL HETEROGENEITY, GEOGRAPHY AND AGGLOMERATION EFFECTS IN EFFICIENCY ANALYSIS: THE CASE OF DAIRY FARMING IN EUROPE
}

\author{
Dissertation \\ to obtain the $\mathrm{Ph}$. D. degree \\ in the International Ph. D. Program for Agricultural Sciences in Göttingen (IPAG) \\ at the Faculty of Agricultural Sciences, \\ Georg-August-University Göttingen, Germany
}

presented by

Daniel Mauricio Castro Medina

born in Bogotá, Colombia

Göttingen, December 2014 
1. Name of the supervisor: Pr. Dr. Bernhard Brümmer

2. Name of the co-supervisor: Pr.Dr. Stephan v. Cramon-Taubadel

3. Name of a further member of the examination committee: Pr. Dr. Thomas Kneib

Date of dissertation: $12^{\text {th }}$ of February 2015 



\section{Acknowledgements}

Over the past four years, I have had the privilege of embarking on a very rewarding journey in my personal and professional life. Like all journeys, there have been memorable moments and frustrating ones. Now that the journey has come to its end, I have been left in no doubt that it was worth it. Thankfully, I have been surrounded by a group of amazing people who have accompanied me along the way: Not only those here with me in Germany, but also those at a distance who have inspired me and supported me to achieve my dreams and goals.

I would like to extend thanks to all those people who I left behind in my home country. Special thanks are due to my mother who has offered so much unconditional support. Thank you for believing in me and my dreams. Thank you for encouraging me to follow them. Most importantly, thank you for always being there for me. To my brother whose support and understanding have been crucial especially in the difficult moments. My father for his support and care.

On this side of the Atlantic, I am grateful to my supervisors Bernhard Brümmer, Stephan von-Cramon and Thomas Kneib whose help and support have made the conclusion of this work possible. I would especially like to express my gratitude to Bernhard Brümmer whose patience, support and guidance have been crucial to get to this point. I am also grateful to all my colleagues of the chair and especially to Jonathan Holtkamp, Tinoush Jamali, Tom Kopp, Mareike Holtkamp and Ioannis Skevas whose comments and help were always there when I needed them. In the RTG I would like to thank Barbara Strauß for all the help she gave me, especially at the beginning.

None of this would have been possible without the help and support of some of my professors back in Colombia and Spain. I would like to mention Andrés Rosas, Luisa Bernat and Nikolaos Georgantzis.

I would also like to thank the research students that contributed with their work on this project. They were not only contributors but some of them became very close friends. Thank you Cristina Romero, Tatiana Romero, Emma Paredes and José Ardura.

The list of friends that have been always there for me is endless. You have become family for me here; life in Göttingen without you would not have been the same. Cristina 
Romeo, Juan Pablo Lopez, Thelma Brenes, Tatiane Beduschi, Jennifer Wagner, Rodrigo Silva, Keno Henneke, Judy Romero, Adam Walker (thank you for your help editing this work), Angelica Blanco, Aneliese Schröder, Pascal Sauer, Ana María Vera. Thank you Olaf for all the support and patience. Those friends in Colombia and other places in the world that always thought I was crazy, but still supported me. Jenny Cárdenas, Carolina Sanabria, Carolina Mendoza, Lorena Torres, Laura Almanza, Andrés Parada, Oscar Camargo, Andrés Celis, Sylvia Aseneyba and Ludovic Masson.

Thanks to all of you who have contributed somehow to make this possible. 



\section{INDEX}

INDEX.

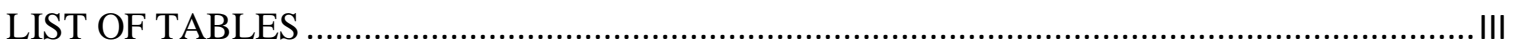

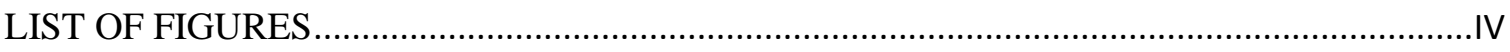

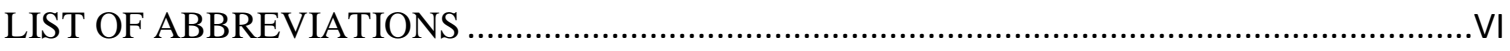

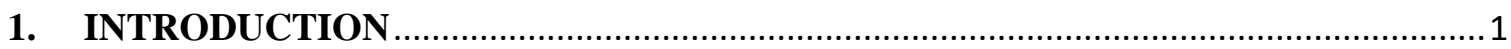

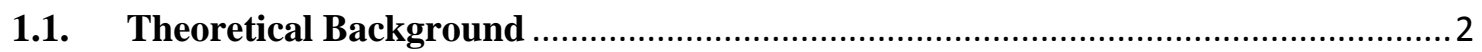

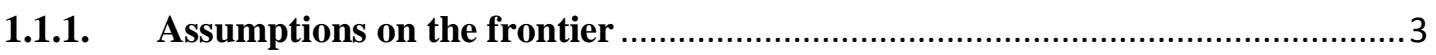

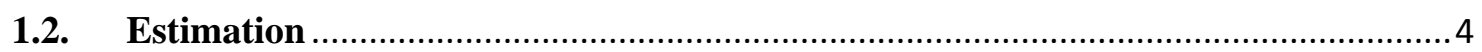

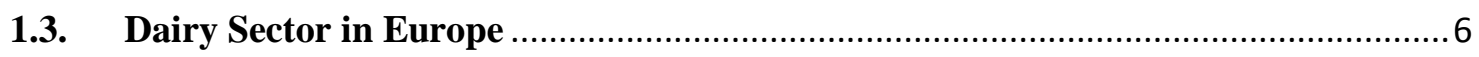

1.4. Regional heterogeneity and local agglomeration and their implication on efficiency

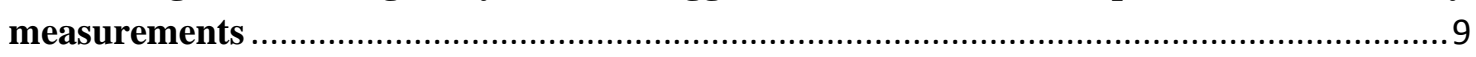

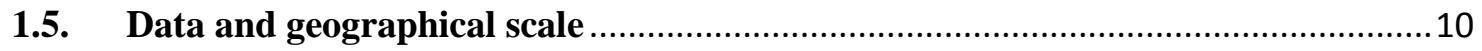

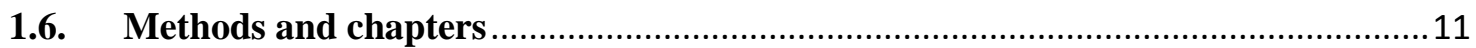

2. MODELING REGIONAL HETEROGENEITY IN STOCHASTIC FRONTIER: A

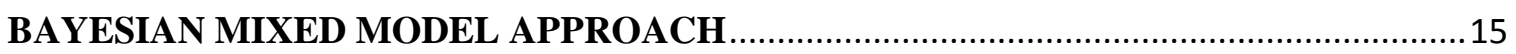

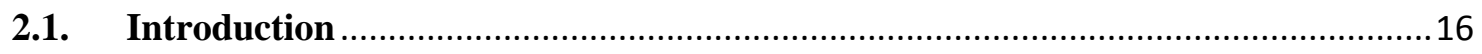

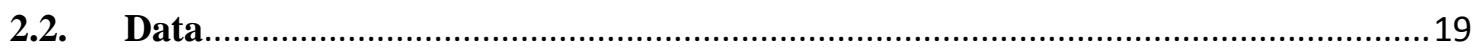

2.3. Farm location, source of regional heterogeneity ….............................................. 19

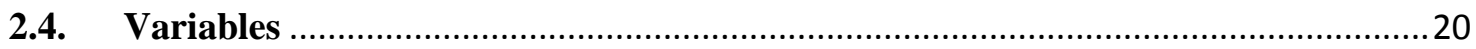

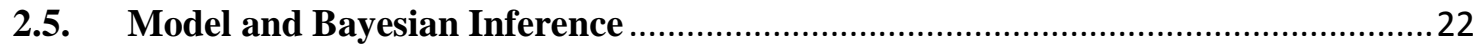

2.5.1. Regional heterogeneity through a mixed model ….........................................22

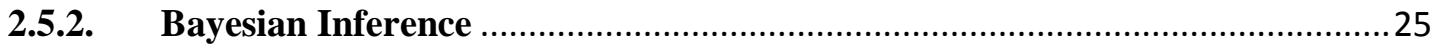

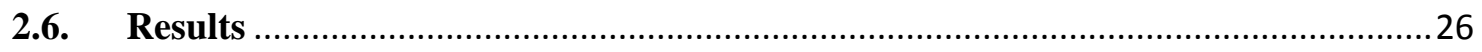

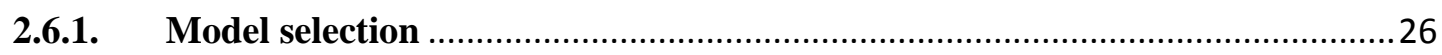

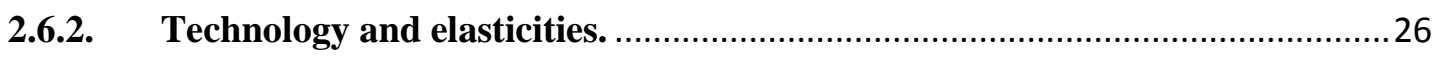

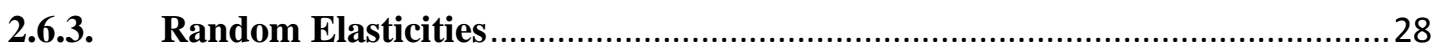

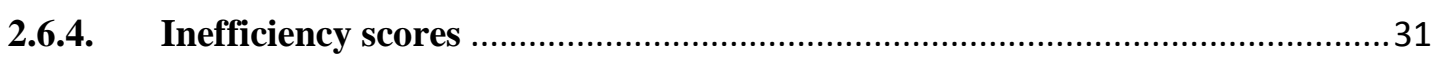

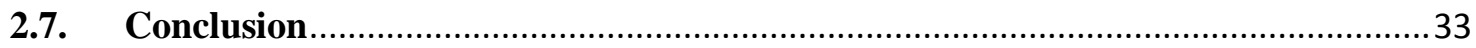

3. PRODUCTION HETEROGENEITY IN THE DAIRY SECTOR: A LATENT CLASS

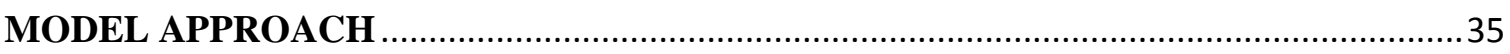

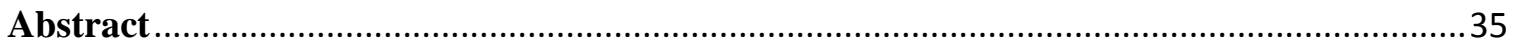

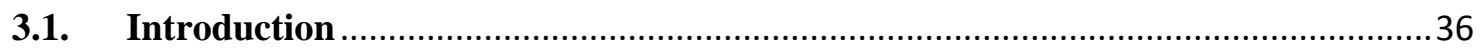

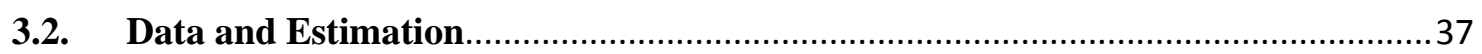




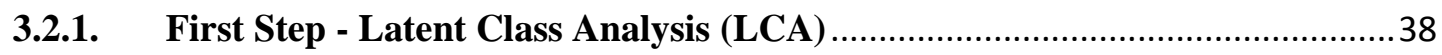

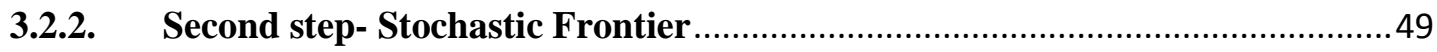

3.3. Total factor productivity growth decomposition (TFP) ......................................57

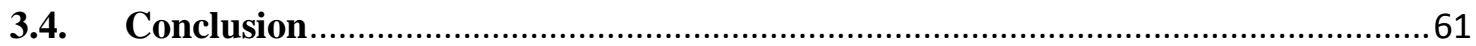

4. ECONOMIES OF AGGLOMERATION AND EXTERNALITIES IN THE DAIRY

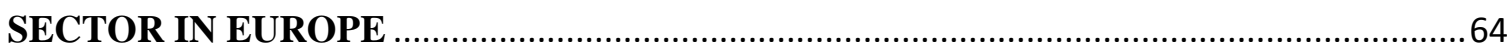

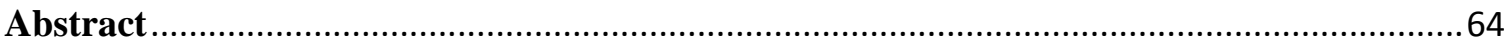

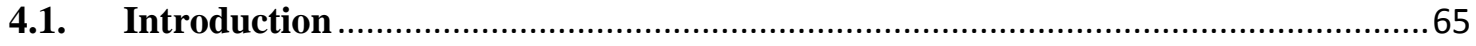

4.2. Local agglomeration and technical stochastic frontier ........................................67

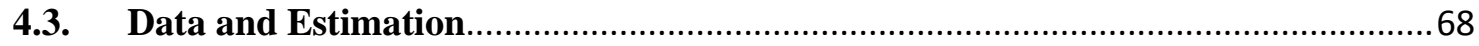

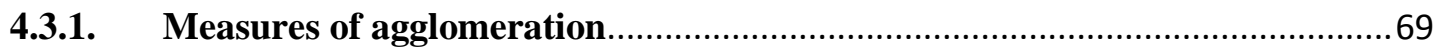

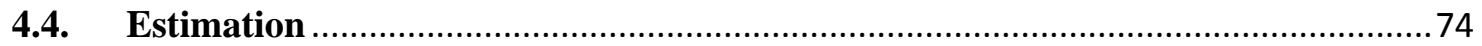

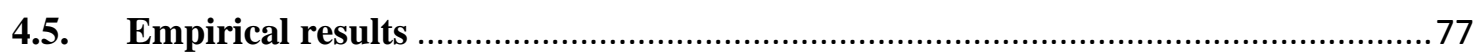

4.5.1. Local agglomeration effects on the frontier .............................................. 78

4.5.2. Local agglomeration effects and farm size effects on efficiency ........................80

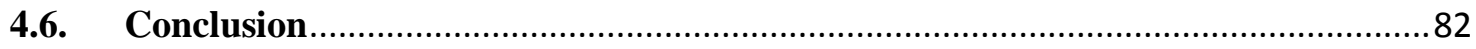

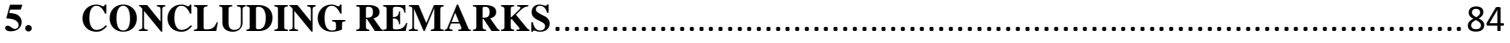

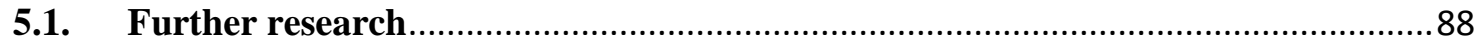

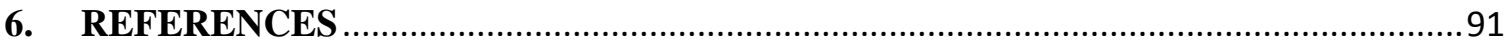

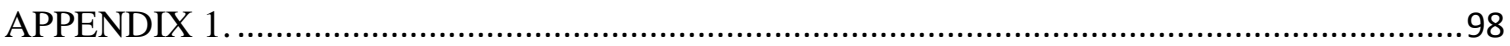

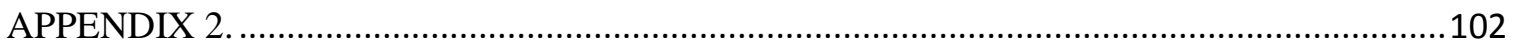

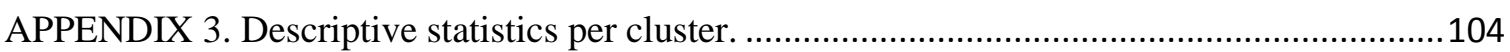




\section{LIST OF TABLES}

Table 2-1 Mean posterior distributions of the models. Standard deviation in parenthesis.

Table 2-2 Annual milk production in the United Kingdom. .28

Table 2-3 Descriptive statistics of the posteriors distributionsof the elasticities plus their random coefficients for selected inputs in Model 2

Table 3-1 LCA results 46

Table 3-2 Names of the clusters according to the location in which they are the most frequent.

Table 3-3 Stochastic frontier estimation in the different clusters. 56

Table 3-4 Average annual growth rates in TFP components.... 60

Table 4-1 Descriptive statistics of the variables in the production function .75

Table 4-2 Coefficients estimates of the production function. .77

Table 4-3 Estimates of local agglomeration on the frontier. .79

Table 4.4 Estimates of efficiency effects .80 


\section{LIST OF FIGURES}

Figure 1.1 Stochastic frontier and measure of inefficiency.........................

Figure 1-2 Average milk yield per cow in eight European countries 1995-2008.........7

Figure 1-3 Average milk yield per cow in 72 regions in Europe 1995, 2001 and 2008_..8

Figure 1-4 Counties in England and Wales........................................ 10

Figure 1-5 Regions in eight selected European countries...........................11

Figure 1-6 Graphical description of the methods in chapter $2 \ldots \ldots \ldots \ldots \ldots \ldots \ldots \ldots \ldots \ldots \ldots \ldots$

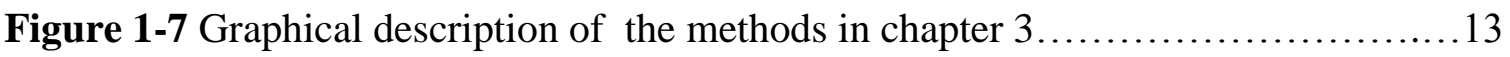

Figure 2-1 Political division of England and Wales at different levels..................19

Figure 2-2 In green counties in which farms are present in the sample................20

Figure 2-3 Variances of random coefficients in the three models......................29

Figure 2-4 Mean Kernel distributions of the random coefficients in the 52 counties....29

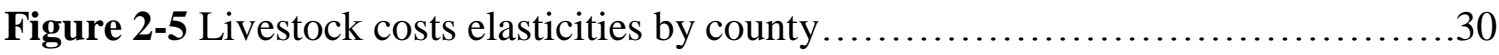

Figure 2-6 Land elasticities by county...................................... 31

Figure 2-7 Labor elasticities by county....................................... 31

Figure 2-8 Kernel densities of the inefficiency scores.............................33

Figure 3-1 Average milk yield per cow in the period $1995-2008 \ldots \ldots \ldots \ldots \ldots \ldots \ldots \ldots . \ldots 40$

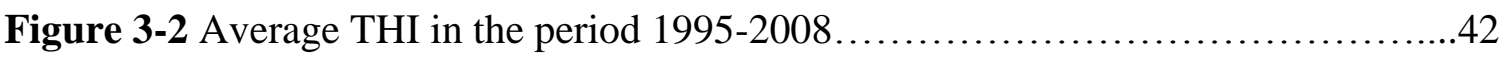

Figure 3-3 Average number of cows per hectare in the period 1995-2008............43

Figure 3-4 Average feed cost per cow in Euros 1995-2008 (Constant prices 2000).....43

Figure 3-5 Average value of buildings per cow in the period 1995-2008 (Constant prices

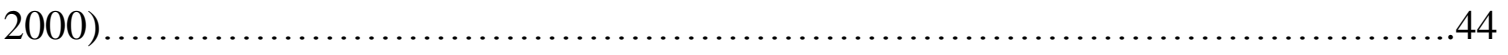

Figure 3-6 AIC and BIC values for different number of clusters.....................45 
Figure 3- 7 Names and Location of the clusters. Manes were chosen after the region in which they are most frequent.

Figure 3-8 Weighted average efficiency in the period 1995-2008 obtained from clusters' frontiers .53

Figure 3-9 Weighted average efficiency in the period 1995-2008 obtained from the complete panel .54

Figure 3-10 Technical change component. .58

Figure 3-11 Scale change .59

Figure 3-12 Technical efficiency component .59

Figure 3-13 Total factor productivity change. 60

Figure 3-14 Total factor productivity components using the complete panel 61

Figure 4-1 Regions present in the sample .68

Figure 4-2 Proportion of dairy farms per region in 2000 and 2007 69

Figure 4-3 Proportion of dairy farms in the neighboring region in 2000 and 2007 .71

Figure 4-4 Average milk quota per region in 2000, 2004 and 2008. One quintal is equivalent to $1000 \mathrm{~kg}$ .72

Figure 4-5 Average THI in the period 2000-2008 .73

Figure 4-6 Average proportion of grassland from the total utilized agricultural area per region. Average from 2000 to 2008 .74 


\section{LIST OF ABBREVIATIONS}

AIC

Akaike Information Criterion

BIC Bayesian Information Criterion

CAP Common Agricultural Policy

DEFRA Department of Environment, Food and Rural Affairs (United Kingdom)

DIC Deviance Information Criterion

EC European Commission

EU European Union

FADN Farm Accountancy Data Network

FAO Food and Agricultural Organization of the United Nations

FBS $\quad$ Farm Business Survey

LCA Latent Class Analysis

LCM Latent Class Model

LFA Less Favored Area

LR Likelihood-ratio test

MASL Meters Above the Sea Level

MCMC Morkov Chain Monte Carlo

NRW North-Rhine Westphalia

TE Technical efficiency

TFP Total Factor Productivity

THI Temperature-Humidity Index

UAA Utilized Agricultural Area

UK United Kingdom 


\section{INTRODUCTION}

There are very few productive processes where natural conditions and location play such as essential a role in technical (in)efficiency as they do in agricultural production. The present work analyzes how location and environmental variables determine production possibilities by means of different model specifications and statistical techniques and how far farmers allocate from their potential production in the dairy sector in Europe.

The aim of this work is to make use of innovative statistical techniques that allow us to have a better understanding of the impact of natural conditions and location where production takes place. Since these conditions are not homogeneous over space and in some cases over time, this source of heterogeneity necessarily impacts the estimators of efficiency when national or transnational analyses are performed. That is, assuming that the technology of all producers in different locations is the same or ignoring the different conditions and spatial interactions in which the production takes place might be a very strong assumption that leads to incorrect conclusions and more seriously, flawed policy decisions.

This work offers some clues as to how regional heterogeneity can be included in the estimation of efficiency. As it will be shown throughout this work, relaxing the assumption of a common technology among producers doesn't necessarily imply the estimation of individual frontiers (technologies). Adding heterogeneity might also imply an improvement of the accuracy of the estimators by explicitly accounting for regional heterogeneity.

Furthermore, this work also explores the implications of a phenomenon in economics that can be attributed to location and natural conditions: local agglomeration economies. The latter is understood to be the potential benefit or loss from concentrating dairy activity in a specific area. Assuming that local agglomeration may be the result of favorable natural conditions, the work explores the implications and impacts of local agglomeration and its associated externalities as a determinant of productivity and efficiency.

The remainder of this chapter is organized as follows. First, the theoretical background of stochastic frontier analysis will be explained. Then in the second section, the econometrical foundations of the estimation of a stochastic frontier will be analyzed. The third section will be dedicated to describe the dairy sector in Europe and its importance in 
the agricultural sector. The fourth section will address in detail the sources of regional heterogeneity and local agglomeration in the European dairy sector. The fifth section will present the data sources used in this work. Finally, the sixth section will describe the methods and aims of the remaining chapters.

\subsection{Theoretical Background}

Figure 1-1 graphically describes a production function and the measure of efficiency. A firm at point A requires $X_{A}$ input to produce $Y_{A}$ output given the technology. Producing at point $A$ is said to be inefficient since with the same amount of inputs the firm can potentially produce $Y^{*} A$ which represents an increase in the volume of output. A firm is said to be fully efficient if it produces the maximum quantity of output possible at a given technology and at a given level of inputs and therefore lies in the frontier $F(x)$. The reason why firms are inefficient is generally due to performance of the producer and might include education, experience but also might include factors out of the control of the producer like weather conditions, market conditions and policy regulations.

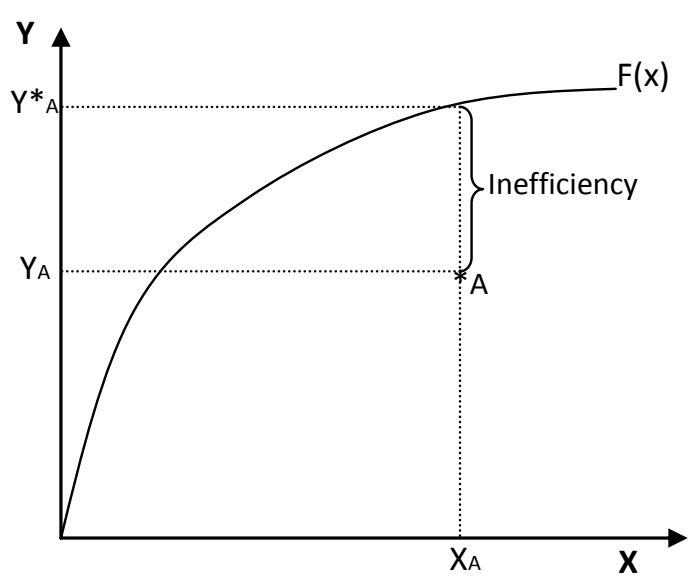

Figure 1-1 Stochastic frontier and measure of inefficiency.

Understanding the technology of the firms and sectors in the economy and reasons why firms operate under below this potential is crucial for policy makers. The estimation of a production function gives a general picture of the possibilities of the firms in terms of output ${ }^{1}$. The development over time of the production possibilities (technical change) may be an indicator of relevance and effectiveness of the investment in research and development. The magnitude with which producers use inputs in the production process

\footnotetext{
${ }^{1}$ Input oriented technical efficiency and economic efficiency are also widely used in literature. This is centered on the estimation of output oriented technical efficiency.
} 
can shed light on the functioning of the input markets, as will be shown later in this work. On the other hand, inefficiency scores might be an indicator of policy effectiveness since it implicitly indicates a lack of capacity of the owners due to education and their capacity to adapt to new technologies.

\subsubsection{Assumptions on the frontier}

Stochastic frontier models are produced with several assumptions that have their roots in microeconomic theory. On the side of the markets, it is assumed that the markets are perfectively competitive and agents are price takers in output and input markets. The agents of the economy are assumed to be rational and maximize (minimize) profit (costs). On the side of the specification of the technology, several assumptions are required to ensure the existence of the production function and a set of feasible production possibilities. These assumptions include:

- Essentiality of the inputs, that is, a positive value of at least one input is required to produce any positive quantity of the output. A null quantity of inputs implies a null quantity of output.

- The set that involves the production function is closed. This means, that the output that can be produced using a given input vector also contains all the points on its boundary.

- This set of production possibilities is bounded. That is, there is a limit in the amount of output that can be produced. This limit is given by the frontier.

- Disposability of inputs and outputs. On the input side, this implies that a given input that can produce a given output can also be produced by a scalar magnification of this input. On the other hand, on the output side this implies that the same inputs required to produce a given output can also produce a scalar contraction of that output.

In general, it is assumed that if a production technology with these characteristics exists, then this production technology is common for all the producers. In reality, this last assumption might not be true. Technologies employed by farms might be heterogeneous for a number of reasons that include firm heterogeneity, that is, size of firm, experience and education of the owner of the firm and accessibility to markets among others. A source of heterogeneity in the technology, the one explored in this work, might also be 
the location and natural conditions. There are obvious reasons why technologies might be different depending on the environment in which they are applied. A later section of this chapter will introduce the idea of regional heterogeneity and its importance in the estimation of stochastic frontiers in the agricultural sector.

\subsection{Estimation}

This work centers its analysis on the estimation of production frontiers and efficiency as Figure 1-1 describes. Efficiency and production functions can be estimated in several ways, parametric and non-parametric. This work will focus particularly on the parametric approach: Stochastic frontier. Stochastic frontier is a parametric technique first introduced by the seminal works of Aigner et al. (1977) and Meeusen and van den Broeck (1977). Later the technique was extended to a panel data setup by Pitt and Lee (1981) and Schmidt and Sickles (1984). Its aim is to estimate a production function, which is assumed to be common among all producers, and determine how far producers allocate from their potential production. In other words, how much production can be increased or inputs reduced to achieve a position on the frontier and be fully efficient. Since this is a parametric framework, a functional form for the production function is assumed to be known. Usually the technologies are assumed to either be Cobb-Douglas or translog ${ }^{2}$. The selection of the technology is at the discretion of the researcher or it van can be chosen by statistical test . Nevertheless, each functional form has advantages and disadvantages and determines the structure of the model and its results. In general, the stochastic frontier has the following form:

$$
y_{i t}=f\left(\boldsymbol{x}_{i t}, \boldsymbol{\beta}\right) * \exp \left(v_{i t}-u_{i t}\right)
$$

Where $y_{i t}$ represents the output of the farm $i$ in period $t . f($.$) represents the technology$ employed in the production process and $\boldsymbol{x}_{i t}$ represents the vector of inputs that are required to produce $y_{i t} . \boldsymbol{\beta}$ represents the parameters that determine the technology and are commonly called elasticities of the inputs. The term $\exp \left(v_{i t}-u_{i t}\right)$ is known as the composed error term. $v_{i t}$ is the stochastic component of the model and is meant to capture any misspecification of the model, errors in the variables and random events out of the control of the producers. It is assumed to have a normal distribution with mean zero and constant variance. On the other hand, $u_{i t}$ is used to measure efficiency and is

\footnotetext{
${ }^{2} \mathrm{~A}$ Cobb-Douglas production function is a special case of the trans-logarithmic production function in which some of the parameters are assumed to be zero.
} 
assumed to be non-negative. These distributional assumptions are required to separate estimates of the statistical noise and the efficiency term. The common approach to obtain estimates of $\beta$ and $u_{i t}$ is maximum-likelihood. Other estimation techniques are also possible and will be used in this work. In particular, the Bayesian approach proposed by van den Broeck et al. (1994) and Griffin and Steel (2004).

The stochastic frontier technique also allows for effects on the efficiency term $u_{i t}$. That is, the model allows incorporating variables that explain efficiency. Kumbhakar et al. (1991), Hang and Lui (1994) or Battese and Coelli (1995) are some of the early works that allow for this possibility, each one with different specifications. This extension of the stochastic frontier will also be explored in this work. Given this framework, Equation 1 can be rewritten as follows:

$$
y_{i t}=\boldsymbol{x}_{i t}^{\prime} \boldsymbol{\beta}+v_{i t}-u_{i}\left(z_{i}, \boldsymbol{\delta}\right)
$$

Where $z_{i}$ are the variables that model the efficiency effects and $\boldsymbol{\delta}$ are the estimated parameters that measure the magnitude of the effects on efficiency. Other efficiency effects might include time invariant efficiencies in an effort to explain how efficiency develops over time. Some examples include Cornwell et al. (1990), Kumbhakar (1990) and Batttese and Coelli (1992).

An additional feature of the estimation of a production function is that it brings the possibility of estimating productivity change. According to Kumbhahar and Lovell (2000), there is productivity change when an index of outputs changes at a different rate to the inputs. The advantage of estimating a production function econometrically it that it allows us to estimate three components of total factor productivity change $\mathrm{e}^{3}$. These components are: Technical change (TC) which indicates shifts of the production function over time. That is, expansions or reductions of the production possibilities. The scale component measures the capacity of the producers to take advantage of the scale economies. Finally, the technical efficiency change (TEC) gives information of how firms are moving towards or away from the frontier over time. This decomposition will be used in this work to fully understand the evolution of the dairy sector in Europe over time.

\footnotetext{
${ }^{3}$ An additional component is allocative efficiency (AE). The estimation of AE requires information on prices of inputs and outputs and is not studied in this work.
} 


\subsection{Dairy Sector in Europe}

According to the European Commission (EC), the dairy sector accounted for $15 \%$ of the total agricultural production in Europe by 2011. Dairy farming is present in all member countries of the European Union (EU). In fact the EU-25 countries produce $21 \%$ of global milk supplies according to the FAO.

Dairy production represents a key sector in the structure of agricultural production. Under the scheme of the Common Agricultural Policy (CAP) it has been historically protected. According to Swinnen (2009), the CAP was a mechanism designed in the mid 1950's and implemented by the mid 1960's to support minimum prices for farmers. These intervention prices were accompanied by a set of trade measures like import tariffs and export subsidies. The aim of these measures was to increase agricultural productivity and technical progress, ensure a fair standard of living for farmers, stabilize markets, assure the availability of supplies and ensure reasonable prices for costumers. As a result, by the 1970's the EU became a net exporter of several agricultural commodities, including dairy products.

Since then, several reforms were introduced to deal with the surplus and make the financial aid received by farmers more efficient. In order to deal with growing output surpluses, by the 1980's production quotas in the dairy sector were introduced, while maintaining the price and trade support. A later reform called Agenda 2000 reduced the intervention prices. However, the most remarkable reform was probably the one introduced in 2003 in which reference prices were again reduced, however this reduction was partially mitigated by increasing the compensation payments to farmers. This reform also started increasing the quota production. The most drastic part of this reform was the decoupling of subsidies from the production. That is, depending on the scheme chosen by each country, farmers would receive a fixed monetary payment based on their historical production. The reform also introduced the cross-compliance instruments, which required the farmers to obey regulations related to the environment, animal welfare, plant protection and food safety. The starting point of the introduction of the reform was at the discretion of each country. Nevertheless, by 2007 all member countries had fully implemented the decoupled payments. 
To this date, the CAP remains one of the most monetarily demanding chapters in the EC budget. According to Swinnen (2009), the total budget of the CAP in 2008 was $€ 52$ billion and from this budget $€ 37$ billion was spent in direct aid (subsidies). The effectiveness of these measures has been widely studied in literature. The results are mixed depending on how subsides are modeled, and which country and sector are analyzed. Nevertheless it is important, as shown later in this work, to understand the scope and the channels by which subsidies affect production and efficiency.

As stated previously, dairy farming is present in all countries of the EU. A closer look at the key measures of performance between countries reveals substantial differences. Figure 1-2 shows the average milk yield per cow in the period 1995-2008 in Belgium, Denmark, Germany, Spain, France, Italy, Netherlands and Austria. The common trend shows increasing yields in all countries. Nevertheless, it is evident that some countries present clear advantages in milk yields.

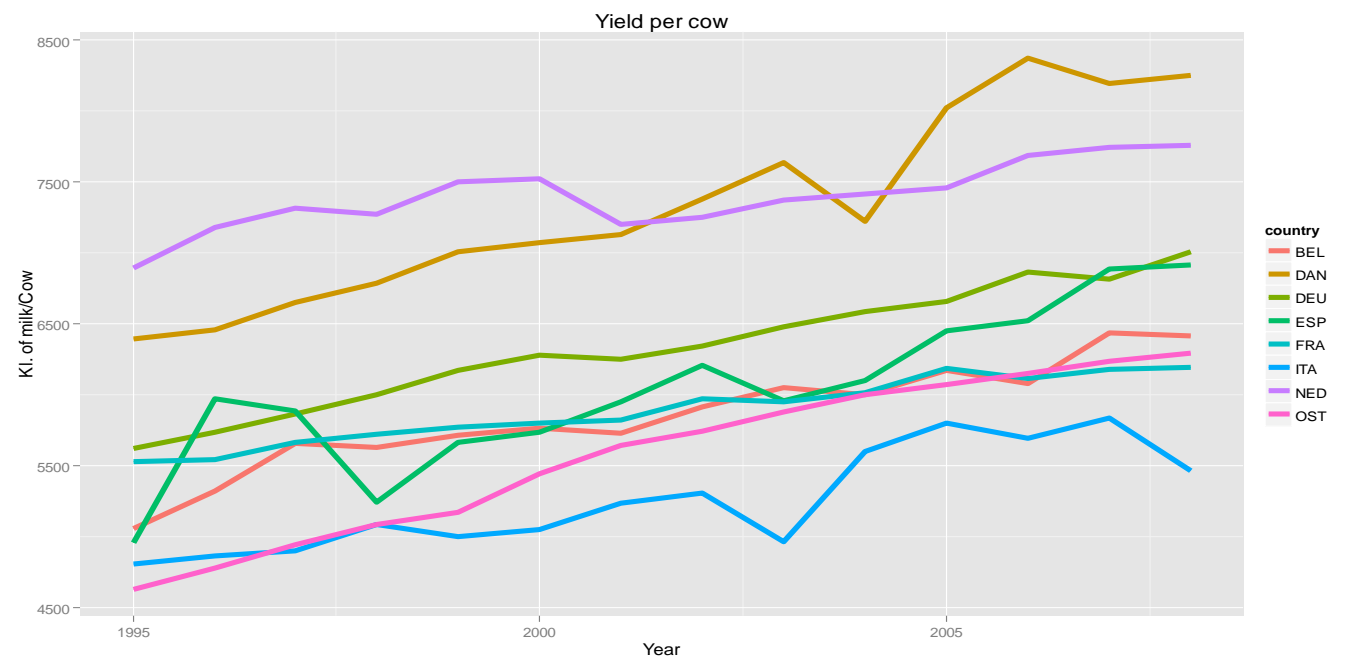

Source: Author's calculations based on EU-FADN - DG AGRI.

Figure 1-2 Average milk yield per cow in eight European countries 1995-2008.

The hypothesis of the present work lies in Figure 1-2. If all countries in the EU share the same agricultural policy, the knowledge and technology is known across countries, and they face similar input and output markets. The drivers of these differences in productivity might be explained by the natural environment and local political, cultural and socio-economic conditions that tend to be similar on different geographical scales. Furthermore, if all the latter points are true, this evident heterogeneity cannot be ignored when estimating efficiency and productivity. 
The heterogeneity in the average milk per cow is also present on a smaller geographical scale. As shown in the previous section, these eight countries are composed by regions. Figure 1-3 shows the evolution of average milk yield per cow in the 72 regions present in the sample. The plot not only shows differences across countries, but also differences within countries.
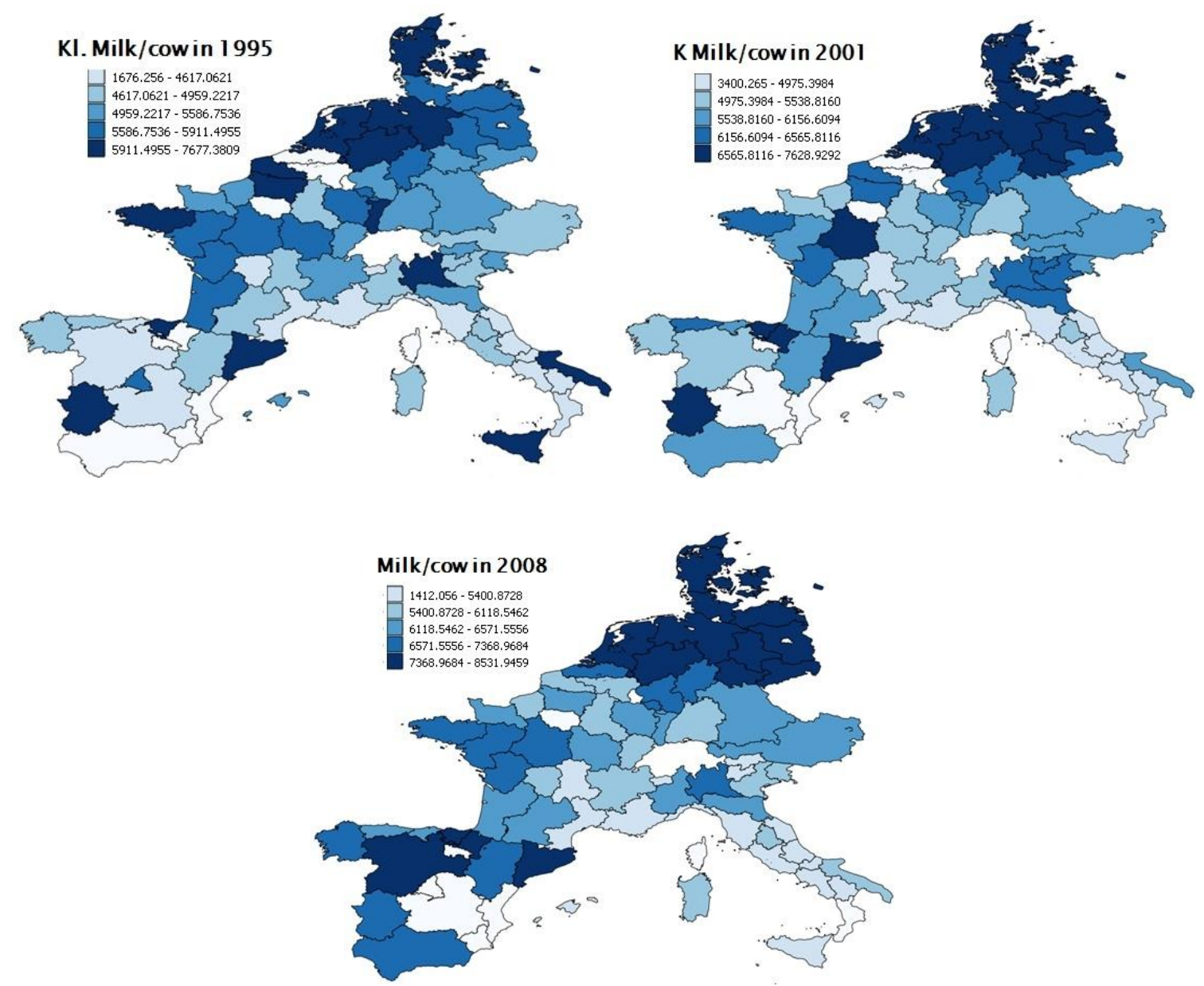

Source: Author's calculations based on EU-FADN - DG AGRI.

Figure 1-3 Average milk yield per cow in 72 regions in Europe 1995, 2001 and 2008.

Figure 1-3 also reveals clusters of high and low milk yields. For example, high yields seem to be more frequent in Northern Europe, whereas lower yields are common in southern regions. This clustering might be explained beyond differences in the natural conditions of the regions. As hypothesized in this work, farms located in the same region might share a common knowledge that leads to similar farming techniques. The dissemination of this knowledge (knowledge spillover) thought space might also explain differences in productivity across regions. 


\subsection{Regional heterogeneity and local agglomeration and their implication on efficiency measurements}

In spite of the fact that the literature has recognized the importance of the natural conditions and location of farms in agricultural production, little research has been done in the study of the real impacts on efficiency and production possibilities. Ignoring such conditions may lead to biased estimators of efficiency and frontiers. Demir and Mahmud (2002), for example, state that ignoring environmental variables when estimating technical efficiency in agriculture may lead to improper specifications of technical efficiency. A review of the literature shows that in most cases, when they are not completely ignored, location or natural conditions are introduced as determinants of the efficiency by means of dummy variables, leaving poor conclusions about the real relevance of these characteristics.

In this work, natural conditions are all the possible characteristics of the environment that affect the production in either a positive and negative way. Naturally, they include precipitation, temperature, altitude, sun light, etc. The main hypothesis in this work is that since these conditions are given and farmers have no possibility to change them, they must therefore adapt their technologies to these environments as an answer to overcome them and make the best out of them. This hypothesis leads to the idea that farms located in the same areas share similar farming techniques that have developed over time. In other words, neighboring farms may use similar farming techniques not only because they face identical natural conditions but also because the political, cultural and socioeconomic conditions are identical.

The possibility that farmers share the same farming techniques in a limited area leads to the idea of knowledge spillover between farmers. Formally, spillovers have been studied under the perspective of local agglomeration. Externalities such as knowledge spillovers are prone to occur in agglomerated environments of the same economic activity. In this regard, abundant literature has addressed the issue especially in the industrial sector. However, little research has been undertaken in the agricultural sector in exploring the effects of local agglomeration on stochastic frontier and efficiency in the dairy sector.

The geographical scope in which these conditions affect the production is also discussed in the present work and is certainly limited by the specificity of the information on the 
location of the farms. The exact location of the farm is not available in any of the data sets used in this work. The only available information on farms' locations is the political division in which each farm is located. In this line, models based in the smallest political division provided by the data have been developed. If neighboring farms use similar farming techniques, they might also be similar at the smallest regional level. This point is crucial since it determines the geographical scale of the present work. The more specific the information of the natural conditions of the farm, the more accurate the results of the estimation are. Taking national scale as reference, the natural conditions are still too general and ignore the immense heterogeneity of the conditions inside each country. The following section is dedicated to data description and will explain in detail the geographical scope.

\subsection{Data and geographical scale}

The results present in this work will be based on two different data sets. In both data sets the unit of study is the farm level:

- The first data set is the Farm Business Survey (FBS) from the Department of Environmental, Food and Rural Affairs (DEFRA) of the United Kingdom (UK). This is an annual survey that provides information of physical and economic performance of the agricultural sector in England and Wales. For this data set, the period of study is 2003-2007. The unit of study is the farm level. Given that we are interested in analyzing the effects of location, the data set provides this information only at the count level. Figure 1-4 shows the map of the counties present in the sample.

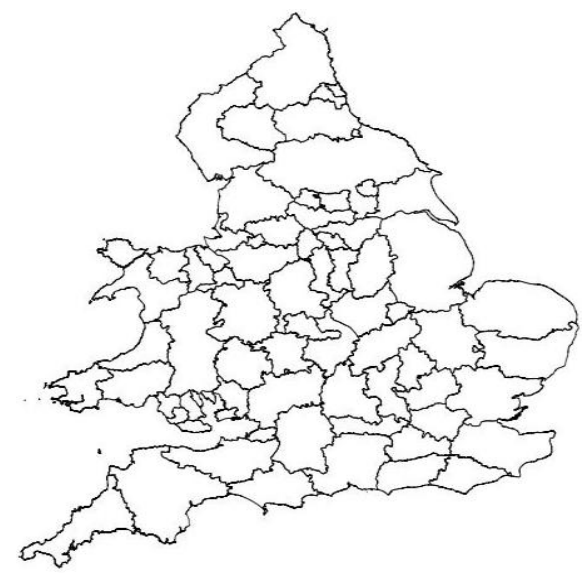

Figure 1-4 Counties in England and Wales. 
- The second data set is the Farm Accountancy Data Network (FADN) EU-FADN - DG AGRI of the EC. Like the FBS, it provides information on physical and economic performance of the agricultural sector in all member states of the EU and the unit of study is the farm level. The period of study is 1995-2008. Similarly, the data does not provide the exact location of the farm; it only provides the region in which the farm is located ${ }^{4}$. The study will focus on eight countries: Austria, Belgium, Denmark, France, Germany, Italy, Netherlands and Spain. Figure 1-5 shows the regions in which the data are located.

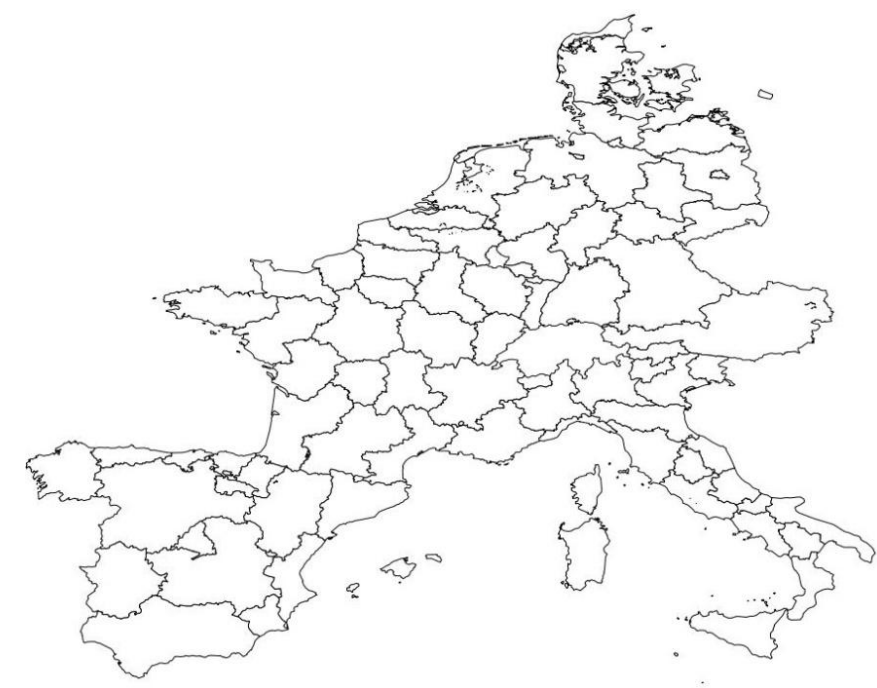

Figure 1-5 Regions in eight selected European countries.

\subsection{Methods and chapters}

The subsequent chapters of this work are dedicated to modeling this regional heterogeneity and local agglomeration in efficiency analysis. Since the goal is to estimate the frontier and the efficiencies at the farm level, all chapters present either modifications to the estimation of the stochastic frontier or use additional data on the natural conditions in an attempt to relax the assumption that all producers share a common technology. Otherwise, as in the case of the last chapter, measures of local agglomeration and natural conditions will be explicitly added to the frontier estimation. The remainder of this work is composed of the following chapters.

\footnotetext{
${ }^{4}$ Regional level means the NUTS1 definition of the European Commission (e.g. a Federal State in the case of Germany, autonomous community in the case of Spain). For the Netherlands, Denmark and Austria the information of the location of the farm is given at NUTSO level, that is, country level.
} 
Chapter 2 uses data from the FBS and is completely dedicated to the UK. In this chapter, regional heterogeneity is modeled under the assumption that there is a hierarchical geographical structure in the data. Since the hierarchical structure is present, a mixed model is developed to account for the possible correlations of the farms at different political divisions in the $\mathrm{UK}^{5}$. In particular, random coefficients are introduced in the coefficients of the production function. The hypothesis is that farms located in the same county share similar conditions that are translated in the technology. Furthermore, farms in the same county will tend to use inputs in the same intensity. Graphically, Figure 1-6 shows the aim of the chapter.

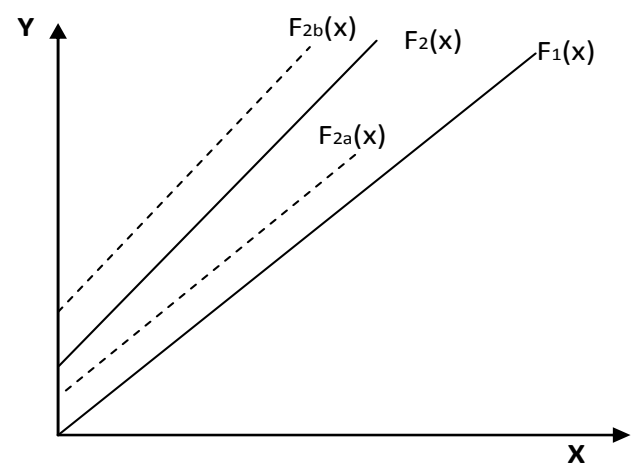

Figure 1-6 Graphical description of the methods in Chapter 2.

For simplicity, in the graphical illustration the frontiers are plotted as lineal. $F_{l}(x)$ represents the frontier estimated ignoring the regional heterogeneity. That is, without random coefficients at the county level. $F_{2}(x)$ represents the frontier estimated with random coefficients at the county level. Since the random coefficients are present in the intercept and in the slope (elasticities) of the frontier, both are allowed to change in the mixed model specification. That is, the frontier has a new shape and new intercept. One additional advantage of the mixed model specification is that in principle it is designed to obtain individual county frontiers. The dashed lines $F_{2 a}(x)$ and $F_{2 b}(x)$ represent the individual county frontiers for count $a$ and $b$, that also may differ in intercept and slope. As discussed in this chapter, the main strength of this technique is that it allows the addition of the effect of the location on the frontier. This is important to know since the frontier has changed intercept and slope and result efficiency scores are different from

\footnotetext{
${ }^{5}$ The chapter will focus on the discussion of the differences at the county level. Nevertheless, more aggregate political divisions are available (Government offices, regions and countries.)
} 
those of the frontier that ignores the regional heterogeneity. This chapter also explores the impact of several types of subsidies on the inefficiency term.

Chapter 3 explicitly uses data of natural conditions to separate the sample in different clusters accordingly. This chapter uses data from the FADN in the eight countries and 72 regions described in the previous section. The baseline of this chapter is that dairy farms which are located in regions with adverse natural conditions perform significantly different than those located in favorable conditions. In turn, these conditions affect the technology used by the farmers and therefore different frontiers are required to match the type of technology with the farms. In dairy science studies, it is recognized that temperature in combination with humidity affects the milk yield of the cows. In particular, the combination of high temperatures and humidity makes cows suffer from heat stress. This chapter will describe how heat stress has serious implications on the performance of the cows. Thus, several measures are required by farmers to mitigate its effects (which suggest different technologies). The geographical scope of the data allows integrating a measure of heat stress at the region level. Other variables describing the natural conditions of the farm are provided by the FAND. Finally, other variables are used to describe the possible ways in which farmers react to the natural conditions. All these variables are used to separate the sample in clusters and estimate the stochastic frontier for each cluster. Figure 1-7 describes graphically the theory behind this chapter.

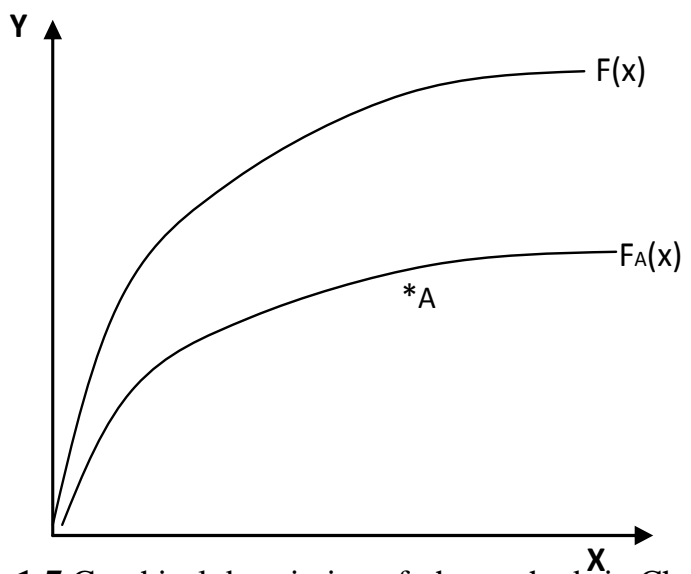

Figure 1-7 Graphical description of the methods in Chapter 3.

Starting with a supposition that farm $A$ faces adverse natural conditions, the frontier $F(X)$ is the frontier estimated from farms located in heterogeneous natural conditions, that is, the complete sample. On the other hand $F_{A}(X)$ is the frontier of the group of farms that face similar conditions of those faced by $A$. It is clear that in the case that those conditions are ignored (frontier $F(X)$ ), the efficiency score will be lower than the 
efficiency score obtained with frontier of its group (frontier $F_{A}(X)$ ). The chapter also estimates total factor productivity and compares the performance across clusters.

Chapter 4 explores the effects of an agglomeration economy in the dairy sector in Europe. The hypothesis lies on the assumption that externalities (negative or positive) are the natural outcome of local agglomeration of a given activity in a specific area. These externalities, in turn can have an impact on the production frontier and efficiency. The chapter incorporates measures of dairy agglomeration at the regional level in the stochastic frontier. This chapter also uses the FADN to measure the impact of local agglomeration on dairy production. The approach presented in the chapter takes into account not only the level of local agglomeration in the region in which the farm is located, but also the level of agglomeration in neighboring regions. The reason for this is that given the low barriers in the European borderlines, externalities might have a greater spatial effect. Since agglomeration might be explained by the favorability of the natural conditions, this chapter accounts for natural conditions in order to establish a clearer impact of agglomeration on productivity and efficiency.

Finally, Chapter 5 summarizes the key findings of the present work and its implications for policy makers. The limitations of each chapter will be discussed and future research topics will be suggested. 


\title{
2. MODELING REGIONAL HETEROGENEITY IN STOCHASTIC FRONTIER: A BAYESIAN MIXED MODEL APPROACH
}

\begin{abstract}
Neighboring farms, firms and in general any economic unit might face similar, if not identical, economical, natural, cultural and political conditions depending on their geographical location. Since the introduction of stochastic frontier models by Aigner et al. (1977) and Meeusen and van den Broeck (1977), little research has been done to analyze the possible effect of the geographical location. In most cases, dummies are employed to control for this possible effect of location on technical efficiency (TE). Further recent studies such as Schmidt el al. (2009), Areal et al. (2012) and Glass et al. (2013) have developed a more precise structure by using a weight distance matrix to study spatial dependence on TE; in either case, location seems to play an important role in the determination of TE. Our approach differs from those described before: By taking advantage of the properties of mixed models, we developed a stochastic frontier that takes into account regional heterogeneity of the farms at the smallest political unit available in our data, a panel data of dairy farms in England and Wales. A Bayesian approach is used to develop the stochastic frontier. Results suggest that regional heterogeneity is present and determines the production function. Different distributions of the inefficiency term were used with highly correlated results in the efficiency scores, showing consistency with our results. Finally, we investigate and discuss some effects on technical efficiency.
\end{abstract}

Keywords: Stochastic frontier, efficiency analysis, linear mixed models, regional heterogeneity, Bayesian analysis

JEL classification: $C 11, C 13, C 23, D 24$ 


\subsection{Introduction}

Since the stochastic frontier models were introduced by the seminal papers of Aigner et al. (1977) and Meeusen and van den Broeck (1977), spatial dependence and correlation in the determination of the production function and technical efficiency has been studied very little. It is important to note that literature has dealt with the problem in two different ways based on the information of the location of the farms. In the case of regional heterogeneity, location is available at a certain political division, and dummy variables are used to account for it. On the other hand, a more precise location of the farm would appeal to the development of the study of spatial dependence by using, for example, a weight matrix.

For the first case, location is added to the model as a dummy variable to account for regional heterogeneity in the inefficiency term. Examples of this approach include Karagiannis and Saris (2005) and Hadley (2006); in either case, regional dummies have a significant impact on technical efficiency. On the other hand, when the location of the farm is known, Schmidt el al. (2009) and Areal et al.(2012) developed a model that takes into account the spatial dependence by using a weight matrix in the inefficiency component. Both studies conclude that the spatial component plays an important role in the determination of technical efficiency. A similar approach was used by Druska and Horrace (2004), and Glass et al. (2013) using a spatial autoregressive production frontier with a weight matrix. They found spatial dependence in the production in different specifications of the weighted matrix.

The reasons behind modeling these possible spatial interactions in agricultural production are easy to understand. Neighboring farms might face similar, if not identical, natural, political, cultural and socio-economic conditions. Neighboring farmers might use a similar farming technique which suggests that they use similar technology in the production process and, of course, the shorter the distance the more similar the conditions are in which production takes place. In this respect, Areal et al. (2012) found that spatial dependence reaches its maximum over a $100 \mathrm{~km}$ distance ${ }^{6}$. Our hypothesis is that if technologies used in neighboring farms tend to be similar, then the intensity with which they use the inputs would tend to be similar; this could imply similar elasticities of inputs in the technology of farms located nearby. Furthermore, farmers' decisions on the

\footnotetext{
${ }^{6}$ Areal et al. (2012) use different cut-off distances in their analysis, $20 \mathrm{~km}, 100 \mathrm{~km}, 180 \mathrm{~km}$ and $240 \mathrm{~km}$.
} 
adoption of new technology to achieve an expansion of production possibilities (technical change) and better practices that improve technical efficiency (technical efficiency change) are influenced by the learning-by-doing process. This process is likely to be spatial dependent because of the influence of local networks. We believe that the random coefficients of the mixed model would describe these possible differences in the technologies taking into account the correlations between farms located in the same political unit.

Previous studies suggest that these mechanisms of propagation seem to be spatial dependent and strongly influenced by local conditions. Dries and Swinnen (2004) showed that local dairy farms in Poland copied successful strategies of foreign companies in the local market. The copied strategies included a vertical integration with small local producers. The vertical integration promoted by the foreign company encouraged an improvement of the product's standards. The copied strategy also included assistance programs to improve access to technology, credit and other inputs. Lewis et al. (2011) found that neighboring dairy farms using organic farming was a powerful explanatory measure of decision on technological conversion. They suggest that the learning process from neighbors can reduce substantially uncertainty and the fixed costs attached to information in a clear example of knowledge spillover.

Our hypothesis is that if technologies used in neighboring farms tend to be similar, then the intensity with which they use the inputs would tend to be similar; this could imply similar elasticities of inputs in the technology of farms located nearby. This work will exploit the geographical structure of the data to explicitly account for regional heterogeneity in the production function. We believe that the random coefficients of the mixed model setup would capture be these possible differences in the technologies taking into account the correlations between farms located in the same political unit. Notice that accounting for regional heterogeneity implies a relaxation of assumption commonly done in stochastic frontier that all firms produce with the same technology. As it will be shown throughout this work, relaxing the assumption of a common technology among producers doesn't necessarily imply the estimation of individual frontiers (technologies). Adding heterogeneity might also imply an improvement of the accuracy of the estimators by explicitly accounting for regional heterogeneity. 
Advantages of mixed models have been recognized in other areas of economics, in particular educational economics uses this approach widely in analysis. Gelman and Hill (2006) enumerated some advantages of this type of analysis. In particular, mixed models use all the data to perform inferences for groups with small sample data. They also lead to more efficient inferences since they do not ignore differences between the groups. Paterson and Goldstein (1991) also described some of the advantages, for example, in the statistical inference they contribute with flexibility and their capacity to respect multiple groupings of the data while incorporating both explanatory processes and random variation at all different levels of analysis. Put simply, mixed models respect the unique nature of each group and at the same time retain the capacity to generalize. Modeling the group differences has another technical advantage; since grouping could have an effect on the estimation of standard errors, when grouping is ignored the group-level effect becomes part of the random error. Goldstein and Silver (1989) discuss how correct estimations in standard errors are achieved by modeling the group structure through a mixed model without losing generalization of the inferences at the individual level.

Some works have used mixed models in the estimation of efficiency and productivity. McCloud and Kumbhakar (2008) developed a Bayesian stochastic frontier that allows heterogeneous input-specific elasticities, technology efficiency and technical change across regions in the dairy sector of Scandinavian countries. Our work differs from this in the sense that we analyze different distributions for the inefficiency term ${ }^{7}$. Similarly, Holloway and Tomberlin (2005) use different hierarchy structures to analyze a hierarchy not related to spatial location in the fishery industry of the West Coast of the United States. In this case, our work differs from this in the hierarchical structure and the use of different distributions for the inefficiency term.

The aim of this work is to develop a Bayesian stochastic frontier that incorporates the features of a mixed model to study the possible regional heterogeneity of the data while producing efficiency estimators for each farm along with effects in the efficiency term. The paper is organized as follows. Sections 2.2 to 2.4 present the data and its spatial hierarchy that can be modeled as a mixed model. Section 2.5 presents the model and the Bayesian inference. Section 2.4 presents the results of the estimation. Finally, Section 2.6 and 2.7 present the discussion and conclusions of the paper.

\footnotetext{
${ }^{7}$ McCloud and Kumbhakar (2008) use the random intercept of the production function to obtain efficiency scores.
} 


\subsection{Data}

Our data consist of an unbalanced panel taken from the Farm Business Survey (FBS) performed by the Department of Environmental, Food and Rural Affairs of the United Kingdom (DEFRA). The geographical scope of the survey only includes farms in England and the Wales and provides financial, physical and environmental performance data for the farms in the sample. A total of 219 farms are analyzed in the period 20032007, producing a total of 920 observations. In the following subsections we explain the geographical location of the farms at different political units and then we provide further detail on the variables used to perform the estimation.

\subsection{Farm location, source of regional heterogeneity}

Since the exact location of the farm is not provided by the FBS, the only available information about the location of the farm is the political unit in which the farm is located. As stated above, the survey is performed in two countries - England and Wales. These two countries are divided into 4 different regions which are subsequently divided up into 10 government offices. Finally, these 10 government offices are divided into 72 counties $^{8}$. Figure 2-1 shows maps of the different political divisions of England and Wales, ordered from top to bottom and from left to right accordingly.
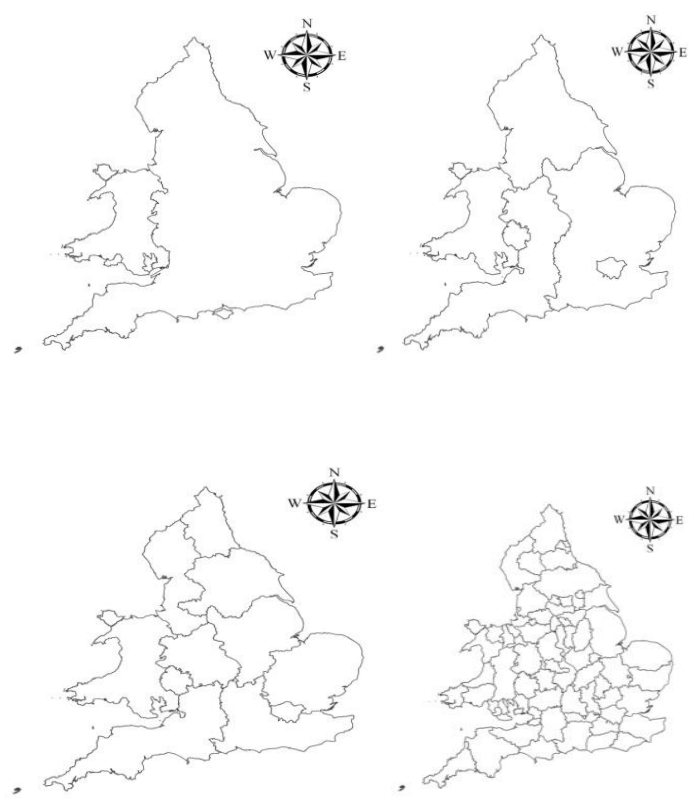

Figure 2-1 Political division of England and Wales at different levels.

\footnotetext{
${ }^{8}$ Counties and Unitary Authorities are the smallest administrative unit in the data.
} 
Our interest in this work concerns the latter political unit - county level - since we believe that farms tend to be more similar to each other in smaller areas. In our sample, farms are distributed in 52 counties. Figure 2 shows the counties where there is at least one farm of the sample.

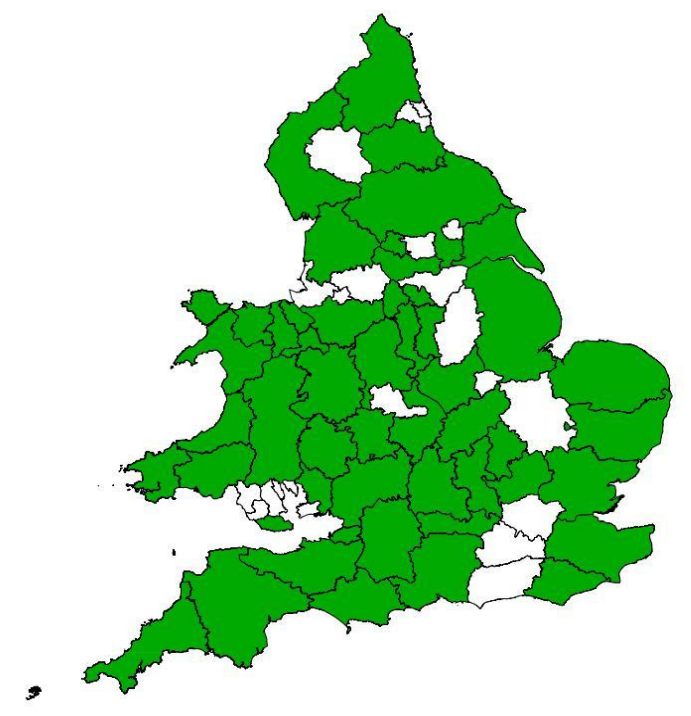

Figure 2-2 In green counties in which farms are present in the sample.

Although we are aware that we cannot expect to completely capture the complex conditions inside each county and the even more complex spatial dependence between the farms, we expect to capture the similarities in natural, political, cultural and socioeconomic conditions. These conditions make the farms similar within each political unit that - as a result - turns into regional heterogeneity between counties.

\subsection{Variables}

Our aim is to estimate the production function for dairy farms. The variables available in the data for this purpose are:

- $\quad$ Output: Revenue of the farm in Pounds $(£)$, farms in our sample are specialized farms, which means that at least $80 \%$ of their revenue is due to dairy activities. Following Hadley (2006), this revenue includes subsidies and grants but excludes income from activities not related with the main activity of the farm.

- $\quad$ Land: We use the utilized agricultural area (UAA) in hectares.

- Labor: Hours of labor family members dedicated to the farm, managerial labor and hired labor. 
- $\quad$ Livestock costs: Includes veterinary and feeding costs in $£$.

- $\quad$ Capital: The sum of machinery, buildings and land maintenance costs in $£$

- $\quad$ Other costs: These include water, electricity and other costs in $£$.

Since the development of stochastic frontier models that allow effects on the efficiency term by Kumbhakar et al. (1991), Huang and Lui (1994) or Battese and Coelli (1995), the literature has proliferated studying all kind of possible influences on inefficiency. In this regard, we want to investigate the effect of subsidies on technical efficiency in this work. Literature has widely discussed the advantages and disadvantages of modeling subsidies as an input in the production function or as an effect on the inefficiency term. Our philosophy in this work (and following that of McCloud and Kumbhakar (2008)) is that subsidies are not necessary for the production of output ${ }^{9}$, so they should be analyzed as an effect on inefficiency. Effects of subsidies on technical efficiency have also been studied previously in different works by Brümmer and Loy (2000), Giannakas el al. (2001), Rezitis et al. (2003) and Karigiannis and Saris (2005) to name a few. The key difference in this work is that we disaggregate the subsidies the farm receives to three different types, depending on their nature. The Common Agricultural Policy (CAP) of the European Union (EU) provides a number of subsidies with different aims for the farmers. We consider this discussion to be important since the CAP consumed about half of the budget of the EU by 2006 and one of its aims is to increase productivity, promote technical progress and ensure optimum use of factors.

We have selected three types of subsidies based on the number of farms that received each kind of subsidy. This means that, for example, "Input Subsidies" were dismissed from our analysis because less than $1 \%$ of the farms in the sample received this kind of subsidy in the period of study. The selected subsides ${ }^{10}$ are:

- Livestock subsidies: A subsidy given to farms producing any kind of livestock output. In our period of analysis this subsidy was attached to production.

- Hill farm allowance (less favored area payments): This a payment that farms located in less favored areas receive as compensation for the difficulties that hill farming might impose on the production. This payment is not attached to production.

\footnotetext{
${ }^{9}$ Authors in this work modeled subsidies in the production function as an input and as a "facilitating input" to study all the effects of subsidies on productivity decomposition.

${ }^{10} \mathrm{Log}$ of the subsidies that are used in the estimation.
} 
- Environmental subsidies: A payment given to farmers as compensation for protecting part of the area of the farm for environmental reasons. This payment is not attached to production.

\subsection{Model and Bayesian Inference}

Since the developments of van den Broeck et al. (1994), Bayesian inference in the estimation stochastic frontier has become popular because of its flexibility and relatively easy programming implementation handled by Markov Chain Monte Carlo (MCMC) methods through the Gibbs sampler ${ }^{11}$. We will take advantage of this flexibility to perform the estimation of our models. This section is organized as follows; the first part is dedicated to explaining the modeling of the regional heterogeneity by means of a mixed model. In the second part we explain the prior and posterior density distributions to conduct the Bayesian inference. Finally, we explain the use of the scaling property to model the effects on the inefficiency term.

\subsubsection{Regional heterogeneity through a mixed model}

The stochastic frontier model was first introduced in the works of Aigner et al. (1977) and Meeusen and van den Broeck (1977). These works considered the composed error term in a production function for the first time. Later the technique was extended to panel data setup by Pitt and Lee (1981) and Schmidt and Sickles (1984) with the following form $^{12}$ :

$$
y_{i t}=\boldsymbol{x}_{i t}^{\prime} \boldsymbol{\beta}+v_{i t}-u_{i t}
$$

In this model, $y_{i t}$ represents the output of the unit of analysis (firm or farms) $i$ in time $t, \boldsymbol{x}_{i t}^{\prime}$ is the vector of $j$ inputs that the firm requires to produce $y_{i t}, v_{i t}-u_{i t}$ is known as the composed error term in which $v_{i t}$ represents the random component of the model which is expected to have a normal distribution with constant variance, $u_{i t}$ is the component that represents efficiency and follows a one-sided distribution. $y_{i t}$ and $x_{i t}$ are presented in logarithms. Inefficiency measures are obtained by $E f f_{i}=$ $\mathrm{E}\left[\exp \left(-u_{i t}\right)\right]^{13} ;$ the value is in the interval $[0,1]$ and an inefficiency score equal to 1

\footnotetext{
${ }^{11}$ To perform our inference we use WinBUGS through "R2WingBUGS" package in R.

${ }^{12} \mathrm{We}$ assume a Cobb-Douglas technology in this work.

${ }^{13}$ The subscript $t$, has been removed, our analysis in this work considers inefficiency as time-invariant.
} 
represents a fully efficient firm, this means the firm obtains the maximum output given its combination inputs.

As stated before, our aim is to develop a model that incorporates the random coefficients of a mixed model into Equation 2.1, following our hierarchical structure described above: farm-county-government office-region country. The fixed part of the model is the one described in Equation 2.1 which varies across time and farms. The random part ${ }^{14}$ of our model varies only across counties and will account for the regional heterogeneity. This work studies the random effects only at the county level in spite of the fact that we have more levels in the hierarchical structure. Two reasons motivate this decision: Firstly, it is reasonable to think that farms tend to be more similar in smaller areas - in our case, at the county level. Hadley et al. (2006) and Areal et all. (2012) support this decision ${ }^{15}$. The second reason is related to the number of groups at a given hierarchy. Paterson and Goldstein (1991) discuss that any analysis with less than 25 units at a higher level are unable to provide an accurate estimation of the variability of the random coefficients. Gelman and Hill (2006) find that a small number of groups might fail to estimate the between-group variation, and the mixed model analysis loses its advantages for modeling the heterogeneity present in the hierarchical structures. At the county level we have 52 groups representing the 52 counties present in the sample. The next level in the hierarchy of political units is government office. This level of the hierarchy has only 10 different groups (see Figure 1.1) and the estimate of the variability of the random elasticities of the production function might be affected. Thus the model takes the following form:

$$
y_{i k t}=\boldsymbol{x}_{i t}^{\prime} \boldsymbol{\beta}+\boldsymbol{x}_{k t}^{\prime} \boldsymbol{\tau}_{k}+v_{i k t}-u_{i t}
$$

Notice that we allow all the inputs (including the intercept) of the production function to vary across county level $k$, for the 52 counties present in our sample ${ }^{16}$. Notice also that the elasticity of the input $j$ now has the form:

\footnotetext{
${ }^{14}$ Here the term "random part" refers to varying coefficients through the counties. Gellman and Hill (2006) define "Random" in the mixed model context as the randomness in the probability model for the grouplevel coefficients (county level, in this application).

${ }^{15}$ Areal et al. (2012) found the spatial dependence reaches a maximum at certain distances - $100 \mathrm{~km}$. Hadley et al. (2006) found strong evidence for regional heterogeneity in dairy farms in England and Wales by means of 6 location dummies in the inefficiency term.

${ }^{16}$ For some of the counties, the number of observations is small. In this regard, the number of observations required in each county is not a concern when performing a Mixed Model Analysis. Gelman and Hill (2006) argue that when groups have a small number of observations, the random coefficients might not be
} 


$$
\frac{\partial y_{i k t}}{\partial x_{j}}=\beta_{j}+\tau_{j k}
$$

In this case, $\tau_{j k}$ is the effect on the elasticity for being located in the county $k$. This means that the model is able to obtain a frontier per county. Now we want to add effects on the inefficiency term that leads us to a model with the following form:

$$
y_{i k t}=\boldsymbol{x}_{i t}^{\prime} \boldsymbol{\beta}+\boldsymbol{x}_{k t}^{\prime} \boldsymbol{\tau}_{k}+v_{i k t}-u_{i}\left(z_{i}, \boldsymbol{\delta}\right)
$$

Where $z_{i}$ are the time-invariant ${ }^{17}$ effects on inefficiency and $\boldsymbol{\delta}$ are the estimated parameters. There are several ways in which effects on inefficiency can be modeled. For example, Kumbhakar et al. (1991), Hang and Lui (1994) or Battese or Coelli (1995) assume that $z_{i}$ affects the location parameter in a truncated normal distribution, that is $u_{i} \sim N^{+}\left(z^{\prime}{ }_{i} \boldsymbol{\delta}, \sigma_{u}^{2}\right)$. On the other hand, works like Caudill et al. (1995) have parameterized the variance of the inefficiency term through an exponential function for a half-normal distribution $u_{i} \sim N^{+}\left(0, \sigma_{u}^{2} * \exp \left(z^{\prime}{ }_{i} \boldsymbol{\delta}\right)\right)$. Other approaches consist of parametrizing both, such as Wang (2002). In any case, the interpretation of $\delta$ is the same: positive values increase inefficiency and negative values decrease inefficiency.

Our approach in this work follows the one proposed by Alvarez et al. (2006), and also used by Galán et al. (2013). A Bayesian approach where the scaling property was used; Alvarez et al. (2006) describes the scaling property as: “...models satisfy the scaling property, which says that $u_{i}\left(z_{i}, \delta\right)$ can be written as a scaling function $h\left(z_{i}, \delta\right)$ times the variable $u^{*}$ that does not depend on $z_{i}$ " (Alvarez et al. 2006, p. 201). $u^{*}$ has a basic distribution (a one-sided distribution in our case) that determines the shape of the function and $h\left(z_{i}, \delta\right)$ determines the scale of it. The results of this method are appealing because it allows us to explore different distributions of the inefficiency term while giving an interpretation of the effect of $z^{\prime}{ }_{i}$ on the expected efficiency. A convenient form for $h\left(z_{i}, \delta\right)$ is chosen. In particular $h\left(z_{i}, \delta\right)=\exp \left(z_{i}^{\prime} \delta\right)$, - this is a monotonic function that makes calculation and interpretation simpler. Our final model has the following form:

$$
y_{i k t}=\boldsymbol{x}_{i t}^{\prime} \boldsymbol{\beta}+\boldsymbol{x}_{k t}^{\prime} \boldsymbol{\tau}_{k}+v_{i k t}-u_{i}^{*} * \exp \left(z^{\prime}{ }_{i} \boldsymbol{\delta}\right)
$$

estimated precisely but they can still provide information of the group level that allows the estimation of the random coefficients and their variance parameters

${ }^{17}$ Although this might seem a restrictive assumption, models with time-varying effects were estimated. In all cases the time-invariant specification was preferred over time-varying specification by DIC criteria. 
For $u^{*}$, the inefficiency term, we test two different distributions - the exponential and half-normal distribution. In the case of the latter, we test two different scale parameters. Model 1 assumes an exponential distribution $u_{i} \sim \operatorname{Exp}\left(\exp \left(z^{\prime}{ }_{i} \boldsymbol{\delta}\right)\right)$ whereas Model 2 assumes a half-normal distribution $u_{i} \sim N^{+}\left(0, \sigma_{u} * \exp \left(z^{\prime}{ }_{i} \boldsymbol{\delta}\right)\right)$ in which $z^{\prime}{ }_{i} \boldsymbol{\delta}$ does not include an intercept. Finally, Model 3 assumes a half-normal distribution $u_{i} \sim N^{+}\left(0, \exp \left(z^{\prime}{ }_{i} \boldsymbol{\delta}\right)\right)$, where $z_{i}{ }_{i} \boldsymbol{\delta}$ has an intercept ${ }^{18}$.

\subsubsection{Bayesian Inference}

The posterior probability density function for the model described by equation 2.5 has the following form:

$p\left(\mathbf{y}, \mathbf{u}, \boldsymbol{\beta}, \boldsymbol{\tau}_{\mathbf{k}}, \boldsymbol{\sigma}^{-2}, \boldsymbol{\sigma}_{\mathbf{\tau}}^{-2}, \boldsymbol{\delta} \mid \mathbf{x}, \mathbf{z}\right) \propto p\left(\mathbf{y} \mid \mathbf{x}, \mathbf{u}, \boldsymbol{\beta}, \boldsymbol{\tau}_{\mathbf{k}}, \boldsymbol{\sigma}^{-2}, \boldsymbol{\sigma}_{\mathbf{\tau}}^{-2}, \boldsymbol{\delta}\right) p(\boldsymbol{\beta}) p\left(\boldsymbol{\tau}_{\mathbf{k}}\right) p\left(\sigma^{-2}\right) p\left(\boldsymbol{\sigma}_{\mathbf{\tau}}^{-2}\right) p(\mathbf{u}, \boldsymbol{\delta} \mid \mathbf{z})$

Notice that $\sigma^{-2}$ represents the total variance of the likelihood function and $\boldsymbol{\sigma}_{\boldsymbol{\tau}}^{-2}$ represents the vector of variances of the random elasticities of the model, those that vary across counties and therefore have the subscript $\tau$.

The prior distributions for each parameter are: $p(\boldsymbol{\beta}) \sim N\left(0, \boldsymbol{\omega}_{\boldsymbol{\beta}}^{-2}\right)$ and $p\left(\boldsymbol{\tau}_{\boldsymbol{k}}\right) \sim N\left(0, \boldsymbol{\sigma}_{\boldsymbol{\tau}}^{-2}\right)$. The variances of the likelihood function and the random coefficients of the model have a Gamma distribution $p\left(\sigma^{-2}\right)=\sim G(a, b), \quad p\left(\boldsymbol{\sigma}_{\tau}^{-2}\right)=\sim G\left(\mathrm{a}_{\tau}, \mathrm{b}_{\mathrm{t}}\right)$. Finally, in Model 1 $p(\mathbf{u}, \boldsymbol{\delta} \mid \mathbf{z}) \sim \operatorname{Exp}(\exp (\mathbf{z} \boldsymbol{\delta}))$, in Model $2 p(\mathbf{u}, \boldsymbol{\delta} \mid \mathbf{z}) \sim \mathrm{N}^{+}\left(0, \sigma_{\mathrm{u}}^{-2} * \exp (\mathbf{z} \boldsymbol{\delta})\right)$ with $p\left(\sigma_{u}^{-2}\right)=$ $\sim G\left(a_{u}, b_{u}\right)$ and in Model $3 p(\mathbf{u}, \boldsymbol{\delta} \mid \mathbf{z}) \sim \mathrm{N}^{+}(0, \exp (\mathbf{z} \boldsymbol{\delta}))$. For all three models, $p(\boldsymbol{\delta}) \sim N\left(0, \boldsymbol{\omega}_{\boldsymbol{\delta}}^{-2}\right)$ with a diffuse covariance matrix.

Parameterization of the prior distributions were conducted following the work of Griffin and Steel (2007) and Galan et al. (2013). In general, they use diffuse priors for the variances of the likelihood function $p\left(\sigma^{-2}\right)$ as well as for the variances of $p(\boldsymbol{\beta})$ and $p(\boldsymbol{\delta})$. We extend the same criteria for the variances of the random elasticities $\boldsymbol{\sigma}_{\tau}^{-2}$ and for the variance of $p(\mathbf{u}, \boldsymbol{\delta} \mid \mathbf{z})$ in Model $2 p\left(\sigma_{u}\right)$.

All the models were estimated using WinBUGS. Each model has two chains with different initial values, each chain uses 240000 iterations where the first 40000 iterations were discarded in a burn-in phase. From the remaining 200000 iterations, every $500^{\text {th }}$

\footnotetext{
${ }^{18}$ Notice that in this model even if subsidies have a null impact on efficiency, the intercept might ensure a variance different from 1.
} 
was used to perform the analysis. This means that a total of 400 iterations per chain were used in the results, with the purpose of reducing the possible correlations of the MCMC.

\subsection{Results}

Table 2-1 presents results for the estimation of models 1,2 and 3. Point estimates presented in the table are the means of the posterior distributions, and standard errors are presented in parentheses ${ }^{19}$. MCMC plot diagnostics are presented in Appendix 1.

\subsubsection{Model selection}

Deviance Information Criteria (DIC) is a common instrument for model comparison in Bayesian inference; lower values of DIC tend to indicate better fitting models. While all models have similar DIC values, Model 3 has the lowest one. A closer look at the MCMC diagnostics reveals that in Model 3 the intercept of the inefficiency effects does not converge satisfactorily, in fact, the MCMC are correlated ${ }^{20}$. Since the DIC values of each model are not considerably different, Model 2 is chosen for further analysis.

\subsubsection{Technology and elasticities.}

At this point, it is important to mention that a model without random elasticities was produced to compare with Models 1, 2 and 3. The DIC of this comparison model is 1233.5, significantly higher than any of the other models presented here. Details of this model (Model 4) are shown in Appendix 2. This means that a model that takes regional heterogeneity into account is preferred to a model without such considerations.

As seen in Table 2-1, variations of input elasticities are very small among the three models presented. This result is to be expected as all three models' elasticities have identical prior distributions. Livestock costs are the most important input in dairy production, followed by land and labor while all of them are statistically significant. Other costs and capital ${ }^{21}$ seem to have no effect on dairy production. Finally, there seems

\footnotetext{
${ }^{19}$ All inputs were normalized; this implies that estimated coefficients are elasticities at the sample mean.

20 Although the issue might be solved by increasing the number of iterations and the thin number, it was decided not to force the convergence of the model.

${ }^{21}$ Griffin and Steel (2007) and Ehlers (2007) suggest to choose a one-sided distribution for the prior distribution of the elasticities to obey regularity conditions. In particular, both pieces of work suggest a half-normal distribution for the input elasticities $p(\beta) \sim N^{+}\left(0, \omega_{\beta}^{-2}\right)$. Since capital has no significance in this application, we decided to keep the normal prior. Maximum-likelihood estimation with the same data set also obtained no significance in capital.
} 
to be a weak setback in the technical change in the analyzed period (trend) which coincides with the observed decline in UK milk production.

\begin{tabular}{lccc}
\hline \multicolumn{1}{c}{ INPUT } & Model 1 & Model 2 & Model 3 \\
\hline Intercept & -0.145 & -0.107 & -0.107 \\
& $(0.043)$ & $(0.045)$ & $(0.043)$ \\
LAND & 0.204 & 0.208 & 0.207 \\
& $(0.044)$ & $(0.045)$ & $(0.043)$ \\
LABOR & 0.187 & 0.193 & 0.194 \\
& $(0.048)$ & $(0.050)$ & $(0.050)$ \\
LIVESTOCK COSTS & 0.581 & 0.581 & 0.581 \\
& $(0.035)$ & $(0.034)$ & $(0.033)$ \\
OTHER COSTS & 0.037 & 0.027 & 0.027 \\
& $(0.033)$ & $(0.033)$ & $(0.033)$ \\
CAPITAL & -0.016 & -0.016 & -0.016 \\
TREND & $(0.025)$ & $(0.023)$ & $(0.024)$ \\
& -0.019 & -0.018 & -0.019 \\
Precision* & $(0.012)$ & $(0.012)$ & $(0.012)$ \\
& 103.766 & 102.231 & 101.967 \\
& $(6.888)$ & $(6.375)$ & $(6.333)$ \\
\hline Interations & Inefficiency effects & \\
\hline \hline
\end{tabular}

* Precision is the inverse of the variance.

Table 2-1 Mean posterior distributions of the models. Standard deviation in parenthesis.

Table 2-2 shows the annual production in millions of liters and its rate of growth. Furthermore, dairy production in the UK has been undergoing through a structural change characterized by a constant decrease in the herd size and in the number of dairy holdings. Total dairy production has little decreased and has remained almost stable due to the constant increase in the yield per cow (DairyCo, 2013). 


\begin{tabular}{lcccc}
\hline \hline \multicolumn{1}{c}{ Year } & 2004-2005 & 2005-2006 & 2006-2007 & 2007-2008 \\
\hline Production (M Liters) & 13767 & 13590 & 13484 & 13205 \\
Rate of growth & & $-1.3 \%$ & $-0.8 \%$ & $-2.1 \%$ \\
\hline \hline
\end{tabular}

Source: DairyCo, authors' calculation

Table 2-2 Annual milk production in the United Kingdom

Compared to Model 4 in Appendix 2, elasticities preserve proportionality and there is an increase in the land elasticity when regional heterogeneity is modeled - as well as an increase in the precision of the model - suggesting a lower variance in the mixed model specifications.

\subsubsection{Random Elasticities}

All elasticities in the models have random coefficients; Figure 2-3 shows the estimate of the posterior distributions of the standard deviations of these random coefficients for Model 2, $\boldsymbol{\sigma}_{\boldsymbol{\tau}}{ }^{22}$. In every model and for all elasticities, the standard deviations are significant. This confirms the presence of regional heterogeneity in the technologies used among counties.

Figure 2-4 shows Kernel distributions of the means' posterior distributions of the random intercepts for the 52 counties. The magnitudes suggest variation among the intensity of the use of the inputs in the production process between counties.

A closer look at the total elasticity magnitudes by county (see Equation 2.3) of livestock costs, land and labor, reveals some differences between counties. Table 2-3 shows descriptive statistics of the means' posterior distributions of these elasticities in the 52 counties.

\begin{tabular}{lccc}
\hline Input & Min. & Mean & Max. \\
\hline Livestock costs & 0.466 & 0.581 & 0.786 \\
Land & -0.213 & 0.209 & 0.325 \\
Labor & -0.031 & 0.192 & 0.430 \\
\hline
\end{tabular}

Table 2-3 Descriptive statistics of the posteriors distributions of the elasticities plus their random coefficients for selected inputs in Model 2.

\footnotetext{
${ }^{22}$ Estimated variances in the other two models do not vary considerably since they all have identical prior distributions.
} 

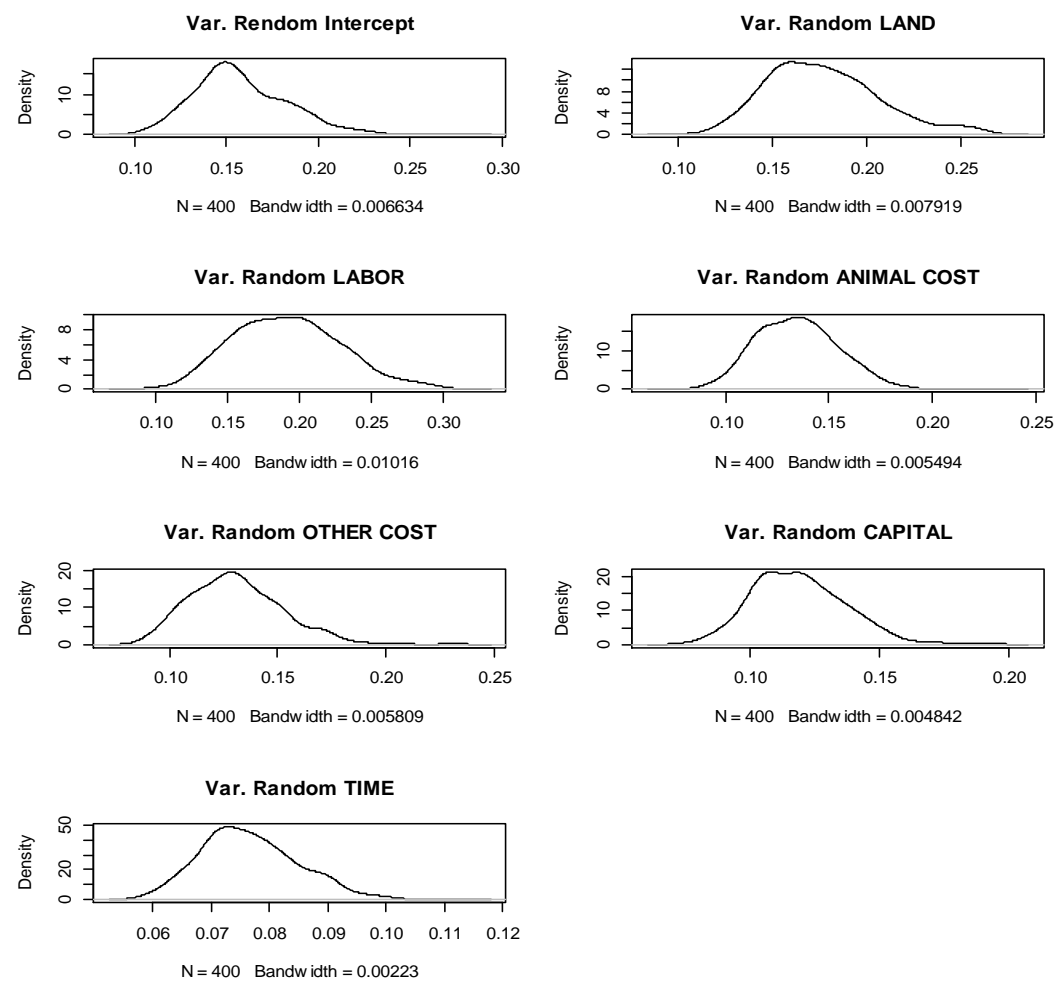

Figure 2-3 Variances of random coefficients in the three models
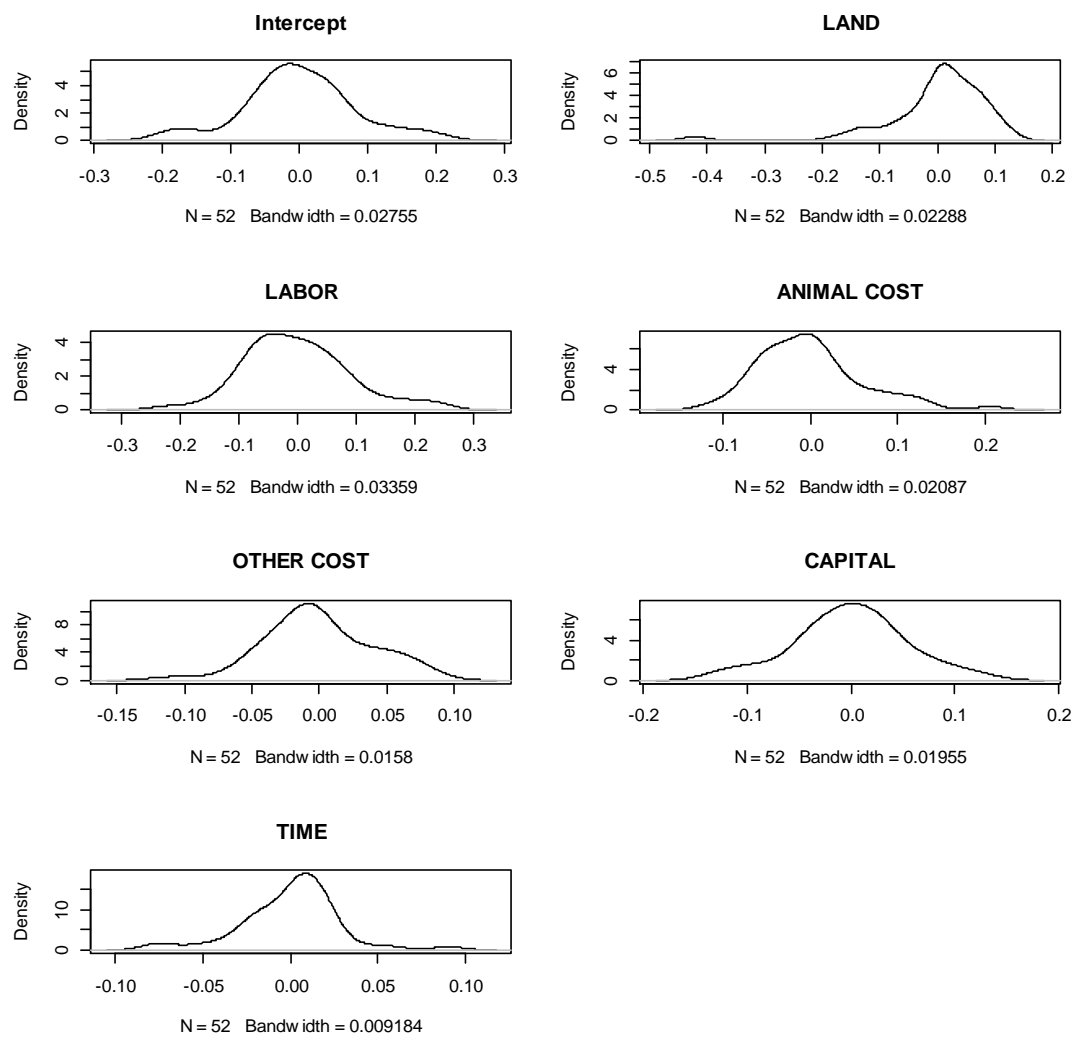

Figure 2-4 Mean Kernel distributions of the random coefficients in the 52 counties. 
The interpretation of these total magnitudes of the elasticities must be analyzed carefully. As explained previously, for some counties the number of observations is small and the estimator of the random coefficient might not be precise. Livestock costs are still the most important input in dairy production among counties with reasonable magnitudes. For land, the minimum value is -0.213 . This is the only negative value and corresponds to the county of Lincolnshire in England. A possible reason for this unexpectedly low number is that there are only 8 observations from 2 farms in this county. Nevertheless, its maximum has a reasonable magnitude. In the case of land, only one county has a small negative value in the elasticity.

Figures 2-5, 2-6 and 2-7 present these elasticities by county in map form. The fixed elasticity estimator was chosen as the threshold. Those counties in red represent values above the fixed elasticity while those in yellow represent values below it.

In the three cases, the regions of the North West and West Midlands of England seem to be especially intense in the use of the inputs, reporting values above the fixed elasticity. These two regions are characterized by intensive dairy production. The $23.4 \%$ of the farms specialized in dairy production in England were located in the North West Region, while $15.3 \%$ were located in the West Midlands ${ }^{23}$. This might suggest that regions with some degree of specialization in dairy production use the main inputs of the production process more intensively.

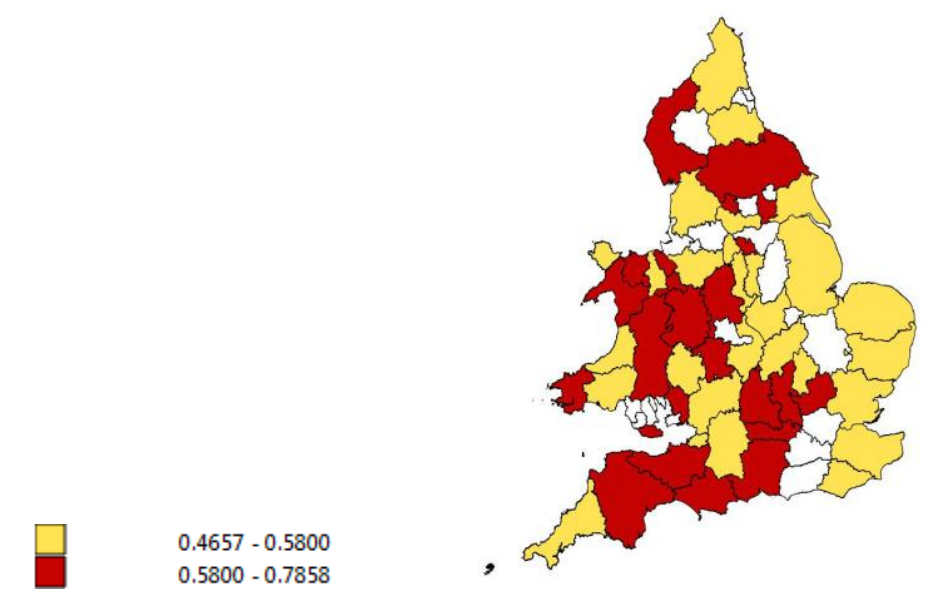

Figure 2-5 Livestock costs elasticities by county.

\footnotetext{
${ }^{23}$ Source: Detailed annual statistics on the structure of the agricultural industry on 1 June in England and the UK, DEFRA. Authors' calculation.
} 
On the other hand, the counties of Ceredigion, Pembrokeshire and Carmarthenshire in the extreme west of Wales seem to be more intense in the use of most of the inputs, in fact these three counties accounted for $59.67 \%$ of the total area dedicated to dairy in Wales by $2011^{24}$.

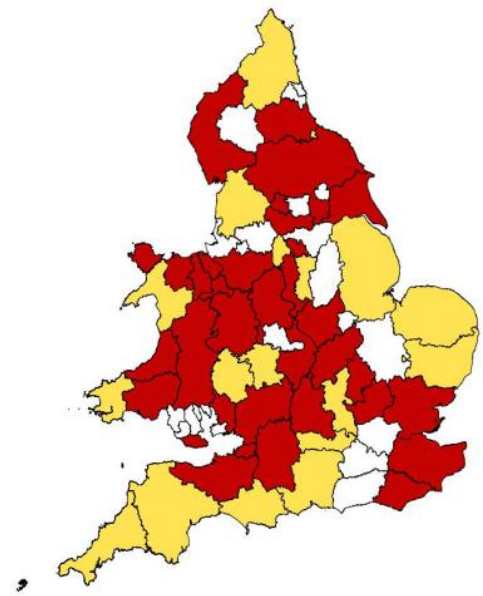

Figure 2-6 Land elasticities by county.

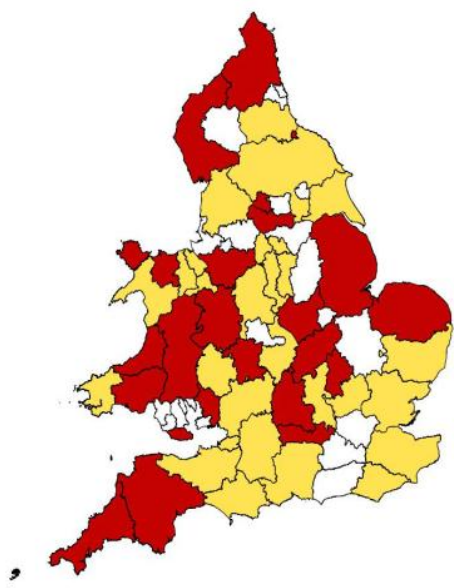

Figure 2-7 Labor elasticities by county.

\subsubsection{Inefficiency scores}

The effects of subsidies on inefficiency are consistent among the three models, while magnitudes vary considerably when comparing model 1 with the other two models in Table 2. The desegregation of the subsidies allows us to analyze the different effects that they have on efficiency. Livestock subsidies increase inefficiency in the dairy farms, this farm is attached to production; this means that only farms with a positive amount of

\footnotetext{
${ }^{24}$ Source: Welsh agricultural statistics, 2011. Authors'calculation.
} 
output are eligible to receive the subsidy. Berström (2000) observed that some subsidies might have a negative impact on efficiency since they represent an additional income that could discourage farmers' motivation. Hill farm allowance payments seem to decrease inefficiency in farms located in less favored areas, this means that farms located in Less Favored Areas benefit from the subsidy that was meant to overcome all the disadvantages that these farms face. Finally, environmental subsidies have no effect on inefficiency; the result might be explained by the low number of farms that receive this type of subsidy that is attached to specific projects in the farms. To our knowledge, this is the first attempt to study the effect of the different types of subsidies that farms receive. Former studies suggest no consensus of the effects of subsidies on inefficiency. A number of them find that subsidies increase inefficiency: Giannakas et al. (2001), Iraizoz et al. (2005), Rezitis et al. (2003) are some examples of this finding; McCloud and Kumbhakar (2008) find the opposite effect on inefficiency. Finally, Hadley (2006) finds different effects for each type of farm: In the case of dairy, subsidies decrease inefficiency.

Posterior means of the inefficiency scores do not vary considerably between the models, regardless of the prior distribution of the inefficiency term and their specification. In fact, inefficiency rankings are significantly correlated at 0.99 . Figure 8 plots the Kernel distributions of the inefficiency scores of the four models (Model 4 does not take into account regional heterogeneity). The highest correlations are present in models 2 and 3, which have the same prior distribution for the inefficiency term - their Kernel distributions are almost identical. Model 4 has a mean inefficiency score of 0.71 , which indicates that modeling the regional heterogeneity increases mean efficiency by $9.6 \%$ compared to Model 2. Model 4 has lower rank correlation with the other three models, between 0.78 for Model 1 and 0.80 for Model 3, suggesting differences in the rankings when regional heterogeneity is accounted for.

The results show that the inefficiency scores are similar to those obtained in former studies of the dairy sector in the United Kingdom. Hadley (2006) found that dairy had a declining mean efficiency per year with a mean efficiency in the last year of his panel of around 0.85. Areal et al. (2013) found mean efficiencies in the range 0.78-0.86, depending on the specification of the model based on distances in the weight matrix. 


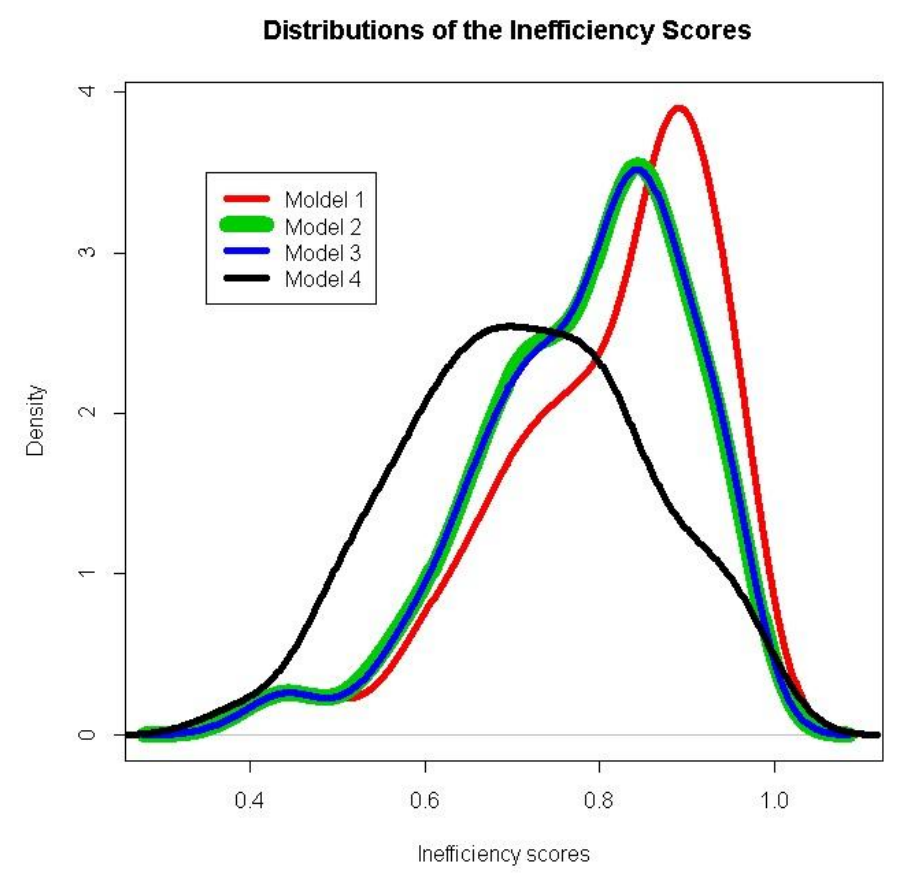

Figure 2-8 Kernel densities of the inefficiency scores.

Our results have a powerful interpretation. First of all, we have showed that models that account for regional heterogeneity by means of a mixed model were always preferred over models that ignore it. This result suggests that technologies used within each county might be similar for reasons exposed previously and ignoring this fact leads to biased estimators. Secondly, we have showed that accounting for regional heterogeneity improves efficiency scores which essentially mean that for this application in dairy farming in the UK efficiency scores were underestimated. Finally, we have also showed that accounting for regional heterogeneity does not imply the estimation of individual technologies. Our model specification has improved the accuracy of the estimators of the elasticities which in turn implies changes in the curvature of the frontier and the efficiency scores.

\subsection{Conclusion}

Data used in the efficiency analysis might have different hierarchical structures. In this work, the geographical hierarchical structure and the possible correlation inside regions in which the farms are located has been explored as a source to study regional heterogeneity. A production function that incorporates features of the mixed models was 
used to account for the regional heterogeneity. A Bayesian approach was used to develop the model since it allows estimating the production function, the random part of the mixed model and efficiency scores with effects in one single step.

The results suggest that models taking into account the regional heterogeneity are able to explain the data better in comparison to those models that ignore it. Essentially, our model relaxes the assumption that all producers share the same technology in a given geographical space and acknowledges the differences possible similarities within counties that in turn represent heterogeneity between counties. The structure of the model is capable of producing elasticity estimators for the different counties, allowing for particular analysis of the technologies in each county. This reveals differences in the intensity of the use of the inputs in the production process.

The results also show an increase of mean efficiency in farms when regional heterogeneity is taken into account independently of the chosen distribution for the inefficiency term. There are also differences in the rankings with a lower rank correlation of the model without random elasticities, suggesting substantial differences in the distribution of the rankings of the farms.

The effects of the subsidies in the inefficiency term are mixed. Livestock subsidies seem to increase inefficiency while farms located in less favored areas seem to benefit from the hill farm allowance. On the other hand, environmental subsidies have no impact on inefficiency. 


\title{
3. PRODUCTION HETEROGENEITY IN THE DAIRY SECTOR: A LATENT CLASS MODEL APPROACH
}

\begin{abstract}
Estimating technical efficiency under the assumption that all producers have the same technology might lead to biased estimates. The common approach to tackle the problem of production heterogeneity is to split up groups in the population with a priori information and then estimate a different production function for each group. In this work we use information on key variables that affect and determine dairy production to classify the farms in different groups by means of a latent class model (LCM). It has long been recognized that natural conditions like temperature and humidity might affect dairy production and that farmers can adapt their technologies to the environment they work in. To our knowledge, little research has been done as to how natural conditions can actually determine the employed technology. We use information on natural conditions such as temperature humidity index, altitude and classification of Less Favored Area (LFA) by the European Commission (EC) along with other variables that describe the technology employed by the farm such as yield per cow, feed per cow and total infrastructure in the farm per cow as latent variables to classify our data set in different groups. Stochastic frontier estimation is performed in each group to analyze technological differences between the groups. Our data consist of an unbalanced panel of dairy farms from Spain, France, Belgium, Netherlands, Germany, Denmark, Austria and Italy in the period 1995-2008 provided by the EC. The results suggest that the latent variables used clearly classify the sample according to the technology of each group. Total factor productivity decomposition reveals that decreasing efficiency and small technical change are common features across groups. All results were compared to estimators that ignore heterogeneity. The results differ in several issues and their implications are analyzed.
\end{abstract}

Keywords: Stochastic frontier, efficiency analysis, latent class model, production heterogeneity.

JEL classification: C13, C33,C81, D24, D13 


\subsection{Introduction}

Classical estimation of production frontiers has been studied under the assumption that all farmers share the same technology. This assumption might be more credible if natural conditions and location characteristics are accounted for. Furthermore, as noted by Alvarez and del Corral (2010), ignoring the different technologies in the sample can lead to biased estimations of efficiency. Orea and Kumbhakar (2004) found that if there is heterogeneity in the technology, a common frontier for all observations may not allow an estimation of the "true" technology for each observation; as a result, the estimation might be biased. If the heterogeneity is ignored, these differences in technology could be addressed as inefficiency. Several different pieces of work have studied the role of production heterogeneity. Some work has been dedicated to developing stochastic frontiers with random coefficients to account for firm heterogeneity; Tsionas (2002) and Green (2005) are some examples.

Other studies have concentrated on firm classification. Form classification which accounts for firm heterogeneity has been divided into two different branches to address the problem. In the first branch the sample is divided into several groups according to farm information such as location, farm ownership and type of farm (Kumbahkar et al., 2009; Battese el al. 2004). Individual frontiers are subsequently estimated for each group. This is the so called two stage-process. Other example of this technique includes Hoch (1962) and Alvarez et al., (2008). In this same two-stage process other authors have decided to use cluster or other statistical analysis techniques to divide the sample into several groups and then estimate the individual frontiers per group. Maudos el al. (2002), Newman and Matthews (2006) and Alvarez et al. (2008) are some examples. The results presented in this work belong to the latter. We employ latent class analysis (LCA) to classify our sample and then we estimate frontiers for each cluster.

On the other hand, the second branch of the literature has been dedicated to the so called single-step process. Specifically, they use latent class models (LCM) in convention with stochastic frontier analysis (Greene, 2005). In this technique, latent variables are included in the production frontier in order to obtain the number of clusters and the firms' membership to the cluster. Examples of this technique include Orea and Kumbhakar (2004) and Alvarez and del Corral (2010). Despite of the benefits of estimating these kinds of models in one single step described by Orea and Kumbhakar (2004), we have 
chosen the two-step process because it allows us to use observable variables in the first step that could be considered endogenous in the single-step procedure, e.g. milk yield. In fact, Alvarez and del Corral (2010) decided not to use two variables as latent variables to avoid this issue.

As stated before, this work employs a two-step process. Our aim is to classify the sample of farms in several groups and then estimate individual frontiers for each group. To classify the sample, we use individual information as latent variables that can describe the technology of the farm. Additionally, we use regional information on the location of the farm, manly climatologic information, and other variables that describe the natural conditions in which the farm is operating. This group of variables - does not appear, to our knowledge, to have been studied in any great detail for the estimation of efficiency in dairy production. Demir and Mahmud (2002) concluded that ignoring environmental variables when estimating technical efficiency in agriculture may lead to improper specifications of technical efficiency. Our hypothesis is that farmers adopt different technologies in an attempt to adapt to natural conditions. After the classification is performed, we estimate a stochastic frontier model for each group in the sample. Our data consist of an unbalanced panel of dairy farms of eight countries in Europe: Spain, France, Belgium, Netherlands, Germany, Denmark, Austria and Italy in the period 1995-2008 with an approximate number of 90000 observations.

The remainder of this work is organized as follows. First, we will describe the data used for the empirical application, paying particular attention to the variables used in each step. At the same time we will describe the first step of the process by explaining the cluster technique employed, Latent Class Analysis. Later we show the results of the second step, that is, the individual stochastic frontiers. We analyze the differences in the technologies and estimate total factor productivity decomposition. Finally we give some conclusions and policy implications of our findings.

\subsection{Data and Estimation}

Our data consists of an unbalanced panel of approximately 90,351 specialized observations of dairy farms $^{25}$ in the period 1995-2008 located in Spain, France, Belgium, Netherlands, Germany, Denmark, Austria and Italy. The data belongs to the Farm

\footnotetext{
${ }^{25}$ According to the Farm Accountancy Data Network, a farm is specialized in a particular activity if at least $75 \%$ of its revenue is provided by this particular activity.
} 
Accountancy Data Network (FADN) ${ }^{26}$ of the European Commission (EC). The data provide financial, physical and environmental performance information for the farms in the sample. Since our goal is also to classify farms according to the natural conditions in which they operate, some of the variables that describe such conditions are measured at the regional level, and not the farm level. This in part because we do not know the exact location of the farms, all we know is the region ${ }^{27}$ in which the farms are located. Additionally, for the construction of some of the variables, only data aggregated at the region level was available.

\subsubsection{First Step - Latent Class Analysis (LCA)}

Data can be grouped in unobserved classifications. Some statistical techniques help researchers to unveil these groups; LCA is one of these techniques. The key idea here is that the latent class is not observed. Instead, the researcher measures the latent variable in an indirect way through a set of observed variables. It is worth mentioning that the technique was developed to deal with observed variables that are discrete. Recent developments allow for continuous variables. Our focus here is on the former type of variables, that is, discrete observed variables.

In order to mathematically formalize the LCA, we will follow the notation suggested by Collins and Lanza (2010). This formalization assumes that the observed variables are discrete, that is, each observed variable has a finite number of options (e.g. Gender= Male or Female). These options are called response categories.

We assume that we have $J$ observed variables, and that each observed variable has $r_{j}=1, \ldots \ldots, R_{j}$ response categories. With this information, a contingency table can be constructed by tabulating all the $J$ variables. We then define $W=\prod_{j=1}^{J} R_{j}, W$ as the total number of cells that the contingency has. Each cell in this contingency table corresponds to a vector of response patterns $\boldsymbol{y}=\left(r_{\mathbf{1}}, \ldots, r_{J}\right)$, where each $\boldsymbol{y}$ is a possible combination of responses for all the observed variables. Let $\boldsymbol{Y}$ be the array of response patterns with $W$ rows and $J$ columns. Each pattern has an associated probability of $P(\boldsymbol{Y}=\boldsymbol{y})$, with $\sum P(\boldsymbol{Y}=\boldsymbol{y})=\mathbf{1}$. The parameters to be estimated are the vectors $\boldsymbol{\gamma}$ and $\boldsymbol{\rho}$. These

\footnotetext{
${ }^{26}$ Data source: EU-FADN - DG AGRI.

${ }^{27}$ Regional level means NUTS1 definition of the European Commission (e.g. Federal State in the case of Germany, autonomous community in the case of Spain). For the Netherlands, Belgium, Denmark and Austria information on the location of the farm is given at NUTS0 level, that is, country level.
} 
vectors represent the prevalences (that is, the probability of each class in sample or probability of membership) and the item response probability (that is, the probability of each response category in each class). Both are probabilities and follow the rules of probabilities. In other words, if $L$ represents a categorical latent variable with $c=1, \ldots . ., C$ latent classes, then $\sum_{c=1}^{C} \gamma_{c}=1$. Furthermore, since $\boldsymbol{\rho}$ is conditional on membership class $c$, that is, $\rho_{j, r_{j} \mid c}$, then $\sum_{r_{j}=1}^{R_{j}} \rho_{j, r_{j} \mid c}=1$.

Let us finally define $y_{j}$, as the element $j$ in the response pattern $\boldsymbol{y}$, and the indicator function $I\left(y_{j}=r_{j}\right)$, that is going to be equal to 1 if $j=r_{j}$ and 0 otherwise. The probability of observing a certain pattern of responses is then a function of $\boldsymbol{\gamma}$ and $\boldsymbol{\rho}$ as follows:

$$
P(\boldsymbol{Y}=\boldsymbol{y})=\sum_{c=1}^{C} \gamma_{c} \prod_{j=1}^{J} \prod_{r_{j}=1}^{R_{j}} \rho_{j, r_{j} \mid c}^{I\left(y_{j}=r_{j}\right)}
$$

The estimation of Equation 3.1 is done with maximum likelihood using the Maximum Expectation Algorithm (see Collins and Lanza, 2010 for further details).

Since our assumption is that natural conditions determine the technology that the farm employs, observed variables have been chosen that describe the technology and natural condition in which the farms operate. Notice that the chosen variables were converted into discrete variables in order to estimate Equation 3.1. In particular, the continuous variables were averaged over the time period and then converted into three categories according to their tertiles.

Milk Yield: The volume of milk produced by a cow as a measure of partial productivity of the farm. Milk yield seems to be determined by many factors like farmers expertise and practices as well as natural conditions (either climatological or those related to the breed of the cow). Certain climatological conditions seem to favor high yields and certain cow breeds seem to be more productive. In any case, this variable is meant to divide the sample according to the productivity of the farms. Furthermore, when the average yield of milk per cow is plotted in a map, there seems to be a geographical pattern in the distribution of the yield. Figure 3-1 plots the average milk yield per cow over the time period in the regions in the sample. In general, northern Europe seems to be more productive than southern Europe. Differences in milk yield are also noticeable between north and south in Spain and Italy. To perform LCA, the tertiles of the distribution for 
this variable expressed in kilograms of milk per cow are: [1000, 5188.5), [5188,5, 6648.7], (6648.7, 10000].

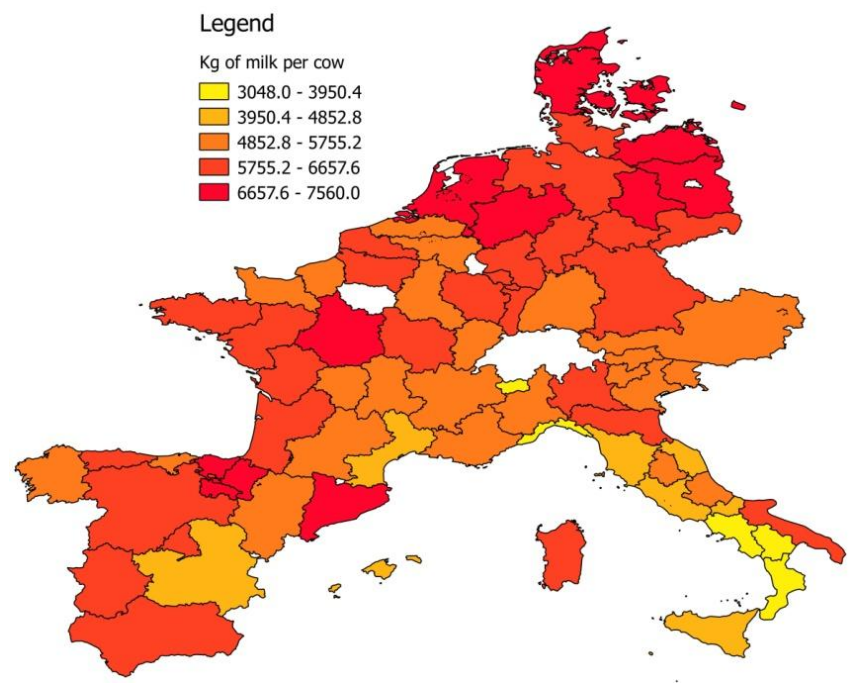

Figure 3-1 Average milk yield per cow in the period 1995-2008.

Temperature-humidity Index (THI): It has long been recognized that temperature and humidity play a key role in the health of cows and their milk yield. According to Bouraoui el al. (2002), high temperature in combination with high humidity for long periods affects the capacity of the cow to dissipate heat. As a result, the cows tend to suffer from heat stress, which in turn negatively affects the physiology and milk yield of the cow. According to West (2003), changes in the physiology and behavior of a cow facing heat stress include reduced feed intake, decreased activity, a tendency to seek shade and wind, increase in respiratory rate and increase in blood flow and sweating. All of these factors result in negative consequences to the milk yield. THI is a widely used index in dairy science that combines measures of both temperature and humidity. It serves as a measure of heat stress. The formula for THI has the following form:

$$
T H I=0.81 * \text { Temperature }\left({ }^{\circ} \mathrm{C}\right)+\text { Relative humidity } *\left(\text { Temperature }\left({ }^{\circ} \mathrm{C}\right)-14.4\right)+46.4
$$

Numerous studies use it to establish the effects of heat stress on the milk yield of the cow. Some include Johnson (1980) and Du Preez et al. (1990 and 1990b) who conclude that milk yield declines when the value of THI is around 72 or greater. Johnson et al. (1962) found that milk yield decreases when THI reaches 77. Ingraham (1979) found a reduction of $0.32 \mathrm{Kg}$. in the milk yield per increased unit of THI. 
We have calculated THI for each region in the sample. We collected monthly data of mean temperature and relative humidity from two distant cities in each region ${ }^{28}$ in the period of 1995-2008. We then calculated the THI for each region. Figure 3-2 shows the differences in THI between the regions. The tertiles of this variable are: $[48.68,51.94)$, [51.94, 56.54], (56.54, 65.08].

As expected, THI tends to be larger in Mediterranean countries, while milder values of THI are more frequent in the regions of the north. None of the regions have average values of THI which would compromise the physiology of the cows. Nevertheless, critical values of THI may be reached in summer, especially in Mediterranean countries.

Altitude: Altitude is a categorical variable that takes the value of 1 if the farm is located under 300 meters above sea level (MASL), 2 if it is between 300 and 600 MASL and 3 if it is above 900 MASL. Higher altitudes might be related with lower values of THI. Nevertheless, high altitudes might be an indicator of adverse natural conditions, isolation and difficulties of communication and extreme weather conditions in winter.

Less Favored Area (LFA) ${ }^{29}$ : LFAs are defined in articles 18 to 20 of regulation (EC) No. $1257 / 1999$. To summarize, a farm is considered to be in an LFA if the farm is located in mountainous areas that face extreme weather conditions and/or make it difficult to use the land. Similarly, a farm is in an LFA if it is in danger of abandonment by the user due to poor productivity of the land and decline of the population, or if the farm is affected by special handicaps due to environmental conservation. The variable takes the value of 1 if the farm is not in an LFA and 2 otherwise.

\footnotetext{
${ }^{28}$ Cities separated by considerable distances were considered to account for the effect of different climatologic areas in each region.

${ }^{29}$ The regulation of the EC allows countries to classify Less Favored Areas under the criteria "Other LFA's". According to a report from the Institute for the European Environmental Policy, this criterion is not well defined and lacks a precise measure. As a result, each member state interprets and defines the measures for classifying areas under "Other LFA's". Much of the increase in LFA's since the late 80's has been attributed to this classification. The report attributes this increase partly to the monetary incentives provided by the European Agricultural Guidance and Guarantee Fund, and the fact that member states are not committed to make any LFA payments.
} 


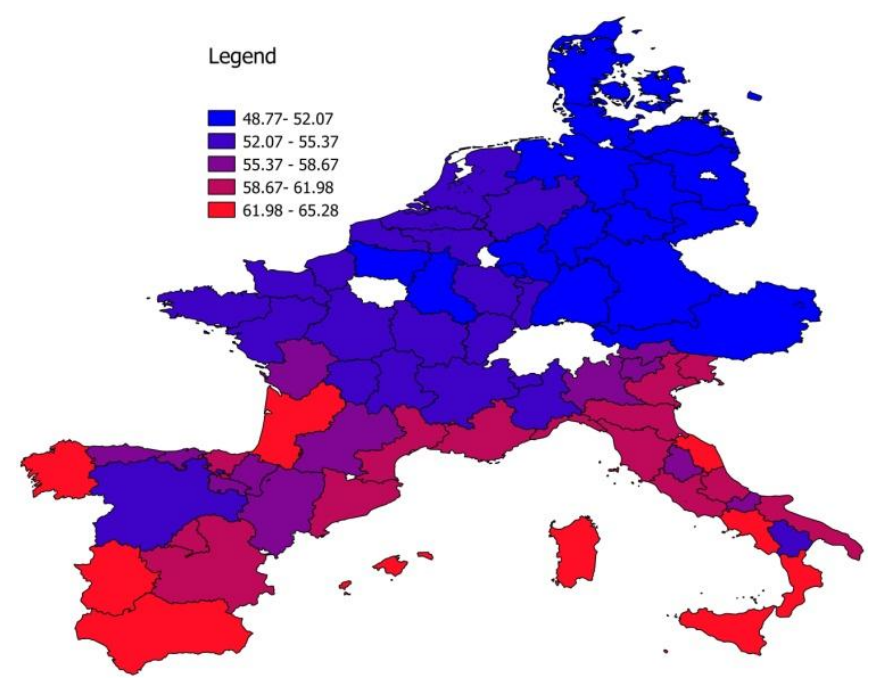

Figure 3-2 Average THI in the period 1995-2008

Cows per hectare: According to Alvarez and del Corral (2010), a higher number of cows per hectare is associated with more intensive technologies. Furthermore, more intensive technologies are, in turn, associated with more productive and efficient farms. Simpson and Conrad (1993) and Reinhard et al. (1999) are other examples of this finding. We expect this variable to capture differences between extensive and intensive technologies. When the average number of cows per region is plotted on a map, there seems to be a pattern showing that regions in southern Europe tend to have more cows per hectare than countries in the north (See Figure 3-3). The tertiles of this variable are: [0.029, 0.76), $[0.76,1.31],(1.31,9.91]$.

Feed per cow: Feed per cow is the cost of feeding stuff and concentrates per cow. Just like cows per hectare, higher values of feed are associated with more intense technologies. Hallam and Machado (1996) and Alvarez and del Corral (2010) are some examples of this conclusion. The geographical pattern of feed cows per hectare seems to replicate in feed per cow: the southern regions tend to spend more on feeding in contrast with northern regions (See Figure 3-4). This pattern seems to be consistent with the idea that cow diet needs to be modified when the cow faces heat stress. West (2003) found that the diet of the cow in high temperatures should take into account the reduced matter intake, greater nutrient requirements in periods of hot weather, dietary heat increment and avoid nutrient excess. Overall, farms located in adverse temperature conditions for the cows should invest more in feeding stuff. This is precisely the kind of weather that might prevail in south Europe. The tertiles of this variable are: [0.065, 460.64), [460.64, 
769.39], $(769.39,1996.05]$. The values of this variable were deflated and are in constant prices of the year 2000 .

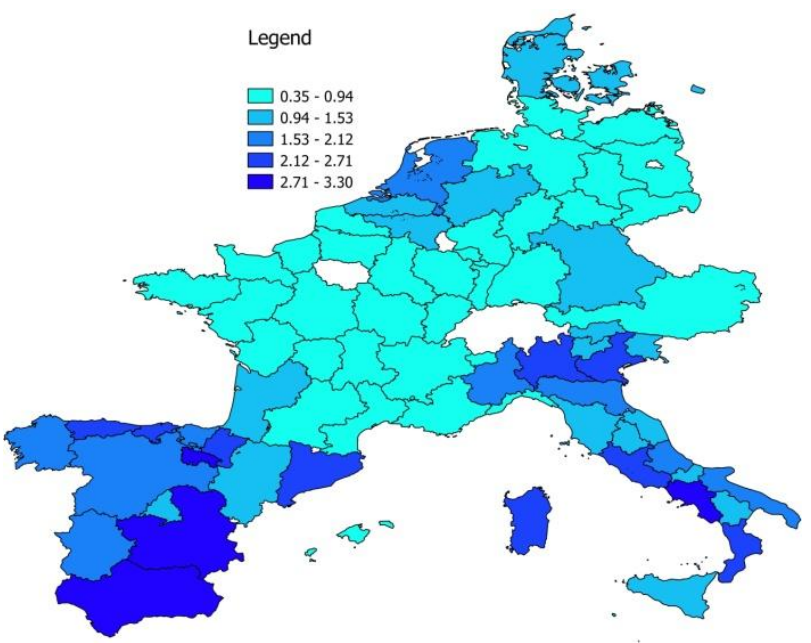

Figure 3-3 Average number of cows per hectare in the period 1995-2008.

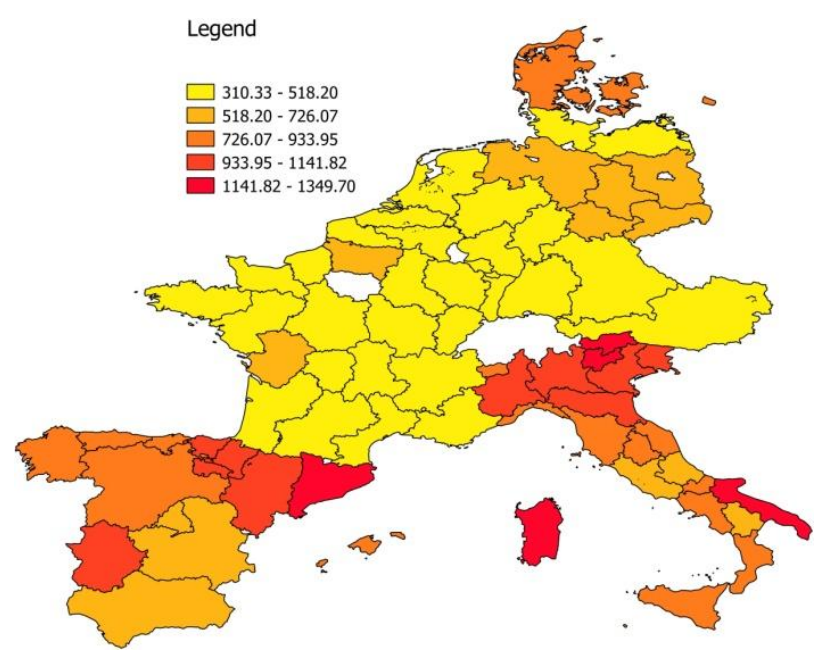

Figure 3-4 Average feed cost per cow in Euros 1995-2008 (Constant prices 2000).

Buildings per cow: This is calculated as the value of the buildings in the farm per cow. We expect this variable to capture the effort of the farmers to mitigate adverse natural conditions. West (2003) describes modifications that framers can make in order to mitigate the effects of high THI. They include shade, barns that improve ventilation together with fans and sprinkles. More advanced technologies might include ventilations tunnels. Figure 3-5 shows the average value of buildings per cow in each region. Regions facing adverse THI seem to have lower values; regions in the east and Austria have higher values. In general, if the variable serves as a proxy for infrastructure, this shows that contrary to expectations, regions with higher temperatures invest less in 
infrastructure for the cows. The values were deflated to constant prices of the year 2000 . The tertiles of this variable are: [0.033, 1254.6), [1264.6, 3062.2], (3062.2, 19922.24].

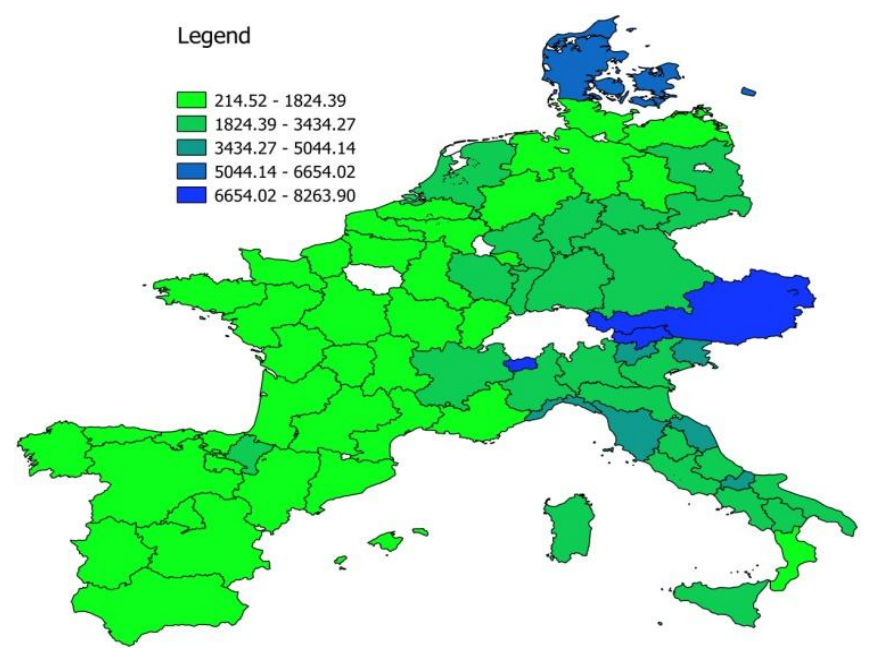

Figure 3-5 Average value of buildings per cow in the period 1995-2008 (Constant prices 2000)

With this set of variables, we can estimate Equation 3.1. Like in any cluster analysis, choosing the number of clusters is a key issue. As noted by Collins and Lanza (2010), there are several criteria which address the issue. We have selected the number of clusters based on the Akaike Information Criteria (AIC) and the Bayesian Information Criteria (BIC). Both include a penalty in the number of parameters that the model estimates. Other criteria include the likelihood-ratio statistic, but as noted by the authors, when the number of degrees of freedom is large, the reference distribution for the likelihood-ratio is unknown, making interpretation difficult.

A set of models was estimated from 2 clusters to 20 clusters. Since local maxima might be reached in the estimation, we have calculated each model 20 times with different initial values. The model with the maximum log-likelihood was chosen in each set of calculations. As stated before, the variables to estimate Equation 3.1 were first transformed into averages over time and then converted into categorical variables according to their tertiles ${ }^{30}$. This means that for the estimation we used the total number of farms present in the sample (cross-sections): 21452 farms.

Figure 3-6 shows the values of AIC and DIC for the estimated models. There is a drastic decrease between 2 clusters and 10 clusters. Values tend to decrease more slowly after 10

\footnotetext{
${ }^{30}$ The results were better under AIC and DIC when variables were divided in tertiles than they were when variable $\mathrm{s}$ were divided by their median.
} 
clusters. When the number of clusters is 17 , BIC reaches its minimum value. This suggests that 17 is the optimal number of clusters. AIC keeps decreasing at a smaller rate at 15 clusters. That is, an additional cluster adds little information to the estimation.

At 17 clusters, the value of BIC is $263,830.8$. With this number of clusters as reference, decisions about the number of clusters should take into account desirable properties such as homogeneity and separability, as pointed by Collins and Lanza (2010). Complete homogeneity refers to item response probabilities with extreme values of 0 or 1 . In other words, the population in the cluster shares strong characteristics in the observed responses. Conversely, separability refers to the differentiation between latent classes or clusters. It is therefore desirable to have latent classes or clusters that differentiate strongly in the item-response probabilities.

With this philosophy, we have chosen 16 as the number of clusters in the sample. We believe that homogeneity and separability in this number of clusters is adequate. Furthermore, the difference in DIC and AIC between 16 and 17 clusters is very small ${ }^{31}$.

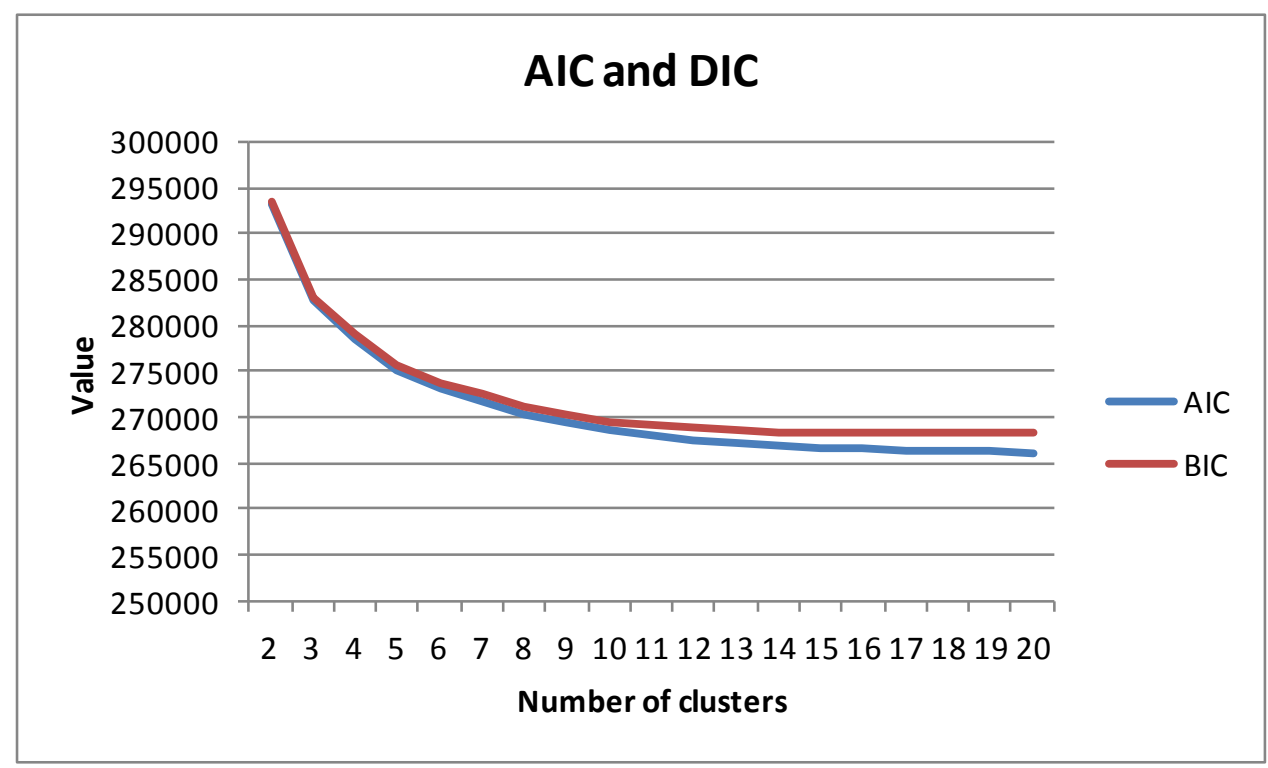

Figure 3-6 AIC and BIC values for different number of clusters.

Table 3-1 shows the estimates for $\gamma$ and $\boldsymbol{\rho}$ in the 16 clusters. Since this is a probabilistic model, each farm`s membership of a particular cluster was defined as the largest probability of belonging to that cluster. The average probability for each farm of being a

\footnotetext{
${ }^{31}$ For 16 clusters, AIC is 266549.4 and DIC is 268327.5 . AIC is 266419 and BIC is 268308.8 for 17 clusters.
} 
member of a particular cluster is 0.77 . The three categories of the visible variables named after their tertiles were named as "low", "mid" and "high"

\begin{tabular}{|c|c|c|c|c|c|c|c|c|c|c|c|c|c|c|c|c|}
\hline CLUSTER & 1 & 2 & 3 & 4 & 5 & 6 & 7 & 8 & 9 & 10 & 11 & 12 & 13 & 14 & 15 & 16 \\
\hline Prevalence & $8.3 \%$ & $7.0 \%$ & $6.5 \%$ & $4.5 \%$ & $6.4 \%$ & $6.6 \%$ & $6.3 \%$ & $6.8 \%$ & $8.4 \%$ & $10.5 \%$ & $6.8 \%$ & $4.5 \%$ & $4.1 \%$ & $4.2 \%$ & $2.8 \%$ & $6.4 \%$ \\
\hline \multicolumn{17}{|c|}{ Milk Yield } \\
\hline Low & $14.2 \%$ & $6.4 \%$ & $87.7 \%$ & $1.5 \%$ & $0.0 \%$ & $69.7 \%$ & $1.0 \%$ & $52.9 \%$ & $67.2 \%$ & $29.5 \%$ & $48.0 \%$ & $53.0 \%$ & $13.3 \%$ & $28.5 \%$ & $38.2 \%$ & $7.5 \%$ \\
\hline Mid & $31.5 \%$ & $33.6 \%$ & $8.7 \%$ & $10.1 \%$ & $24.5 \%$ & $22.9 \%$ & $15.8 \%$ & $41.8 \%$ & $27.0 \%$ & $48.5 \%$ & $45.6 \%$ & $40.4 \%$ & $46.3 \%$ & $50.6 \%$ & $49.7 \%$ & $43.3 \%$ \\
\hline High & $54.3 \%$ & $60.0 \%$ & $3.5 \%$ & $88.4 \%$ & $75.5 \%$ & $7.4 \%$ & $83.1 \%$ & $5.3 \%$ & $5.8 \%$ & $22.1 \%$ & $6.5 \%$ & $6.6 \%$ & $40.4 \%$ & $20.9 \%$ & $12.1 \%$ & $49.2 \%$ \\
\hline \multicolumn{17}{|c|}{$\mathrm{HTI}$} \\
\hline Low & $1.2 \%$ & $0.0 \%$ & $0.0 \%$ & $100.0 \%$ & $70.1 \%$ & $0.0 \%$ & $0.0 \%$ & $8.9 \%$ & $0.0 \%$ & $20.8 \%$ & $94.1 \%$ & $96.6 \%$ & $100.0 \%$ & $0.0 \%$ & $100.0 \%$ & $84.5 \%$ \\
\hline Mid & $37.7 \%$ & $3.3 \%$ & $56.1 \%$ & $0.0 \%$ & $28.7 \%$ & $11.4 \%$ & $100.0 \%$ & $85.9 \%$ & $4.7 \%$ & $79.0 \%$ & $5.3 \%$ & $3.4 \%$ & $0.0 \%$ & $0.0 \%$ & $0.0 \%$ & $14.6 \%$ \\
\hline High & $61.1 \%$ & $96.7 \%$ & $44.0 \%$ & $0.0 \%$ & $1.2 \%$ & $88.6 \%$ & $0.0 \%$ & $5.3 \%$ & $95.3 \%$ & $0.3 \%$ & $0.6 \%$ & $0.0 \%$ & $0.0 \%$ & $100.0 \%$ & $0.0 \%$ & $0.9 \%$ \\
\hline \multicolumn{17}{|c|}{ Altitude } \\
\hline Less than $300 \mathrm{mts}$. & $85.2 \%$ & $34.0 \%$ & $2.0 \%$ & $100.0 \%$ & $91.6 \%$ & $77.6 \%$ & $99.6 \%$ & $22.7 \%$ & $14.5 \%$ & $99.1 \%$ & $46.1 \%$ & $0.0 \%$ & $91.9 \%$ & $6.9 \%$ & $0.0 \%$ & $8.8 \%$ \\
\hline $300-600 \mathrm{mts}$ & $13.4 \%$ & $52.9 \%$ & $15.2 \%$ & $0.0 \%$ & $7.3 \%$ & $20.3 \%$ & $0.4 \%$ & $39.6 \%$ & $56.9 \%$ & $0.8 \%$ & $53.9 \%$ & $28.0 \%$ & $7.7 \%$ & $14.4 \%$ & $53.7 \%$ & $67.7 \%$ \\
\hline$>600$ mts. & $1.4 \%$ & $13.1 \%$ & $82.8 \%$ & $0.0 \%$ & $1.1 \%$ & $2.1 \%$ & $0.0 \%$ & $37.7 \%$ & $28.6 \%$ & $0.1 \%$ & $0.0 \%$ & $72.0 \%$ & $0.5 \%$ & $78.8 \%$ & $46.3 \%$ & $23.5 \%$ \\
\hline \multicolumn{17}{|c|}{ Less Favored Area } \\
\hline Not in LFA & $100.0 \%$ & $2.0 \%$ & $0.0 \%$ & $98.5 \%$ & $61.2 \%$ & $78.3 \%$ & $100.0 \%$ & $1.8 \%$ & $0.0 \%$ & $100.0 \%$ & $26.9 \%$ & $1.1 \%$ & $100.0 \%$ & $0.0 \%$ & $11.2 \%$ & $0.8 \%$ \\
\hline In LFA & $0.0 \%$ & $98.0 \%$ & $100.0 \%$ & $1.5 \%$ & $38.8 \%$ & $21.7 \%$ & $0.0 \%$ & $98.2 \%$ & $100.0 \%$ & $0.0 \%$ & $73.1 \%$ & $98.9 \%$ & $0.0 \%$ & $100.0 \%$ & $88.8 \%$ & $99.2 \%$ \\
\hline \multicolumn{17}{|c|}{ Cows per $\mathrm{Ha}$} \\
\hline Low & $3.0 \%$ & $5.2 \%$ & $51.0 \%$ & $20.3 \%$ & $55.1 \%$ & $5.1 \%$ & $16.0 \%$ & $71.3 \%$ & $12.7 \%$ & $45.6 \%$ & $52.5 \%$ & $84.9 \%$ & $26.1 \%$ & $16.5 \%$ & $0.0 \%$ & $59.6 \%$ \\
\hline Mid & $18.0 \%$ & $16.2 \%$ & $31.5 \%$ & $64.4 \%$ & $40.7 \%$ & $17.9 \%$ & $20.7 \%$ & $23.2 \%$ & $29.9 \%$ & $43.2 \%$ & $42.1 \%$ & $15.2 \%$ & $56.3 \%$ & $37.6 \%$ & $84.9 \%$ & $35.3 \%$ \\
\hline High & $79.0 \%$ & $78.6 \%$ & $17.5 \%$ & $15.3 \%$ & $4.3 \%$ & $77.1 \%$ & $63.3 \%$ & $5.4 \%$ & $57.4 \%$ & $11.3 \%$ & $5.4 \%$ & $0.0 \%$ & $17.7 \%$ & $45.9 \%$ & $15.1 \%$ & $5.1 \%$ \\
\hline \multicolumn{17}{|c|}{ Feed per cow } \\
\hline Low & $0.0 \%$ & $0.0 \%$ & $4.0 \%$ & $0.0 \%$ & $20.4 \%$ & $19.1 \%$ & $35.9 \%$ & $76.9 \%$ & $8.4 \%$ & $86.3 \%$ & $83.7 \%$ & $88.5 \%$ & $15.0 \%$ & $0.2 \%$ & $97.0 \%$ & $4.0 \%$ \\
\hline Mid & $1.2 \%$ & $6.4 \%$ & $30.5 \%$ & $36.0 \%$ & $67.1 \%$ & $56.6 \%$ & $57.2 \%$ & $20.9 \%$ & $55.0 \%$ & $13.7 \%$ & $15.8 \%$ & $11.1 \%$ & $76.7 \%$ & $0.0 \%$ & $3.0 \%$ & $82.9 \%$ \\
\hline High & $98.8 \%$ & $93.6 \%$ & $65.4 \%$ & $64.0 \%$ & $12.6 \%$ & $24.3 \%$ & $6.9 \%$ & $2.1 \%$ & $36.7 \%$ & $0.0 \%$ & $0.5 \%$ & $0.4 \%$ & $8.3 \%$ & $99.8 \%$ & $0.0 \%$ & $13.1 \%$ \\
\hline \multicolumn{17}{|c|}{ Buildings per cow } \\
\hline Low & $33.6 \%$ & $47.0 \%$ & $14.9 \%$ & $0.3 \%$ & $42.7 \%$ & $53.7 \%$ & $15.7 \%$ & $62.4 \%$ & $52.7 \%$ & $61.9 \%$ & $29.0 \%$ & $0.0 \%$ & $7.2 \%$ & $7.5 \%$ & $16.0 \%$ & $12.3 \%$ \\
\hline Mid & $37.1 \%$ & $41.6 \%$ & $18.6 \%$ & $2.3 \%$ & $49.1 \%$ & $31.0 \%$ & $57.7 \%$ & $35.1 \%$ & $36.1 \%$ & $32.9 \%$ & $43.4 \%$ & $9.0 \%$ & $18.8 \%$ & $17.8 \%$ & $34.0 \%$ & $39.7 \%$ \\
\hline High & $29.3 \%$ & $11.4 \%$ & $66.5 \%$ & $97.5 \%$ & $8.2 \%$ & $15.3 \%$ & $26.6 \%$ & $2.5 \%$ & $11.2 \%$ & $5.3 \%$ & $27.6 \%$ & $91.0 \%$ & $74.0 \%$ & $74.8 \%$ & $50.0 \%$ & $48.0 \%$ \\
\hline
\end{tabular}

Table 3-1 LCA results

For illustrative purposes, all the clusters were named after a region. Figure 3-7 shows the most frequent clusters in each region. Notice that the North-Europe and Austro-German clusters are not plotted in the figure as they do not occur most frequently in any region. Each region has different clusters, on average each region has 6.4 clusters. Table 3-2 shows the chosen names for the clusters. 


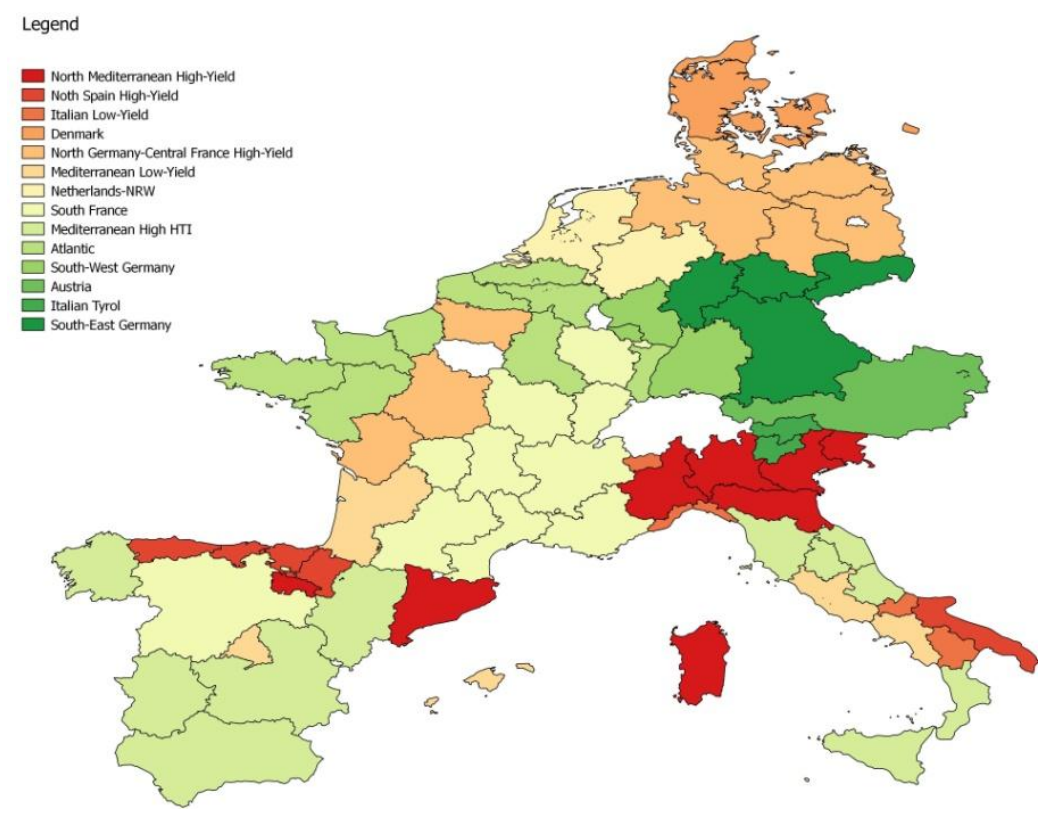

Figure 3- 7 Names and location of the clusters. Names were chosen after the region in which they are most frequent.

\begin{tabular}{|cl|}
\hline Number & \multicolumn{1}{c|}{ Name } \\
\hline 1 & North Mediterranean- High-yield \\
3 & North Spain -High yield \\
4 & Italian low yield \\
5 & Nonmark \\
6 & Mediterrenian low yield \\
7 & Netherlands-NRW \\
8 & South France \\
9 & Mediterranian high THI \\
10 & Atlantic \\
11 & South-west Germany \\
12 & Austria \\
13 & North Europe \\
14 & Italian Tyrol \\
15 & Austro-German \\
16 & South-east Germany \\
\hline
\end{tabular}

Table 3-2 Names of the clusters according to the location in which they are the most frequent.

Figure 3-7 also reveals that neighboring regions share clusters and possibly technologies. For example, the Denmark (4) cluster is mainly located in the county it was named after. However, it is also present - albeit with less frequency - in regions of north Germany. Still, this cluster is never present in regions of south Europe. Another example is the North Spain high yield (2) cluster. While this cluster is mainly frequent in the region it 
was named after, it is also present in southern France but practically absent in regions of northern Europe.

To confirm the separability of clusters, we carried out an ANOVA on the visible variables. In all seven variables, the null hypothesis was rejected. This suggests that there is a difference between the means of each variable between the clusters ${ }^{32}$.

As seen in Table 3-1, high milk yield is frequent in clusters Denmark (4), North Germany-Central France high yield (5) and Netherlands-NRW (7). In all these regions, THI tends to take low or mid-range values. In general, these clusters are located at low altitudes and are not in less favored areas. This suggests that high yields seem to be associated with favorable natural conditions. The cows per hectare variable doesn't seem to have a clear pattern in these clusters, although Netherlands-NRW (7) seems to have, on average, a higher density of cows. The same applies for buildings per cow in which Denmark (4) tends to invest more in infrastructure. It is worth mentioning that in the case of Denmark and Netherlands-NRW, these types of farms are almost endemic from the regions they were named after. In the case of Denmark, 67\% of the farms in the country belong to the cluster named Denmark. And in the case of the Netherlands, $79 \%$ of the farms in this country belong to the cluster named Netherlands-NRW.

On the other hand, low yields are persistent in Italian low yield (3), Mediterranean low yield (6) and Mediterranean high THI (9). On average, these clusters all seem to be in locations with high THI values. Altitude is high for the cluster Italian low yield, and all the farms are located in less favored areas in the clusters Italian low yield (3) and Mediterranean high THI (9). In contrast with clusters characterized with high yields, cluster facing low yields seem, in general, to face adverse natural conditions. Density of cows seems to be high (on average) in the Mediterranean low yield (6) cluster. In general, low yield clusters have higher densities of cows than clusters with high yields. This is also the tendency in feed per cow: in general, low yield clusters seem to spend more on feeding, probably as a consequence of the adverse THI. With the exception of Italian low yield (3), clusters with low yields tend to invest less in infrastructure than clusters with high yields. If buildings per cow is effectively capturing the amount of infrastructure in

\footnotetext{
${ }^{32}$ A Tukey test was also carried out. Due to the large number of clusters, some the means are not statistically different when pairwise clusters are compared. Nevertheless, no pair of clusters has statistically significant equal means in all variables.
} 
the farm, the result suggests that clusters with low yields do little to mitigate the impact of high THI on the cows.

In general, favorable natural conditions seem to be associated with high yields. One exception is the North Spain high yield (2) cluster. This is characterized by a high THI and less favored area designation. Nevertheless, this cluster is among the top feeding spenders along with Italian Tyrol (14) and North Mediterranean high yield (1). In all three clusters, high values of THI seem to be common.

A multitude of clusters share a feature of low expenditure in feeding, including South France (8), Atlantic (10), South-west Germany (11), Austria (12) and Austro-German (15). In general, these clusters are located in north and central Europe with either low or mid-range values of THI. With the exception of the Atlantic (19) cluster, they seem to be located mainly in less favored areas. Milk yields in these clusters are either mid or low. Cluster Austria (12) invests more in infrastructure than the others. The latter cluster is also almost endemic of the country it was named after with $47 \%$ of the farms in the country belonging to this cluster.

Finally, clusters North Europe (13) and South-east Germany (16) have either high to mid milk yields. Both are located in regions with low THI. Nevertheless, cluster South-east Germany (16) is persistently located in less favored areas.

To summarize the cluster analysis, there seems to be a clear connection between milk yields and natural conditions, especially THI. The results also suggest that clusters facing low yields, possibly due to high THI, tend to invest more in feeding but not in infrastructure. Adapting the diet of the cows to the conditions requires less investment than sophisticated cooling systems.

\subsubsection{Second step- Stochastic Frontier}

In this section, we describe the estimation of the stochastic frontiers for each cluster. The stochastic frontier model was first developed in the works of Aigner et al. (1977) and Meeusen and van den Broeck (1977). Its aim is to estimate a production function that describes the technology and allows us to measure efficiency. The production function takes the form:

$$
y_{i t}=f\left(\boldsymbol{x}_{i t}\right) * \exp \left(v_{i t}-u_{i t}\right)
$$


Where $y_{i t}$ represents the output of the farm $i$ in time $t, x_{i t}$ represents $\boldsymbol{x}$ represents the vector of inputs required to produce $y$ and $f($.$) is the technology. The term exp \left(v_{i t}-\right.$ $u_{i t}$ ) is also called the composed error term, where $v_{i t}$ represents the random component of the model and is expected to have a normal distribution with mean zero and constant variance. Meanwhile, $u_{i t}$ is a non-negative term that aims to measure technical efficiency. A fully efficient farm will have an efficiency value of 1 , meaning that it is located right on the frontier. On the other hand, a fully inefficient farm will have an efficiency value of 0 . Its distribution is positive. $v_{i t}$ and $u_{i t}$ are assumed to be independent.

Now we describe the variables employed in the estimation of Equation 3.3. All monetary values were deflated with their corresponding price deflators with base year 2000 . Output, the dependent variable is the total revenue of the farm measured in Euros. Land is the utilized agricultural area of the farm in acres. Labor is measured as the number of hours of work dedicated to the farm; it includes family and hired labor. Feed cost is the expenditure in Euros of feeding stuffs. Cows are the number of dairy cows in the farm, and finally farm expenses are measured in Euros. Other farm expenses include veterinary costs, energy, fuel, water, depreciation, milk tests and storage. Descriptive statistics are presented in Appendix 3.

We have chosen a translog production function ${ }^{33}$ in which a time trend was added and allowed to interact with inputs to capture technical change. Furthermore, to capture efficiency growth in $u_{i t}$ we chose a time varying efficiency specification. In particular we follow the specification of Battese and Coelli (1992). This specification assumes a common identical time trend in the variation of technical efficiency in each group. According to Lee (2010), agricultural production is influenced by geographical characteristics; this implies that farms in the same region may have similar temporal efficiency behavior. At first glance, this may be seen as a strong assumption that ignores the heterogeneity of the firms, and measurement error and statistical noise in the determination of technical efficiency. Moreover, it strongly drives the trends over time of efficiency and Total Factor Productivity as will be shown later. We have chosen this specification because it allows us to consistently compare the development over time of

\footnotetext{
${ }^{33} \mathrm{Cobb}-$ Douglas production function was also estimated. In all clusters the likelihood-ratio test favored the translog technology.
} 
technical efficiency across groups, which is the aim of this work. The chosen specification has the following form:

$$
u_{i t}=u_{i} * \exp [-\gamma(t-T)]
$$

Negative values of $\gamma$ imply an increase in inefficiency over time, while positive values imply a decrease of inefficiency. The values of the variables are in logs and divided by their means. The final form of the production function is:

$$
\begin{aligned}
\ln y_{i t}=\beta_{0}+\sum_{n=1}^{N} \beta_{n} & \ln x_{n i t} \\
& +\beta_{t} t \frac{1}{2} \sum_{n=1}^{N} \sum_{k=1}^{K} \beta_{n k} \ln x_{n i t} \ln x_{k i t}+\frac{1}{2} \beta_{t t} t^{2}+\sum_{n=1}^{N} \beta_{n t} \ln x_{n i t} t+v_{i t}+u_{i} * \exp (-\gamma(t-T))
\end{aligned}
$$

Where $u_{i t}$ has a half-normal distribution. The results of the estimation of the stochastic frontiers are presented in Table $3-3^{34}$. All elasticities are positive and significant in all clusters. In general, the three most important inputs according to the magnitude of their elasticities are cows, farm expenses and feed costs. On the other hand, in all clusters the elasticities with smaller magnitudes are labor and land. In order to compare the results of the clusters, a stochastic frontier with the complete panel was estimated (last column in Table 3-3). From the table it is apparent that, when considering the elasticities, the importance of the inputs is roughly the same as in the clusters. Cows are clearly the most important input in the production process.

Feeding is especially important in a number of clusters, including North Spain-High Yield (2), Italian low yield (3) and Denmark (4), Italian Tyrol (14) and North Mediterranean High-Yield (1). With the exception of Denmark, the rest of the clusters are located in regions characterized by high THI. This supports the idea that clusters facing adverse THI tend to spend more on feeding. On the other hand, clusters with favorable THI tend - in general - to have lower values of elasticity of feed cost. This is the case for Austria (12), Atlantic (10), Netherlands-NRW (7) and Austro-German (15).

In general, the elasticity of farm expenses tends to be lower in clusters located in south Europe and higher in clusters located in the north. Atlantic (10), Austria (12) and South

\footnotetext{
${ }^{34}$ All inputs were normalized; this implies that estimated coefficients are elasticities at the sample mean.
} 
France (8) have the largest magnitude in this input. On the other hand, North Mediterranean High-yield (1), North Spain high-yield (2) and Mediterranean high THI (9) have the smallest.

The variable trend is meant to capture technical change, that is, expansions of the production frontier are mainly due to technological change. As seen in Table 3-3, all clusters present positive technical change over the analyzed period. Nevertheless, the magnitude of this change does not seem economically significant. Only clusters North Mediterranean High-Yield (1) and Austria (12) seem to experience no change. The largest changes are in Italian low yield (3) and Denmark (4). The same reasoning applies when the stochastic frontier model is applied to the complete panel.

Mean efficiency of the clusters in the analyzed period ranges from 0.67 in the Austria (12) cluster to 0.87 in Denmark (4). There seems to be no strong connection between efficiency and natural conditions. Italian Tyrol (14), North Spain High Yield (2) and North Mediterranean High-Yield (1) are some examples of adverse natural conditions and high efficiency scores. On the other hand, examples of favorable conditions in terms of THI and low efficiency scores include Austria (12), Netherlands-NRW and South-west Germany (11). The time variable is meant to capture efficiency change in the period as described in Equation 4. In all clusters with the exception of Austria (12), it is significant and negative. This suggests that inefficiency has consistently increased in the period.

When the stochastic frontier of the complete panel is analyzed, it is worth to note that the mean efficiency is 0.76 , lower than the mean efficiency across all clusters which is close to $0.80^{35}$. This suggests that efficiency scores might be underestimated under the assumption of a common frontier in all countries. Our explanation for this phenomenon lies in the structure of the stochastic frontier model. Highly efficient farms allocate their outputs closer to the frontier; therefore these farms determine the frontier itself. When the frontier is estimated using the complete panel, the variation of the efficiency scores is larger and more farms will allocate their outputs below those farms that determine the frontier. Whereas, when individual frontiers in each cluster are estimated, farms are compared to those similar to them in terms of natural conditions and technology. Thus, it seems plausible that efficiency scores are higher than those obtained from the frontier that

\footnotetext{
${ }^{35}$ There is a significant correlation of 0.83 between the efficiency scores obtained with the frontiers in the clusters and the efficiency scores from the complete panel.
} 
uses the complete panel. The dynamics of this decrease over time and will be analyzed in more detail in the section describing total factor productivity change.

To visualize the geographical spread of the efficiency in more detail, we have plotted average efficiency over the time period in the different regions of the sample. The average efficiency per region was calculated as a weighted average with the form $u_{k}=$ $\sum_{i=1}^{N} \theta_{i k} u_{i j k}$, where $u_{k}=u_{1}, \ldots, u_{K}$ are the efficiencies of the $K$ regions present in the sample, and subscript $i j k$ stays for the farm $i$ that belongs to cluster $j$ and is located in region $k$. And $\theta_{i k}=y_{i k} / \sum_{i=1}^{N} y_{i k}$ is the weight of the output of the farm $i$ in region $k$. Figure 3-8 shows the described weighted efficiencies obtained from the clusters' frontiers.

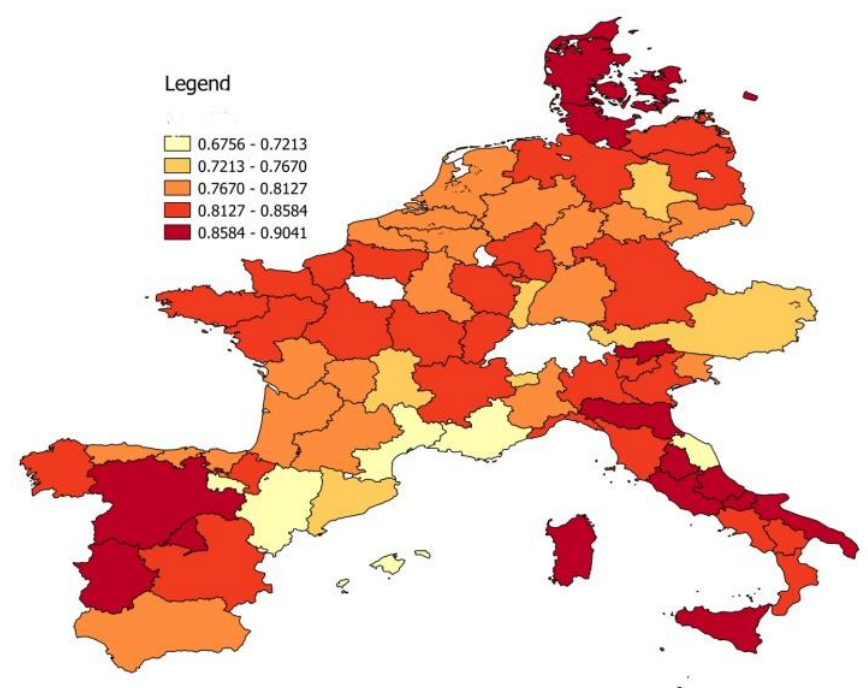

Figure 3-8 Weighted average efficiency in the period 1995-2008 obtained from the clusters' frontiers.

Efficiency scores in the regions have no clear geographical pattern. High efficiency scores are present in regions of the extreme north (Denmark and North Germany) and in regions of the extreme south (Italy and Spain). In general, efficiency tends to be lower in south France, Austria and some regions of North Spain when compared to the rest of the countries. Contrary to the presumption that more productive technologies are associated with higher efficiencies, the results reported here suggest that regions with lower yields in south Europe also achieve high efficiency scores. This might be the result of the adaptation of the technology to the adverse environment through good farming 
techniques. A Moran's I test was carried out to test possible spatial autocorrelation in the efficiency scores. We found a significant spatial autocorrelation of $0.193^{36}$.

The same exercise was done with the weighted efficiency scores obtained from the complete panel. Figure 3-9 plots the weighted average efficiency per region. First of all, the range in which these efficiency scores vary is significantly different from the one in Figure 3-8. Maximum and minimum efficiency scores are lower in the case of the complete panel.

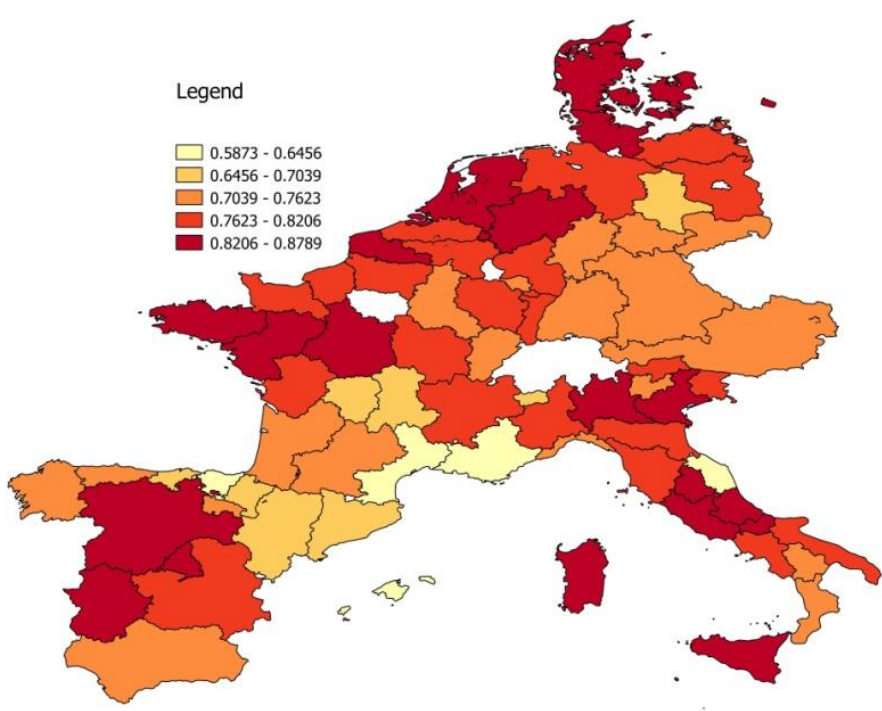

Figure 3-9 Weighted average efficiency in the period 1995-2008 obtained from the complete panel.

High efficiency scores are also present in the extreme north (Denmark and North Germany) and also in the extreme south, Spain and Italy. Northern France, the Netherlands and Belgium notoriously achieve higher efficiency scores when a common technology for the whole sample is assumed. Moran's I test for spatial correlation is slightly higher, with a value of $0.215^{37}$.

To summarize, in the period 1995-2008, two phenomena have characterized the dairy sector regardless of the cluster. A small expansion of the production possibilities, that is,

\footnotetext{
${ }^{36}$ Based on a row standardized spatial matrix, p-value 0.006 . To avoid zero weight rows, insular regions were omitted from the test.

${ }^{37}$ Based on a row standardized spatial matrix, p-value 0.009 .
} 
technological changes have increased the total output of the dairy sector and resulted in a persistent increase in inefficiency.

This means that, in spite of the expansion of production, farmers have been progressively allocating their outputs further away from the production frontier. On the other hand, efficiency scores do not have a significant spatial pattern. In the next section, we analyze the changes in productivity and efficiency by cluster over time in more detail by decomposing the total factor productivity. 


\begin{tabular}{|c|c|c|c|c|c|c|c|c|c|c|c|c|c|c|c|c|c|}
\hline INPUT & CLUSTER 1 & CLUSTER 2 & CLUSTER 3 & CLUSTER 4 & CLUSTER 5 & CLUSTER 6 & CLUSTER 7 & CLUSTER 8 & CLUSTER 9 & CLUSTER 10 & CLUSTER 11 & CLUSTER 12 & CLUSTER 13 & CLUSTER 14 & CLUSTER 15 & CLUSTER 16 & Total panel \\
\hline Intercept & $0.197^{* * *}$ & $0.145^{* * *}$ & $0.275 * * *$ & $0.064 * * *$ & $0.176^{* * *}$ & $0.241 * * *$ & $0.307^{* * * *}$ & $0.228 * * *$ & $0.262 * * *$ & $0.204^{* * *}$ & $0.247^{* * *}$ & $0.354 * * *$ & $0.182 * * *$ & $0.205^{* * *}$ & $0.241 * * *$ & $0.158^{* * *}$ & $0.253^{* * *}$ \\
\hline Land & $0.087 * * *$ & $0.052 * * *$ & $0.026 * * *$ & $0.126 * * *$ & $0.083 * * *$ & $0.044 * * *$ & $0.061 * * *$ & $0.043 * * *$ & $0.038 * * *$ & $0.075 * * *$ & $0.097 * * *$ & $0.035 * *$ & $0.133 * * *$ & $0.084 * * *$ & $0.132 * * *$ & $0.080 * * *$ & $0.025 * * *$ \\
\hline Labor & $0.073 * * *$ & $0.099 * * *$ & $0.042 * *$ & $0.090 * * *$ & $0.048 * * *$ & $0.130 * * *$ & $0.115 * * *$ & $0.066 * * *$ & $0.098 * * *$ & $0.100 * * *$ & $0.094^{* * *}$ & $0.186 * * *$ & $0.042 *$ & $0.108 * * *$ & $0.144 * * *$ & $0.072 * * *$ & $0.077^{* * *}$ \\
\hline Feed cost & $0.253 * * *$ & $0.298 * * *$ & $0.281 * * *$ & $0.274 * * *$ & $0.168 * * *$ & $0.227 * * *$ & $0.127 * * *$ & $0.202 * * *$ & $0.226 * * *$ & $0.123 * * *$ & $0.149 * * *$ & $0.104 * * *$ & $0.183 * * *$ & $0.262 * * *$ & $0.133 * * *$ & $0.203 * * *$ & $0.202 * * *$ \\
\hline Cows & $0.533 * * *$ & $0.509 * * *$ & $0.404 * * *$ & $0.339 * * *$ & $0.457 * * *$ & $0.527 * * *$ & $0.454 * * *$ & $0.410 * * *$ & $0.534 * * *$ & $0.442 * * *$ & $0.411 * * *$ & $0.359 * * *$ & $0.407 * * *$ & $0.430 * * *$ & $0.420 * * *$ & $0.400 * * *$ & $0.503 * * *$ \\
\hline Farm expenses & $0.122 * * *$ & $0.128 * * *$ & $0.210 * * *$ & $0.209 * * *$ & $0.247 * * *$ & $0.205^{* * *}$ & $0.225 * * *$ & $0.268 * * *$ & $0.164^{* * *}$ & $0.304 * * *$ & $0.241 * * *$ & $0.301 * * *$ & $0.260 * * *$ & $0.185 * * *$ & $0.219 * * *$ & $0.235 * * *$ & $0.267^{* * *}$ \\
\hline Trend & 0.001 & $0.004 * *$ & $0.021 * * *$ & $0.021 * * *$ & $0.009 * * *$ & 0.004 & $0.017 * * *$ & $0.010^{* * *}$ & $0.014 * * *$ & $0.014 * * *$ & $0.013 * * *$ & 0.002 & $0.010^{* * *}$ & $0.015 * * *$ & $0.011 * * *$ & $0.011^{* * *}$ & $0.010^{* * *}$ \\
\hline Land ${ }^{\wedge} 2$ & -0.007 & 0.008 & $-0.027 * *$ & $0.103 * * *$ & $-0.139 * * *$ & 0.040 & -0.023 & 0.039 & -0.031 & $0.060 *$ & 0.009 & 0.006 & -0.075 & $-0.045 * *$ & 0.043 & $-0.046 *$ & $-0.025 * * *$ \\
\hline Land*Labor & 0.013 & -0.013 & -0.010 & $-0.091 * *$ & -0.029 & $0.063 * *$ & $-0.129 * * *$ & $-0.040 *$ & 0.011 & $-0.058 * * *$ & 0.032 & $-0.082 * * *$ & 0.074 . & $0.051 *$ & -0.069 & 0.008 & $-0.024 * * *$ \\
\hline Land*Feed & 0.013 & 0.015 & $0.029 *$ & -0.037 & $0.018 *$ & $0.050 *$ & $0.081 * * *$ & $0.041 * *$ & $-0.054 * *$ & 0.012 & 0.006 & -0.021 & -0.017 & -0.013 & -0.049 & -0.015 & $0.007^{* *}$ \\
\hline Land*Cows & $0.050 *$ & 0.029 & $-0.036 *$ & 0.056 & 0.058 . & $-0.102 * *$ & $0.177 * * *$ & $-0.056 *$ & $0.100 * * *$ & $0.067 * *$ & $-0.130 * * *$ & $0.053 *$ & 0.035 & 0.032 & 0.043 & 0.000 & 0.000 \\
\hline Land*Farm Exp. & $-0.040 * *$ & 0.021 . & -0.013 & $-0.071 *$ & $0.078 * *$ & -0.012 & $-0.166 * * *$ & $0.034 *$ & -0.006 & $-0.121 * * *$ & 0.040 & 0.034 & 0.031 & $-0.036 *$ & 0.062 & $0.088 * * *$ & 0.000 \\
\hline Land*trend & $0.003 *$ & -0.001 & 0.002 & 0.000 & $0.007 * * *$ & 0.001 & $-0.007 * * *$ & -0.002 & 0.002 & $0.004 * *$ & 0.001 & $-0.006 * *$ & $0.006 *$ & 0.002 & 0.000 & $0.003 *$ & $0.003^{* * *}$ \\
\hline Labor^2 & 0.019 & $0.085 * *$ & 0.047 & -0.063 & -0.016 & 0.008 & $0.083 * * *$ & 0.005 & 0.056 & -0.005 & -0.010 & $0.105 *$ & -0.057 & 0.022 & 0.045 & $0.087^{* * *}$ & $0.038 * * *$ \\
\hline Labor*Feed & -0.026 & $0.075 * * *$ & $-0.083 * *$ & 0.021 & $0.016 *$ & $0.075 * *$ & $-0.081 * * *$ & $-0.054 * * *$ & -0.021 & -0.011 . & $-0.042 * * *$ & 0.000 & -0.022 & -0.008 & $-0.073 * *$ & $-0.110 * * *$ & $-0.035 * * *$ \\
\hline Labor*Cows & 0.004 & $-0.100 * * *$ & $0.061 *$ & 0.042 & -0.020 & $-0.116 * *$ & 0.028 & 0.005 & 0.011 & 0.024 & -0.045 & -0.074 . & 0.007 & -0.028 & -0.079 & -0.025 & -0.005 \\
\hline Labor*Farm exp. & 0.008 & -0.015 & 0.036 & $0.074 *$ & 0.035 . & -0.022 & $0.137 * * *$ & $0.068 * * *$ & 0.009 & $0.035 *$ & & 0.011 & -0.027 & 0.026 & $0.151 * * *$ & 0.032 . & $0.024^{* * *}$ \\
\hline Labor*trend & 0.000 & $-0.005 *$ & 0.000 & $-0.009 * * *$ & 0.002 & 0.005 & 0.002 & 0.002 & $-0.005 *$ & 0.002 & $0.005 *$ & 0.000 & -0.006 . & 0.001 & -0.001 & -0.001 & 0.000 \\
\hline Feed ${ }^{\wedge} \mathbf{2}$ & $0.197 * * *$ & $0.102 * * *$ & $0.139 * * *$ & $0.219 * * *$ & $0.031 * * *$ & $0.057 * *$ & $0.096 * * *$ & $0.075 * * *$ & $0.209 * * *$ & $0.026 * * *$ & $0.040 * * *$ & $0.031 * * *$ & $0.036 * * *$ & 0.057 & $0.066 * * *$ & $0.054 *$ & $0.043 * * *$ \\
\hline Feed*Cows & $-0.166 * * *$ & $-0.213 * * *$ & $-0.090 *$ & $-0.152 * * *$ & 0.013 & $-0.092 * *$ & $-0.042 *$ & $-0.060 * *$ & $-0.217 * * *$ & 0.009 & 0.031 & $0.046 *$ & $0.053 *$ & 0.038 & $0.089 * *$ & $0.103 * * *$ & $0.037^{* * *}$ \\
\hline Feed*Farm exp. & $-0.098 * * *$ & -0.003 & -0.024 & $-0.054 *$ & $-0.078 * * *$ & -0.021 & $-0.084 * * *$ & $-0.059 * * *$ & $0.034 *$ & $-0.044 * * *$ & $-0.052 * *$ & $-0.040 *$ & -0.031 & $-0.097 * *$ & $-0.089 * * *$ & $-0.052 *$ & $-0.046 * * *$ \\
\hline Feed*trend & $-0.005 *$ & $-0.011 * * *$ & -0.005 & 0.003 & -0.001 & $-0.007 * *$ & -0.002 & 0.002 & $-0.007 * *$ & $-0.002 * * *$ & -0.002 & $0.009 * * *$ & 0.002 & -0.003 & $0.008 * * *$ & $0.006 * * *$ & 0.000 \\
\hline Cows $^{\wedge} \mathbf{2}$ & $0.221 * * *$ & $0.429 * * *$ & $0.142 * *$ & $0.194 *$ & 0.011 & $0.243 * * *$ & $0.154 * * *$ & $0.135 * *$ & $0.276 * * *$ & -0.067 & $0.313 * * *$ & 0.114 & -0.096 & 0.016 & -0.155 & $0.099 *$ & $0.057^{* * *}$ \\
\hline Cows*Farm exp. & -0.002 & $-0.115 * * *$ & -0.039 & $-0.211 * * *$ & -0.044 & -0.028 & $-0.323 * * *$ & $-0.065 * *$ & $-0.097 * * *$ & $-0.076 * * *$ & $-0.156 * * *$ & $-0.231 * * *$ & -0.068 & 0.014 & $2 * *$ & $-0.230 * * *$ & $-0.076 * * *$ \\
\hline Cows*trend & -0.001 & $0.013 * * *$ & -0.007 & $0.006 *$ & 0.002 & 0.001 & 0.002 & -0.002 & -0.004 & 0.003 & $0.005 *$ & 0.003 & -0.007 & $-0.017 * * *$ & $-0.007 *$ & -0.002 & 0.001 \\
\hline Farm exp.^2 & $0.071^{* * *}$ & $0.100 * * *$ & $0.129 * * *$ & $0.343 * * *$ & 0.037 & $0.065 * * *$ & $0.455 * * *$ & $0.123 * * *$ & $0.049 * * *$ & $0.242 * * *$ & $0.196 * * *$ & $0.244 * * *$ & $0.101 *$ & $0.104 * * *$ & $0.207^{* * *}$ & $0.232 * * *$ & $0.099^{* * *}$ \\
\hline Farm exp. ${ }^{*}$ trend & 0.001 & -0.001 & 0.000 & $0.005 *$ & $-0.006 * *$ & 0.000 & $0.007 * * *$ & $-0.003 *$ & $0.008 * * *$ & $-0.002 *$ & & 0.000 & 0.001 & & & $-0.005 * *$ & $-0.002 * * *$ \\
\hline Trend^2 & 0.001 & 0.000 & $0.002 * *$ & $0.003 * * *$ & $-0.001 * *$ & 0.000 & 0.000 & $0.001 *$ & 0.000 & $0.002 * * *$ & $0.002 * * *$ & $0.002 * * *$ & $0.002 * * *$ & $0.002 * *$ & $0.001 * *$ & 0.000 & $0.001 * * *$ \\
\hline sigmaSq & $0.090 * * *$ & $0.091 * * *$ & $0.184 * * *$ & $0.040 * * *$ & $0.072 * * *$ & $0.192 * * *$ & $0.167 * * *$ & $0.155 * * *$ & $0.240 * * *$ & $0.117 * * *$ & $0.196 * * *$ & $0.260 * * *$ & $0.093 * * *$ & $0.080 * * *$ & $0.144 * * *$ & $0.109 * * *$ & $0.163 * * *$ \\
\hline Gamma & $0.783 * * *$ & $0.685 * * *$ & $0.791 * * *$ & $0.817^{* * *}$ & $0.787 * * *$ & $0.834 * * *$ & $0.939 * * *$ & $0.865 * * *$ & $0.843 * * *$ & $0.862 * * *$ & $0.903 * * *$ & $0.895 * * *$ & $0.869 * * *$ & $0.757 * * *$ & $0.881 * * *$ & $0.859 * * *$ & $0.867 * * *$ \\
\hline Time & -0.003 & $-0.024 * *$ & $-0.028 * * *$ & $-0.022 * * *$ & $-0.013 * *$ & $-0.030 * * *$ & $-0.019 * * *$ & $-0.025 * * *$ & $-0.043 * * *$ & $-0.030 * * *$ & $-0.031 * * *$ & 0.001 & $-0.029 * * *$ & -0.020 & $-0.019 * * *$ & $-0.013 * * *$ & $-0.016^{* * *}$ \\
\hline Observations & 6095 & 6333 & 4641 & 4261 & 6368 & 3298 & 7243 & 6861 & 5523 & 11200 & 5343 & 5617 & 2202 & 2672 & 4322 & 8372 & 90351 \\
\hline Mean Eff. & 0.810 & 0.837 & 0.783 & 0.880 & 0.833 & 0.776 & 0.727 & 0.792 & 0.775 & 0.819 & 0.768 & 0.676 & 0.842 & 0.841 & 0.778 & 0.797 & 0.765 \\
\hline Prevalence & $6.7 \%$ & $7.0 \%$ & $5.1 \%$ & $4.7 \%$ & $7.0 \%$ & $3.7 \%$ & $8.0 \%$ & $7.6 \%$ & $6.1 \%$ & $12.4 \%$ & $5.9 \%$ & $6.2 \%$ & $2.4 \%$ & $3.0 \%$ & $4.8 \%$ & $9.3 \%$ & - \\
\hline Log-likelihood & 2006.6 & 1436.9 & 142.5 & 3618.6 & 3243.3 & 239.8 & 4545.7 & 2268.4 & 145.8 & 5172.9 & 1837.7 & 999.4 & 1277.2 & 998.6 & 1924.1 & 4103.2 & 25688.83 \\
\hline
\end{tabular}

.Significance at the $5 \%$ level

* Significance at the $1 \%$ level

** Significance at the $1 \%$ level

*** Significance at the $0 \%$ level

Table 3-3 Stochastic frontier estimation in the different clusters. 


\subsection{Total factor productivity growth decomposition (TFP)}

According to Kumbhakar and Lovell (2000), productivity change occurs when an index of outputs changes at a different rate than an index of inputs. They also pointed out that this productivity change comes from three different sources: technical change, technical efficiency change and the contribution of returns to scale.

Following their implementation of a translog production function, we desegregate the total factor productivity growth for the 16 clusters. This requires the estimated parameters of the production function in Table 3-3 and also the actual values of the inputs. For further detail, see Kumbhakar and Lovell (2000). The total factor productivity growth is given by the sum of all three components as follows:

$$
T F P=T \Delta+(\epsilon-1) * \sum_{n=1}^{N}\left(\frac{\epsilon_{n}}{\epsilon}\right) \frac{d x_{n}}{d t}+T E \Delta
$$

Where the first component is technical change which, for a translog production function, is given by:

$$
T \Delta=\beta_{t}+\beta_{t t} t+\sum_{n=1}^{N} \beta_{n t} \ln x_{n i t}
$$

The second component in 6 is the scale component in which $\epsilon_{n=\beta_{n}+\sum_{k=1}^{K} \beta_{n k} \ln x_{k i t}+\beta_{n t} t}$ and $\epsilon=\sum_{n=1}^{N}\left(\beta_{n}+\sum_{k=1}^{K} \beta_{n k} \ln x_{k i t}+\beta_{n t} t\right)$. Finally, the last component of Equation 3.6 is the technical efficiency change that is given according to Equation 4 as follows:

$$
T E \Delta=u_{i} * \gamma * \exp [-\gamma(t-T)]
$$

Indexes for each component were calculated with 1995-1996 as the base year. The calculations for a pair of two consecutive years were performed as the average of the two years.

Figure 3-10 shows the development of the index for the technical change component. As expected by the signs of the trend estimators in Table 3-3, there is an increase in the production possibilities for all clusters. The figure also confirms the magnitude of the trend variable. Italian low yield (3), Denmark (4) and Netherlands-NRW (7) overtake the rest of the clusters in technical change with expansions of the frontier of $29.4 \%, 24.8 \%$ and $21.8 \%$ respectively over the period 1995-2004. At the other extreme, but still with positive change, are Austria (12) with $0.6 \%$, North Mediterranean High-Yield (1) with $1.5 \%$ and Mediterranean low yield (6) with $6.3 \%$. On average, the technical change has increased $14.03 \%$ over the analyzed period for all 16 clusters. 


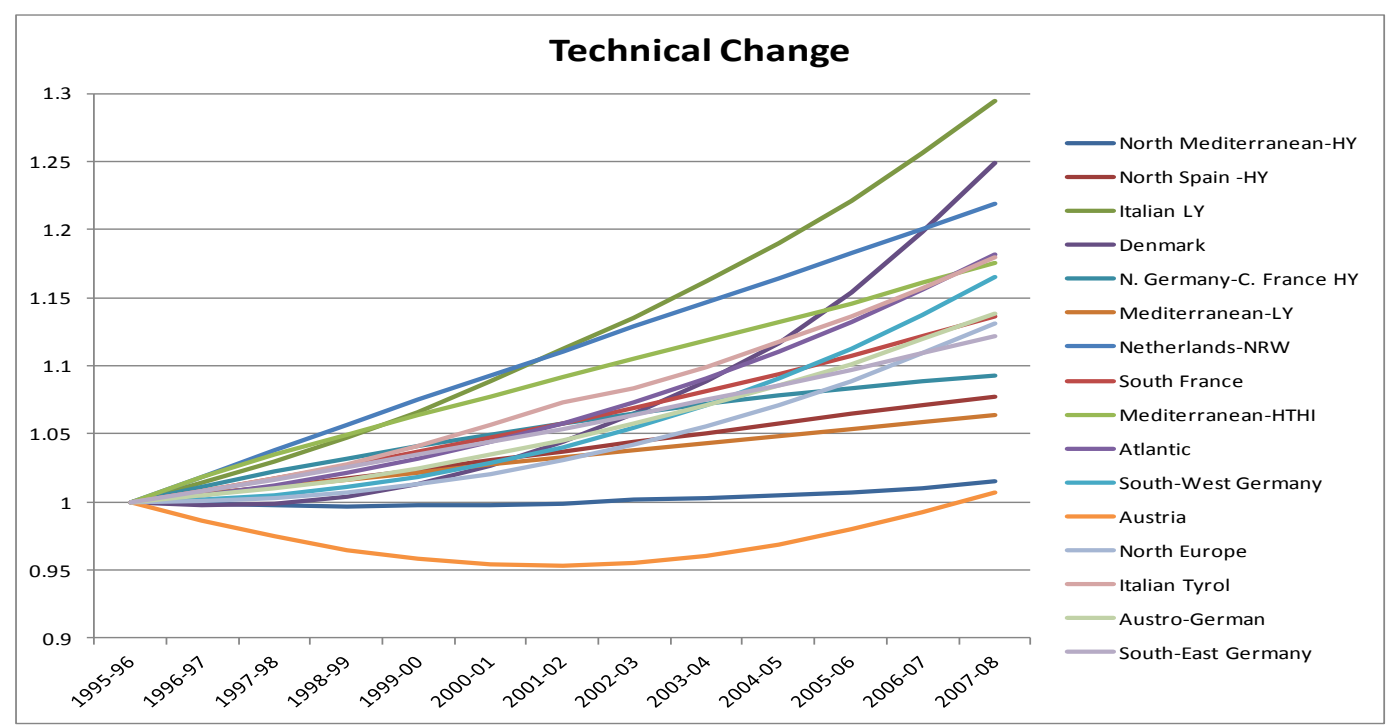

Figure 3-10 Technical change component.

The scale component of total factor productivity shown in Figure 3-11 suggests mixed results. In any case, it is worth to notice that positive and negative tendencies change little in magnitude. Over the period 1995-2008, North Spain high yield (2) leads the positive changes with a total change of 5.4\%. Conversely, Austrogerman (15) shows a total loss of $6 \%$. Most of the clusters seem to have almost no change in the scale component. By looking at the returns to scale of the clusters in Table 3-3, all technologies appear to be operating close to constant returns to scale. On average, the returns to scale of the 14 clusters are 1.02. Notorious increasing returns to scale are present in the Mediterranean low yield (6) cluster with a value 1.13 and North Spain high-yield (2) with 1.08. At the other extreme, decreasing returns to scale are present in Italian low yield (3) with a value of 0.96 and Netherlands-NRW (7) with 0.98. Given the prevalence of constant returns to scale, this suggests that in general expansions of the input quantities make almost no contribution to the total factor productivity.

As predicted by the variable time in Table 3-3, there is a continuous decline in the efficiency of all clusters. Figure 3-12 shows the index for this component. Leading the decline in the period 1995-2008 is Mediterranean high THI (9) with $-13.2 \%$, followed by North Europe (13) with $-11 \%$ and Atlantic (10) with $-10.9 \%$. The clusters in which the decline is less severe are North Spain high yield (2) with $-1.42 \%$ and South-east Germany (16) with $-5,3 \%$. The only cluster whose efficiency improves slightly is Austria (12) with an increase of $0.5 \%$. Since we have not included effects of the efficiency component, it is difficult to determine information about the drivers of this consistent decline. This result is also coherent when a pooled panel is estimated. The time component of the efficiency term is also negative and statistically significant. 


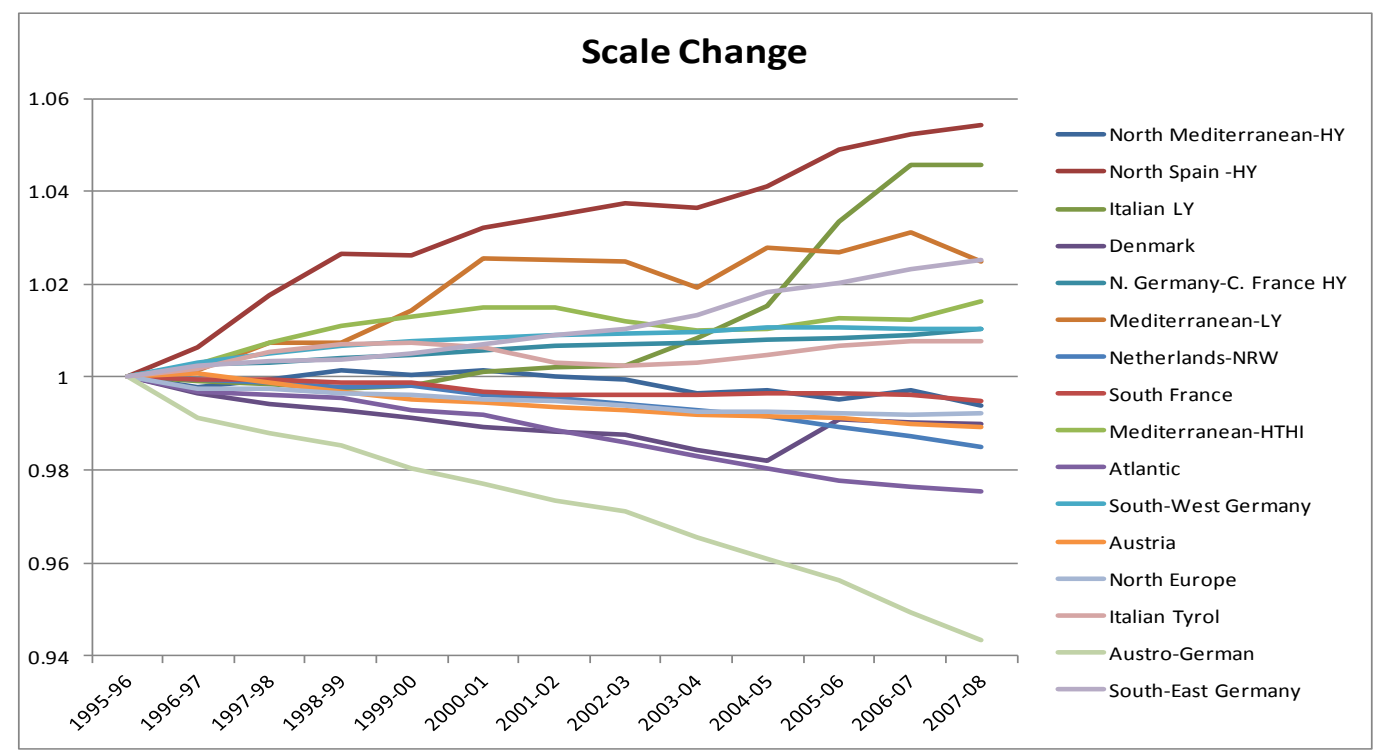

Figure 3-11 Scale change.

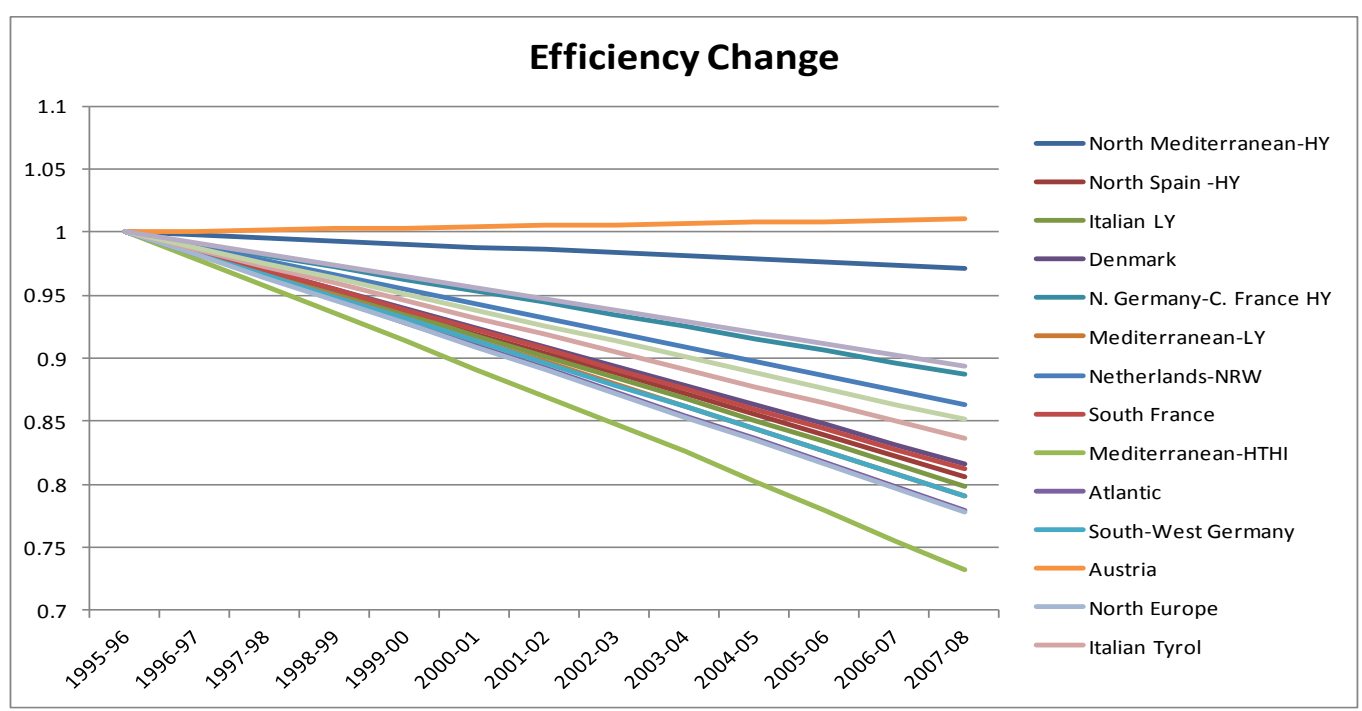

Figure 3-12 Technical efficiency component.

The index for the total factor productivity change in shown in Figure 3-13. Leading the change is Italian low yield (3) with an increase of $8.12 \%$ mainly driven by its growth in the technical change component. Followed by this cluster is Netherlands-NRW (7) with $3.6 \%$ and South-east Germany (16) with $2.77 \%$. On the negative change side are Mediterranean low yield (6) with $-13.9 \%$, North Europe (13) with $-12.6 \%$ and Mediterranean high THI (9) also with $12.6 \%$. On average, the change was $-4.4 \%$ across the 16 clusters. 


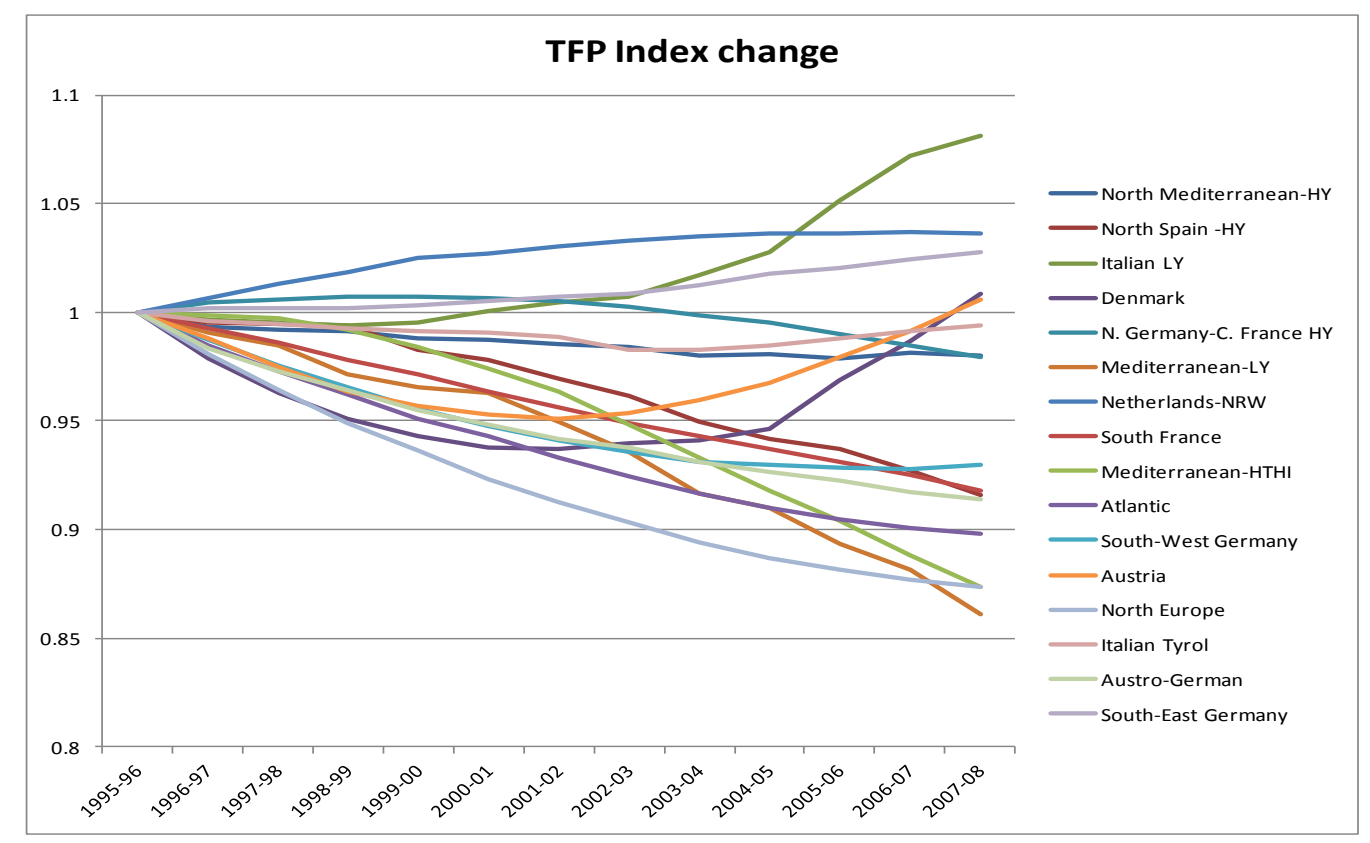

Figure 3-13 Total factor productivity change.

\begin{tabular}{|c|c|c|c|c|}
\hline Cluster & $\begin{array}{c}\text { Technical } \\
\text { change }\end{array}$ & Scale change & $\begin{array}{c}\text { Technical } \\
\text { efficiency change }\end{array}$ & $\begin{array}{c}\text { TFP } \\
\text { change }\end{array}$ \\
\hline 1 & $0,1 \%$ & $-0,1 \%$ & $-0,2 \%$ & $-0,2 \%$ \\
3 & $0,6 \%$ & $0,4 \%$ & $-1,8 \%$ & $-0,7 \%$ \\
4 & $2,2 \%$ & $0,4 \%$ & $-1,9 \%$ & $0,7 \%$ \\
5 & $1,9 \%$ & $-0,1 \%$ & $-1,7 \%$ & $0,1 \%$ \\
6 & $0,7 \%$ & $0,1 \%$ & $-1,0 \%$ & $-0,2 \%$ \\
7 & $0,5 \%$ & $0,2 \%$ & $-1,9 \%$ & $-1,2 \%$ \\
8 & $1,7 \%$ & $-0,1 \%$ & $-1,2 \%$ & $0,3 \%$ \\
9 & $1,1 \%$ & $0,0 \%$ & $-1,7 \%$ & $-0,7 \%$ \\
10 & $1,4 \%$ & $0,1 \%$ & $-2,6 \%$ & $-1,1 \%$ \\
11 & $1,4 \%$ & $-0,2 \%$ & $-2,1 \%$ & $-0,9 \%$ \\
12 & $1,3 \%$ & $0,1 \%$ & $-1,9 \%$ & $-0,6 \%$ \\
13 & $0,1 \%$ & $-0,1 \%$ & $0,1 \%$ & $0,1 \%$ \\
14 & $1,0 \%$ & $-0,1 \%$ & $-2,1 \%$ & $-1,1 \%$ \\
15 & $1,4 \%$ & $0,1 \%$ & $-1,5 \%$ & $0,0 \%$ \\
16 & $1,1 \%$ & $-0,5 \%$ & $-1,3 \%$ & $-0,7 \%$ \\
\hline \multirow{2}{*}{ Total } & $1,0 \%$ & $0,2 \%$ & $-0,9 \%$ & $0,2 \%$ \\
\hline Sverage & $1,1 \%$ & $0,0 \%$ & $-1,5 \%$ & $-0,4 \%$ \\
\hline
\end{tabular}

Source: Own calculation.

Table 3-4 Average annual growth rates in TFP components.

To analyze the dynamics of the changes in TFP in more detail, Table 3-4 shows the average annual growth rate of each component in each cluster. The main components of change in TFP are clearly technical change and technical efficiency change, while scale change seems to 
add little to the growth of the TFP. In all clusters there is positive annual growth of technical change and a negative annual growth in the efficiency component. Overall, the total effect of annual growth of TFP seems to be driven by the negative growth of the efficiency change. Similar conclusions are obtained when the decomposition is performed over the frontier that uses the complete panel. Figure 3-14 plots the components of the TFP over time. In a similar fashion to the TFP decomposition obtained by the clusters, TFP is strongly driven by the technical efficiency change, in spite of the fact that technical change undergoes positive growth. Special attention should be paid to the fact that when TFP is calculated for the complete panel, specific behavior observed in one of the clusters is invisible (for example, the fact that some regions have positive growth in TFP and the scale component). Even when the components have similar behavior in both setups, magnitudes differ when clusters are analyzed. It is rather unsurprising that the efficiency component has similar behavior in both cases. As revealed in section 2, the chosen frontier specification assumes an identical time trend in the frontier which was negative in both cases.

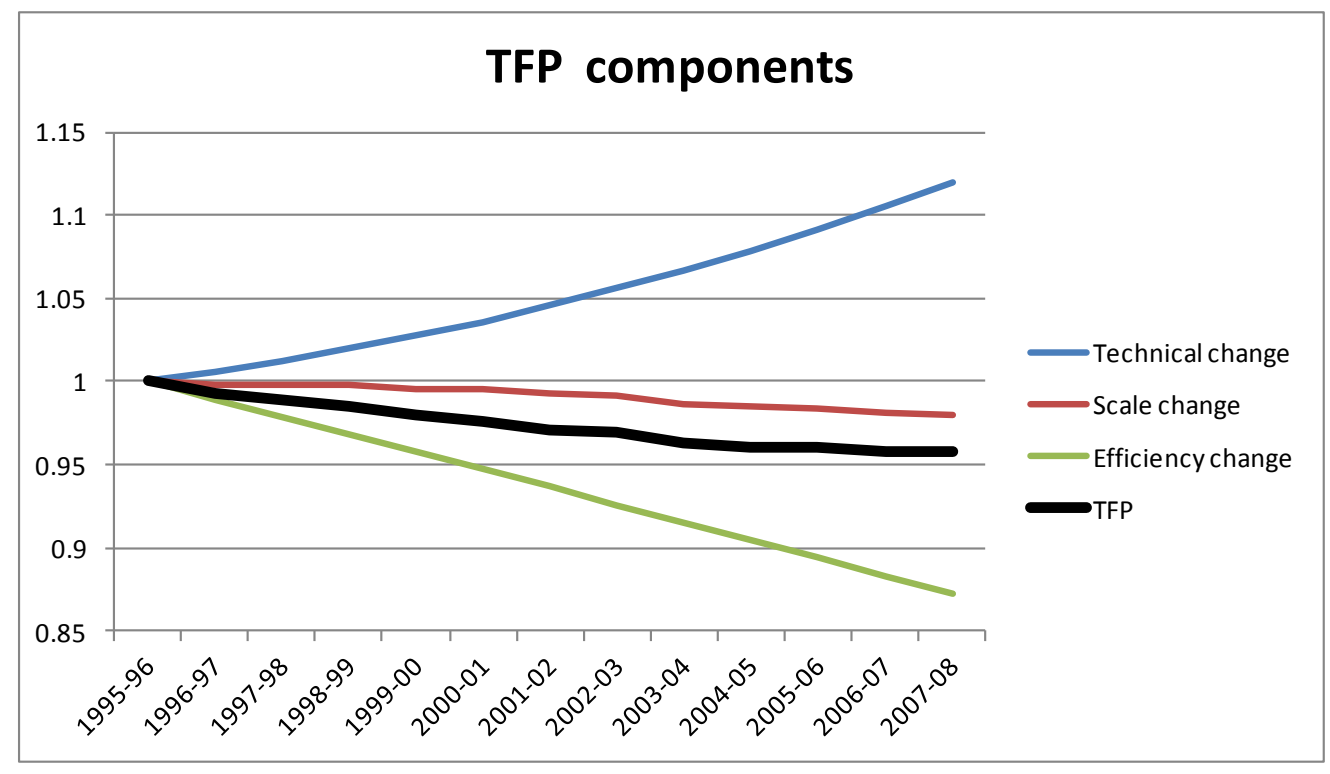

Figure 3-14 Total factor productivity components using the complete panel.

\subsection{Conclusion}

This work explicitly acknowledges the regional heterogeneity and farm heterogeneity in dairy production across Europe. In doing so, we have relaxed the common assumption in SFA that all producers share a common frontier (technology). As explained earlier in this work, ignoring such sources of heterogeneity can lead to mistaken conclusions about efficiency scores and technology. By grouping our sample according to the results of LCA, we allow each farm to be compared to farms that face similar natural conditions and technological 
characteristics. Using key variables that determine the technology employed by the farmers, our LCA results suggest that farms located in regions with favorable conditions for the performance of the cow tend to achieve higher yields. The opposite happens in regions that face adverse natural conditions. As a result, farms seem to adapt their technologies to the environment in an effort to maximize their production potential. For instance, feeding seems to be especially important for farms in locations with high THI, a key determinant of milk yield.

SFA estimation presented in this work reveals differences and common features in the technologies across the clusters. The magnitude of the inputs is relatively homogeneous in all clusters and the number of cows is the most important input in the production process. More dispersion was observed in the mean efficiency scores. High technical efficiency scores are present equally across Europe. This geographical dispersion of the efficiency scores suggests a fair degree of adaptation for farms located in adverse environmental conditions. Spatial correlation in the efficiency scores at the regional level showed weak correlation. When the clusters are compared to the typical stochastic frontier (complete panel), differences appear in the magnitudes of the efficiency scores. In particular, higher average efficiencies are achieved when clustering is applied. The result is relevant since it indicates efficiency scores improve when farms are compared to those that share similar natural conditions and technological characteristics. Since differences in the geographical spread of the efficiency were also observed, our results validate our hypothesis that regional heterogeneity needs to be accounted for when national and regional comparisons are performed.

TFP decomposition leads to several conclusions. Firstly, there has been positive technical change in all clusters. Nevertheless, the growth rates of this change vary substantially across them. The scale component of the TFP shows little variation across clusters; its effect is neutralized even more since most of the clusters operate near constant returns to scale. Technical efficiency change has been decreasing in almost all clusters and heavily drives the growth of the TFP. This feature is in part due to the chosen model specification. This leads to the conclusion that while potential output has been increasing, farmers seem to allocate their outputs further from their potential.

TFP decomposition was also calculated for the complete panel and compared to the TFP calculated in the clusters. It is likely that by doing this comparison, the need for accounting for regional heterogeneity is clearer. TFP calculated in the clusters showed individual behaviors in all its components that were complete left out by the TFP calculated using the 
complete panel. Technical change has positive growth in both setups, but large variability in growth rates is observed when clusters are analyzed. By analyzing the scale component with the complete panel, one could conclude that expansions of the inputs make no contributions to productivity change. Nevertheless, this is not true for all farmers, as showed in the scale change component of the cluster decomposition. Some clusters, in fact, have a small positive contribution to the scale component. Finally, the efficiency component in both setups has a negative growth. Our model selection has assumed that farms are allowed to have different temporal patterns between groups, but those farms that belong to a given group have the same temporal pattern. Nevertheless, growth patterns in the efficiency component vary considerably when this component is analyzed in the clusters. In fact, one cluster has positive technical efficiency change.

The results presented here have strong policy implications. Ignoring regional and farm characteristics when comparing national or trans-national technologies and efficiencies has proven to lead to misguided conclusions. Policies derived from generalized analysis like the one assumed in the typical SFA might waste resources and ignore the real needs and lacks of specific groups.

Finally, further research should be done on how regional heterogeneity and other sources of heterogeneity can be implemented in SFA. Relaxing the assumption of a common temporal variation in technical efficiency needs to be tested. For instance, models with firm specific variation would open the possibility for further analysis in the real behavior of the efficiency scores; it is the authors' belief that this component is completely firm specific. Finally, it is important to note that measuring TFP is very different from explaining it and that further research needs to be done to understand the drivers of TFP and its components. 


\title{
4. ECONOMIES OF AGGLOMERATION AND EXTERNALITIES IN THE DAIRY SECTOR IN EUROPE
}

\begin{abstract}
An agglomeration economy is present when there are both negative and/or positive effects from the concentration of economic activities in a given area. Effects can be present in both, the production frontier and in the efficiency achieved by the firms. For example, knowledge spillovers can benefit both the production frontier and efficiency. Concentration of knowledge and ideas in an area can improve the present technology (technical change) in a particular sector. Knowledge can also improve firms' efficiency since firms tend to learn from mistakes and the experience of other firms in the area to improve their efficiency. Agglomerated activities might also get a more skilled labor force and lower costs that, in turn, benefit technology and efficiency. Nevertheless, some disadvantages might appear in agglomerated environments. Congestion costs, biological congestion and high competition are some examples. To our knowledge little research has been done on the spatial scope of the agglomeration effects in the dairy sector. If agglomeration effects exist, then they are bounded in areas. Our approach here uses agglomeration information at the regional level for eight countries in Europe. To measure the impact of regional agglomeration, we incorporate regional agglomeration of dairy activities not only for the region in which the farm is located, but also for the neighboring regions. A stochastic frontier approach is used in a panel data of 27000 farms in the period 2000-2008. Since agglomeration might be explained by advantageous natural conditions, we also control for natural characteristics at the regional level. The results suggest that farms consistently benefit from agglomeration in productivity, that is, production tends to increase in agglomerated environments in their region and in neighboring regions. On the other hand, efficiency benefits from agglomeration in the region where the farm is located. However, agglomeration in neighboring regions has no impact on efficiency.
\end{abstract}

Keywords: Local agglomeration, stochastic frontier, size of firms.

JEL classification: C13, C33, D21, D24 


\subsection{Introduction}

Marshall (1920) first proposed the idea that firms of the same industry can benefit from their spatial concentration in a specific area. Later this led to the definition of economies of agglomeration. Economies of agglomeration occur when there is a high concentration of a specific economic activity in a limited area. Recent literature suggests that there is a positive relationship between the level of agglomeration of an industry in a location and productivity. Some examples of such results include Caballero and Lyons (1990 and 1992) and Morrison Paul and Siegel (1999). Even more recently, Tveteras and Battese (2006) and Nakamura (2012) state that these externalities might have a relationship with the productivity of the firms belonging to the agglomerated area. When the concentration of the activity in a region is high, externalities are expected to occur. The idea that firms might perceive benefits (loss) derives from the concentration of firms. In particular, there can be natural conditions and also external economies, like access to specialized inputs and higher demand that can benefit firms due to their location in the same geographical area as many other firms. Furthermore, these externalities are limited to the relationships between the firms, but also to the complete productive activity, that is, vendors and customers.

It is important to note that externalities ${ }^{38}$ derived from local agglomeration might have both negative and positive impacts on productivity and efficiency. Diez-Vidal (2011) summarizes the possible impacts of agglomeration on productivity. First of all, on the side of the advantages thy might include:

- Reduction in the production costs due to access to specialized inputs like labor, capital and suppliers.

- Knowledge spillovers, associated with flowing information and knowledge from the interaction of the forms in agglomerated spaces.

- Lower transaction costs, agglomerated industries may stimulate suppliers to develop specialized machinery for the industry as observed by Alvarez-Suescun (2011).

- Finally, concentration of firms from the same industry attracts demand and in turn it increases the firm's performance. In other words, the proximity of firms from a common industry allows customers to evaluate a number of products in a single location.

\footnotetext{
${ }^{38}$ In this work externalities are understood as any effect in the productivity and efficiency of the dairy sector derived from agglomeration in this activity. Externalities generated by agglomeration of the dairy activity that benefit and/or affect another parties not involved in dairy activities are not of the scope of this work .E.g. Habitat degradation, contribution to anthropogenic greenhouse gas emissions, and deterioration of water resources that affect other parties. (See Bulletin of the International Dairy Federation 443/2010).
} 
On the other hand, there might also be disadvantages to agglomeration:

- Congestion costs reflected due to an increase of transport and traffic costs.

- Agglomerated industries might also impact the inputs market, land and labor prices can increase.

- As found by Tveteras and Battese (2006), there might also be biological congestion in agriculture activities; diseases may spread easily in dense areas of the same species of animal and plants.

- Shared resources like water sources might also be affected by the excessive exploitation of a concentrated activity.

- Baun and Mezias (1992) found that clustered firms are prone to resemble their competitors and, in general, clustered firms tend to focus more on competitors in the proximity rather than on competitors at a distance. Dei Attoti (2002) exposes that this phenomena turns into a homogenization of the firms in a clustered space, which is an advantage in the flow of information and communication but as pointed by Diez-Vial (2011) homogenization can also be set back in the ability of change of the firms.

So far, most of the literature that studies the effects of local agglomeration has studied the industrial sector of the economy. According to Tveteras and Battese (2006), these effects can also be observed in the agricultural sector. An increase in the sophistication of the technology used in primary agricultural activities has led to specialization and indivisibilities in the use of physical capital and labor. According to Schimmelpfennig and Thirle (1999), there was a technological proximity between some countries in Europe that explained their advantages in total factor productivity in the agricultural sector. They argued that this technological productivity was due to knowledge and technological spillovers. Foster and Rosenzweig (1995) found that profitability of rice farmers in India was significantly higher when they had experienced neighbors. This supports the idea that imitation via learning by doing and learning spillovers plays a key role in the performance of agricultural activities.

Our hypothesis is that such effects might be present in the dairy sector in Europe. To our knowledge, no study has addressed the effects of local agglomeration in the dairy sector by means of a stochastic frontier analysis. However, other studies with different approaches to ours find support for the effects of agglomeration. Dries and Swinnen (2004) showed that local dairy farms in Poland copied successful strategies of foreign companies in the local market. These strategies included vertical integration with small local producers. The vertical integration promoted by the foreign company encouraged an improvement of the product's 
standards. The copied strategy also included assistance programs to improve access to technology, credit and other inputs. Lewis et al. (2011) found that neighboring dairy farms using organic farming was a powerful argument that explained the decision to move to organic farming. They found that, in a clear example of knowledge spillovers, the learning process from neighbors can substantially reduce uncertainty and the fixed costs attached to information.

\subsection{Local agglomeration and technical stochastic frontier}

Several studies have addressed the issue of local agglomeration and stochastic frontier analysis. Some studies use regional level data to estimate production frontiers while estimating effects of local agglomeration in a second step by regressing efficiency scores with agglomeration variables (Beenson and Husted (1989)). Regional estimates at the state level were also proposed by Puig -Junoy (2001). On the other hand, other studies have focused on firm level data and indicators of regional agglomeration. This approach is featured in studies by Mitra (1999) and Lall et al. (2004), the latter for industries in India. More recent studies include Tveteras and Battese (2006) for the salmon industry in Norway, and Nakamiura (2011) for different types of industry in Japan. The findings of all these works show no specific consensus in the impacts of agglomeration on productivity and efficiency. The wide variety of econometrical approaches and the variety of measures of agglomeration might be an explanation. Nevertheless, most of the listed studies show that their measures of agglomeration have positive impacts on efficiency and/or productivity.

As previously established, agglomeration can bring both advantages and disadvantages to firms. However, it is not clear through which processes and by which mechanisms local agglomeration has an impact on the performance of firms. When these effects are analyzed by means of a stochastic frontier analysis, the processes are mechanisms are even more diffuse.

Stochastic frontier analysis has two main parts. The first one is devoted to exploring the technology of the firms by estimating elasticities of the inputs that describe the employed technology; the second in known as the composed error term that measures efficiency. Efficiency is understood to be the magnitude by which a firm allocates its output from the estimated frontier. A firm is said to by efficient if, and only if, it is able to allocate its output on the estimated frontier. Notice that both the technology (frontier) and the efficiency are susceptible to being affected by externalities derived from local agglomeration. For Tveteras and Battese (2006), externalities derived from agglomeration are already embodied in the frontier production technology in a form of existing knowledge. Thus, the benefits of the 
externalities are assumed to mainly reduce the technical inefficiency of the firms. Nevertheless, they also argue that knowledge spillovers may lead to the creation of new knowledge that will inevitably be translated into expansions of the production frontier.

On the other hand, according to Nakamura (2012) the effects of the local agglomeration are firstly embodied in the production process (frontier) and the intangible effects might also affect the efficiency of the firms. In either case, the effects of the externalities of the local agglomeration have an impact on both frontier and efficiency.

The remainder of this work is organized as follows. In Section 2 we describe the data and geographical scope of the analysis. We also describe the variables that we use to measure local agglomeration. Finally, this section introduces the econometric estimation. Section 3 presents the results of the estimation and their interpretation. Finally, Section 4 summarizes the results and analyzes the policy implications of the findings.

\subsection{Data and Estimation}

The goal of the work is the estimation of a stochastic frontier that takes into account the agglomeration effects in both the frontier and the efficiency term. Our data consist of an unbalanced panel of 27721 observations of dairy farms in the period 2000-2008. The farms are located in eight countries in Europe: Spain, France, Belgium, Netherlands, Germany, Denmark, Austria and Italy. The data belongs to the Farm Accountancy Data Network (FADN) of the European Commission (EC). Conversely, agglomeration information is measured at the regional level ${ }^{39}$ and was taken from the Eurostat data base. Figure 4-1 presents the regions present in the sample.

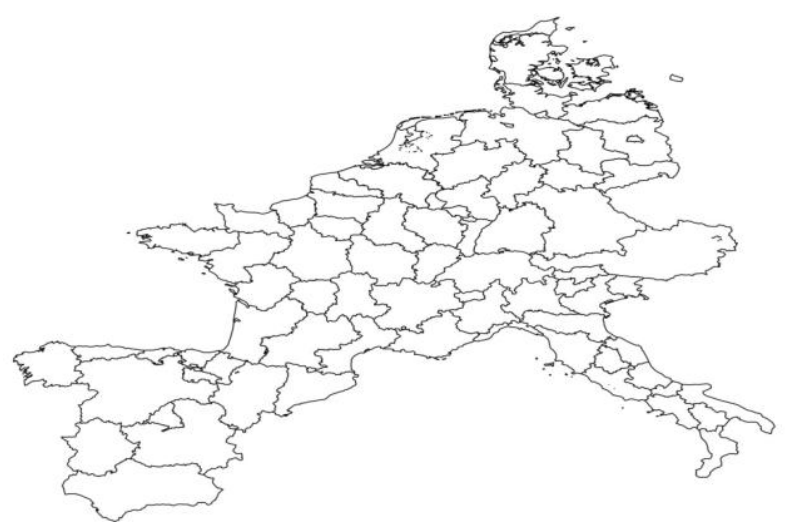

Figure 4-1 Regions present in the sample.

\footnotetext{
39 Regional level means the NUTS1 definition of the European Commission (e.g. Federal State in the case of Germany, autonomous community in the case of Spain). For the Netherlands, Belgium, Denmark and Austria the information on the location of the farm is given at NUTS0 level, that is, country level.
} 


\subsubsection{Measures of agglomeration}

Since our aim is to introduce measures of agglomeration in the stochastic frontier model, proper measures of agglomeration need to be developed. For each farm, local agglomeration is measured as the proportion of dairy farms of the total number of farms in the region the farm is located in. We expect externalities to be positively related to the proportion of dairy farms in the region. As discussed by Tveteras and Battese (2006), farmers that share the same location might benefit the most from knowledge generation through face-to-face contact. Furthermore, they also suggest that if physical proximity is important for the transmission of knowledge, these spillovers increase with spatial concentration of the industry. On the other hand, a high concentration of dairy farms might also encourage biological congestion e.g. it might facilitate the spread of diseases. The availability of the data of total number of farms and the number of dairy farms is biannual, starting in 2000. Figure 4-2 shows the evolution the proportion of dairy farms per region in 2000 and 2007.

As seen in the maps in Figure 4-2, higher proportions of dairy farms are present in northern Spain, northern France, the Netherlands, western Germany, Austria and Denmark. Conversely, lower proportions are more frequent in southern Europe. Note that proportions vary little over time, suggesting that dairy farming tends to be concentrated in specific regions. This specificity might be related to advantages in natural conditions. In this regard, Ellison and Glaeser (1999) found that natural condition explain only $20 \%$ of agglomeration, even in the agricultural sector.
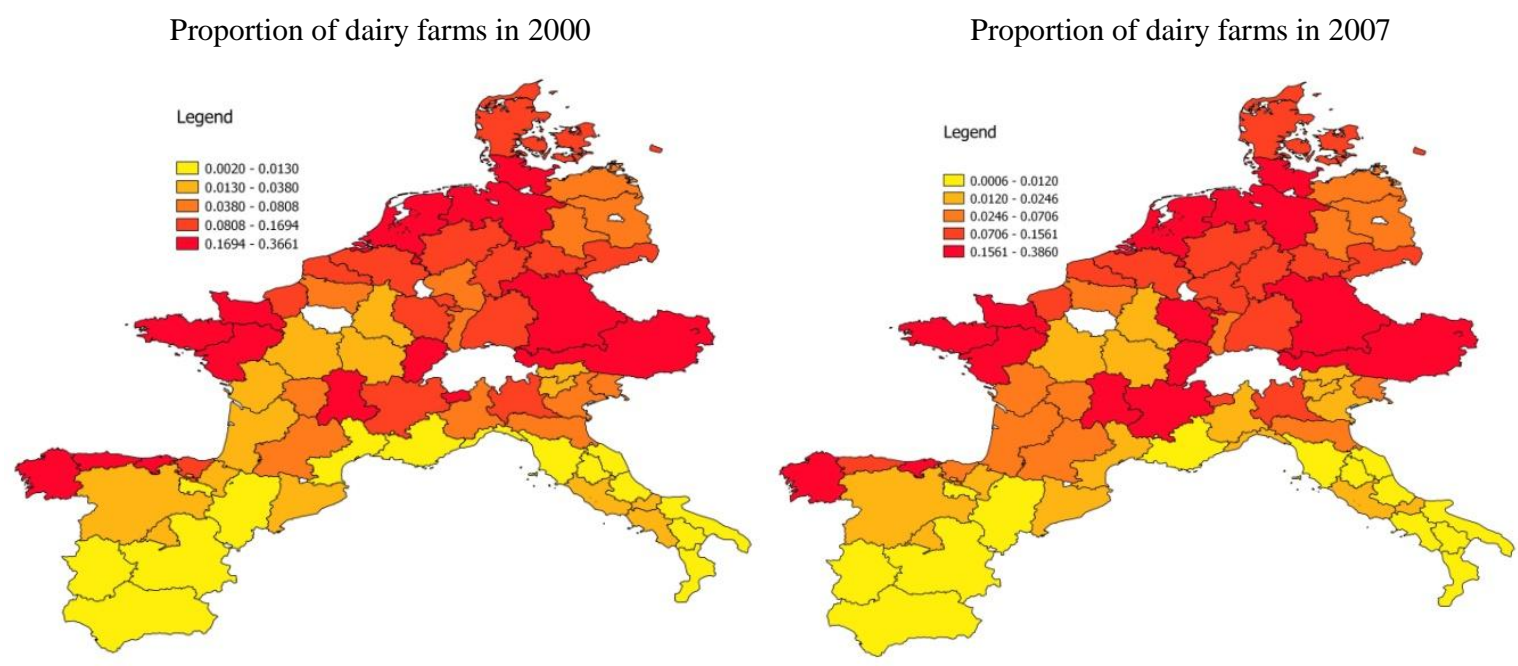

Source: Own calculation.

Figure 4-2 Proportion of dairy farms per region in 2000 and 2007. 
Our approach to the effects of local agglomeration is not limited to the region in which the farm is located. We also extend the possible effects of agglomeration to neighboring regions. Greunz (2003), in a study of the geographical scope of knowledge spillovers between regions in Europe, found that knowledge generated in neighboring regions has a significantly positive impact on the generation of knowledge in the "home" region. As seen in Figure 4-2, regions with a high proportion of dairy farms don't seem to be isolated. This clustering of regions might have also an impact on the generation of externalities derived from agglomeration. This is especially true in a continent in which barriers resulting from international borderlines are limited. Labor force, capital and trade can move freely between countries. This might encourage a constant exchange of information and knowledge beyond national regions. Furthermore, the farms present in the sample also share, to a large extent, the same agricultural policy. All things considered, this might result in an appropriate environment in which externalities might easily propagate.

Using this perspective, we have incorporated a measure of agglomeration in the neighboring regions. We consider $W$ a $N x N$ shared-boundary weighted matrix that captures spatial relationships based on shared boundaries, where each component of $W$ has the following form:

$$
l_{i j}=\left\{\begin{array}{c}
\mathbf{1} \text { if region } i \text { and } j \text { share boundary } \\
\mathbf{0} \text { ither wise }
\end{array}\right.
$$

The row standardization requires that each value is divided by the sum of values of its row $w_{i j}=l_{i j} / \sum_{k \neq i} l_{i k}$. This matrix is then multiplied by the vector that contains the values of proportion of dairy farms per region. In essence, the result is the average proportion of farms in the neighboring regions. Figure 4-3 displays a map showing the average proportion of dairy farms in the neighboring regions in 2000 and 2007.

As shown in Figure 4-3, proportions vary little over time. The geographical spread seems to be similar to the one in Figure 4-2. In general, regions in northern Europe tend to have neighboring regions with higher proportions of dairy farms.

As noted by Diez-Vial (2011), not all farms contribute and benefit equally from externalities caused by agglomeration. In particular, larger firms are able to make larger investments and take the lead in strategies to improve their performance from which smaller firms can benefit. Furthermore, Porter (1990) found that close proximity to larger firms allows the smaller ones to learn from their practices and strategies. Larger firms also tend to invest more in education of a specialized labor force. Smaller firms can benefit from this by hiring skilled workers, 
therefore avoiding the expensive training process as reported by Brunello and Gambarotto (2004). Larger firms also find it easier to become exporters allowing firms which are close to also become exporters by trying to access the same markets as the regional leaders, as found by Koening (2009).

Proportion of dairy farms in the neighboring region in 2000

Proportion of dairy farms in the neighboring region in 2007
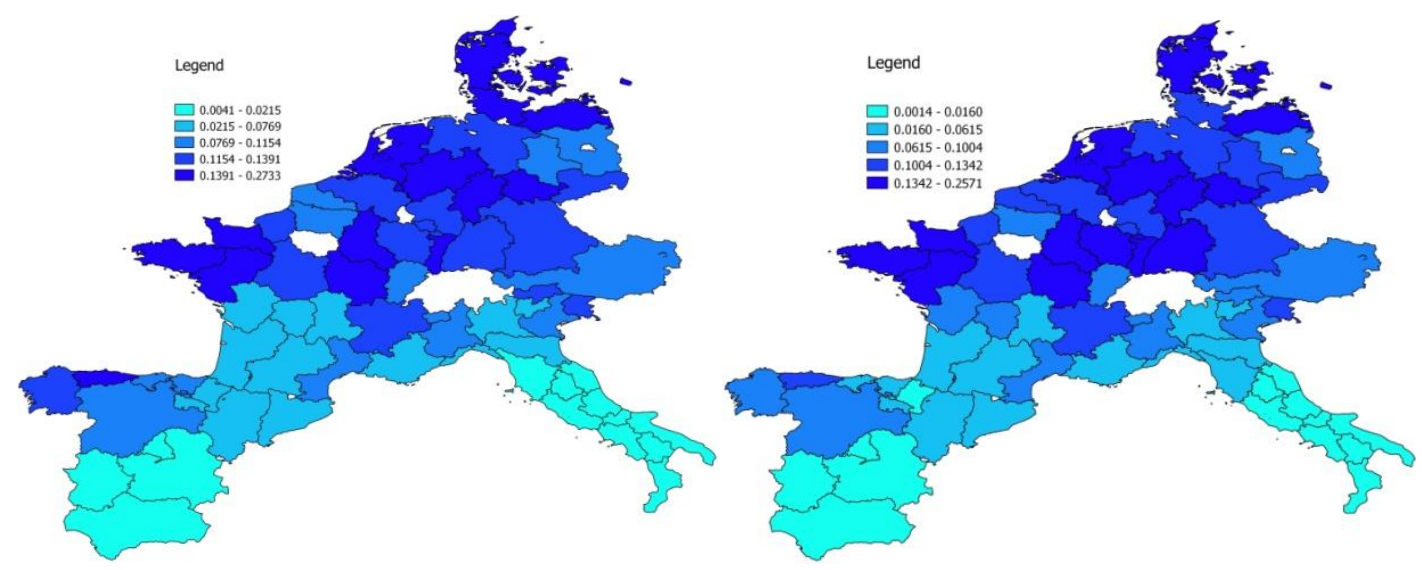

Source: Own calculation.

Figure 4-3 Proportion of dairy farms in the neighboring region in 2000 and 2007.

We use the average volume of milk quota per region as a proxy for the size of the firm and industry at the regional level. Since its introduction in 1984, the quota system limits the amount of milk that farmers can deliver to dairies, in an attempt to reduce milk production in Europe. The quota is attached to the holding, nevertheless subsequent changes to the policy have allowed quotas to be traded. As a consequence, farms that overtake their quota can buy more quotas and increase their production or sell their quota in case they don't need it and abandon dairy production. According to Alvarez and del Corral (2010), the number of dairy farms in Europe has been reduced in recent decades. Furthermore, as a consequence of the introduction of the quota system, farm size has been constantly increasing. This increase in the farm size has been accompanied by changes in the production techniques; farms increasingly adopt more extensive systems. From this perspective, we expect that average quota per region can capture the average size of a farm in the region. Since larger farms are associated with extensive systems that imply more sophisticated technologies, we also expect that this variable captures how the region benefits from the externalities of larger firms.

Figure 4-4 shows the average quota per region in quintals in the years 2000, 2004 and 2008 calculated from the FAND. The figure shows large variation in milk quota across regions in Europe. In particular, the figure shows larger values of quota in Denmark, northern Germany and the Netherlands in every year. Meanwhile in the other regions, quota tends to be smaller. 
Milk quota is also comparatively larger in northern Spain and Italy and central France. Conversely, milk quota increases significantly over time in every region, which supports the fact that dairy farm sizes have been increasing over time.

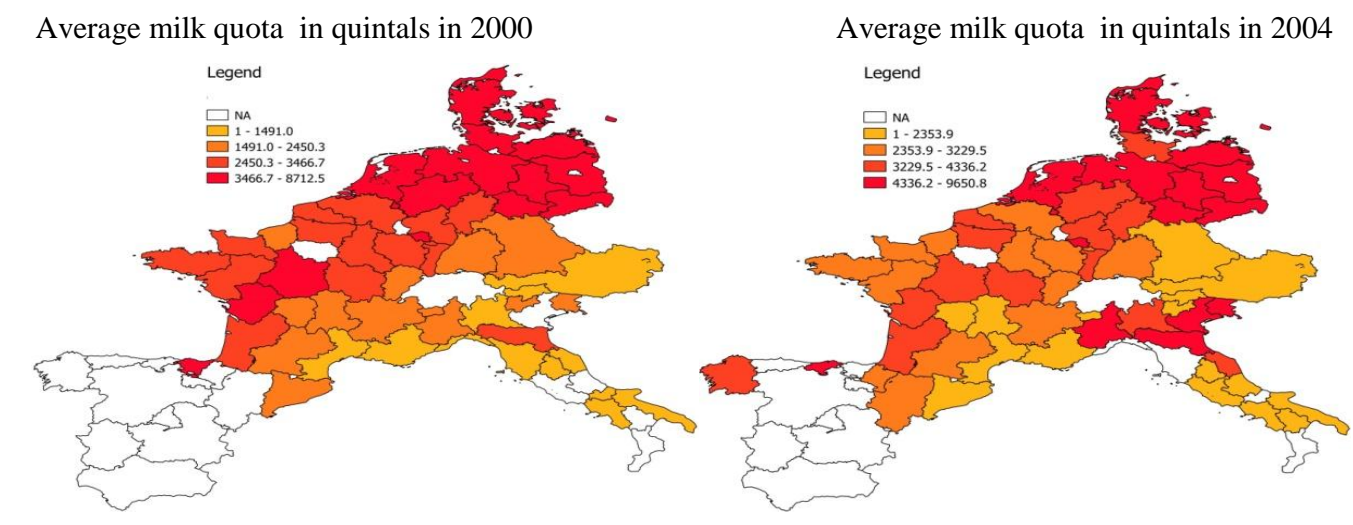

Average milk quota in quintals in 2008

Source: Own calculation.

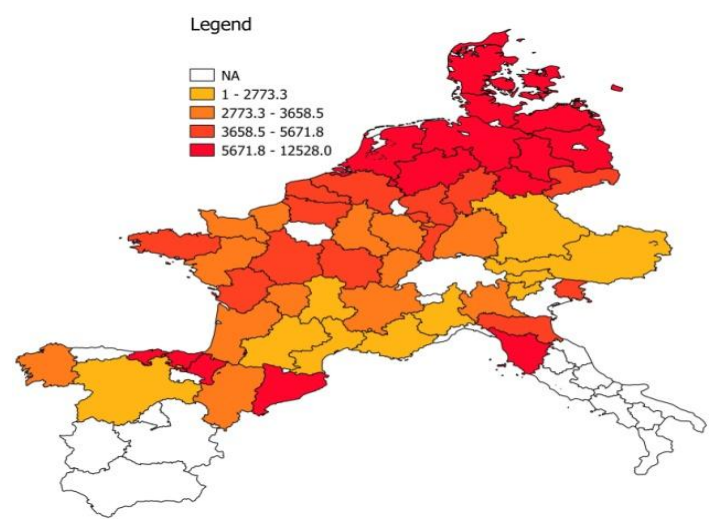

Figure 4-4 Average milk quota per region in 2000, 2004 and 2008. One quintal is equivalent to $1000 \mathrm{~kg}$.

Since natural conditions may explain part of the economies of agglomeration, that is, favorable natural conditions might be positively related to the intensity of agglomeration. We have decided to incorporate measures of natural conditions into the stochastic frontier model. In particular, we will use two measures, the Temperature-Humidity Index (THI) and the proportion of grass land from the total utilized agricultural area at the regional level.

High temperatures in combination with humidity can affect the physiology of the cows and in turn their milk production. According to West (2003), changes in the physiology and behavior of a cow facing heat stress include reduced feed intake, decreased activity, seeking shade and wind, an increase in respiratory rate and an increase in blood flow and sweating. All of these factors would result in negative consequences for the milk yield. THI is a widely used index in dairy science that combines measures of both temperature and humidity, serving as a measure of heat stress. The formula for THI has the following form: 
Numerous studies use it to establish the effects of heat stress on the milk yield of the cow. Certain studies, including Johnson (1980) and Du Preez et al. (1990 and 1990b), conclude that milk yield declines when THI reaches a value of 72 or more. Johnson et al. (1962) found that milk yield decreases when THI reaches 77. Ingraham (1979) found a reduction of $0.32 \mathrm{Kg}$. in the milk yield per increased unit of THI.

We have calculated THI data for each region in the sample. We collected monthly data on mean temperature and relative humidity from two cities, separated by distance, in each region $^{40}$ in the period 2000-2008. We then calculated the THI for each region. The variable will be added as a dummy variable based in its tertiles. The tertiles of this variable are: [48.77, 52.72), [52.72, 58.18], (58.18, 65.28]. Figure 4-5 shows the tertiles in the THI. As expected, the higher values of THI are located in the Mediterranean countries in the south, whereas lower values of THI are present in the northern regions of the continent.

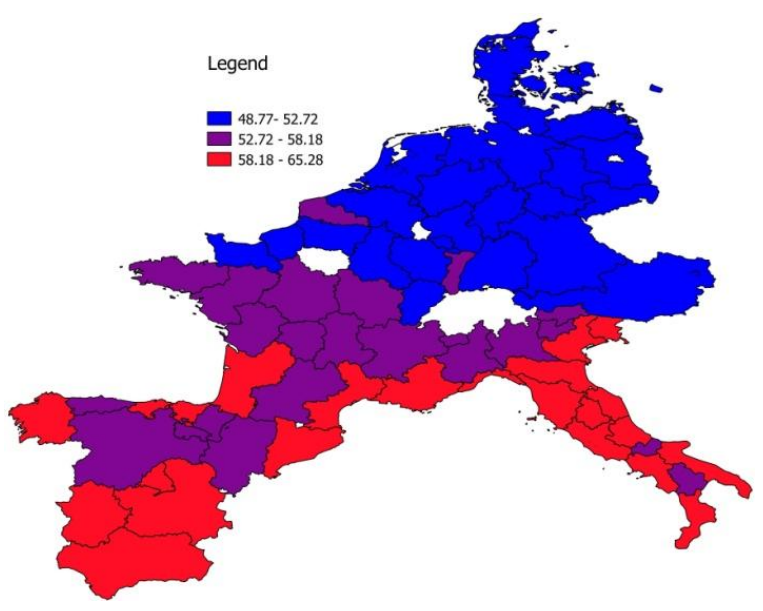

Source: Own calculation.

Figure 4-5 Average THI in the period 2000-2008.

As an additional measure of natural conditions, we use the proportion of grass land from the total utilized agricultural area. According to Stypinski (2011), there has been an increasing specialization in farming in Europe in recent decades. As a consequence, some regions have specialized in arable crops. Those regions rich in grassland have specialized in animal husbandry, milk and meat production. Furthermore, Stypinski estimates that around $74 \%$ of the cows in Europe are located in lowlands rich in grassland in the Atlantic climate zone. The

\footnotetext{
${ }^{40}$ Cities separated by considerable distances were considered to account for the effect of different climatologic areas in each region.
} 
specialization due to favorable natural conditions has increased milk yields as noted by Peeters (2008) and Kristensen et al. (2008).

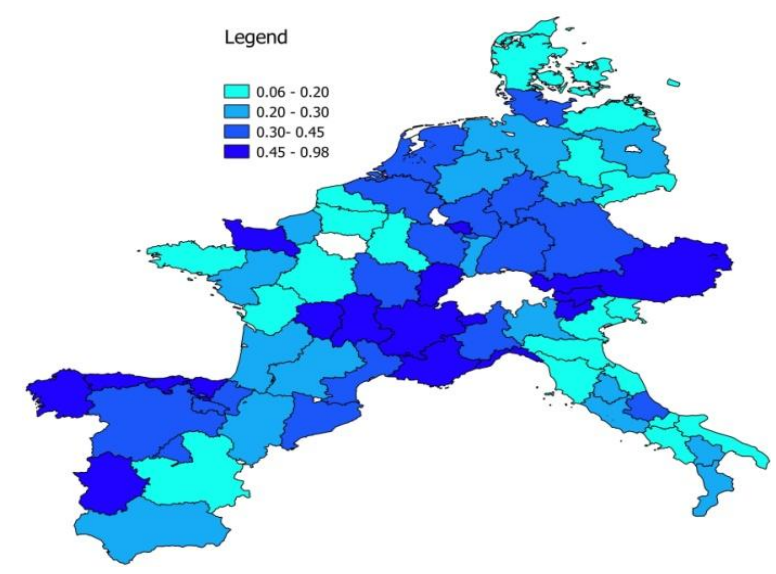

Source: Own calculation.

Figure 4-6 Average proportion of grassland from the total utilized agricultural area per region. Average from 2000 to 2008 .

Grassland proportion per region was calculated based on the data of EUROSTAT. As there was very little variation in the proportion of grassland over time, Figure 4-6 shows calculations for an average proportion of grassland in the period 2000-2008. As seen on the map, regions with higher proportions of grassland are located in northern Spain, central and southern France, Austria, southern Germany, Belgium and the Netherlands.

\subsection{Estimation}

Stochastic frontier analysis was first introduced by the seminal works of Aigner et al. (1977) and Meeusen and van den Broeck (1977). Its aim is to estimate a production function that describes the technology and allows us to measure efficiency. The production function takes the form:

$$
y_{i t}=f\left(\boldsymbol{x}_{i t}\right) * \exp \left(v_{i t}-u_{i t}\right)
$$

Where $y_{i t}$ represents the output of the farm $i$ in time $t, x_{i t}$ represents the vector of inputs required to produce $y, f($.$) is the technology. The term \exp \left(v_{i t}-u_{i t}\right)$ is also called the composed error term, where $v_{i t}$ represents the random component of the model and is expected to have a normal distribution with mean zero and constant variance. Meanwhile, $u_{i t}$ is a non-negative term that aims to measure technical efficiency. A fully efficient farm will have an efficiency value of 1 , meaning that it is located right on the frontier. On the other 
hand, a fully inefficient farm will have an efficiency value of 0. Its distribution is positive. $v_{i t}$ and $u_{i t}$ are assumed to be independent.

Since our aim is to estimate the effects of agglomeration in the frontier and on efficiency, we will use the Battese and Coelli (1995) approach. This specification allows us to introduce efficiency effects in the term $u_{i t}$. This specification implies that $u_{i t}=z_{i t} \boldsymbol{\delta}+e_{i t}$, where $z_{i t}$ is a vector of determinants of technical efficiency, and $\boldsymbol{\delta}$ is the parameter to be estimated. The stochastic frontier model proposed has the following form:

$$
\ln y_{i t}=\beta_{0}+\sum_{j=1}^{J} \beta_{j} \ln x_{j i t}+\frac{1}{2} \sum_{j=1}^{J} \sum_{l=1}^{L=J} \beta_{j l} \ln x_{j i t} \ln x_{l i t}+\beta_{t} t+\frac{1}{2} \beta_{t t} t^{2}+\sum_{j=1}^{J} \beta_{t j} \ln x_{i j t} t+R_{k t}+v_{i t}-u_{i t}
$$

Equation 4.4 is a translog production frontier ${ }^{41}$. Output $y_{i t}$ is the revenue of the farm measured in Euros. Five inputs are used: Land is the utilized agricultural area of the farm in acres. Labor is measured as the number of hours of work dedicated to the farm, including family and hired labor. Feeding cost is the expenditure in Euros on feeding stuffs. Capital is measured as machinery and building costs plus depreciation in Euros, and finally farm expenses are measured in Euros. Among others, farm expenses include veterinary costs, energy, fuel, water, depreciation, milk tests and storage. We also introduce a time trend $t$, to account for technical change. Table 4-1 summarizes the descriptive statistics for each variable of the production function ${ }^{42}$.

\begin{tabular}{lccccc}
\hline \multicolumn{1}{c}{ Variable } & Unit & Minimum & Mean & Maximum & Standard Deviation \\
\hline Output (revenue) & $€$ & $15,280.0$ & $154,800.0$ & $1,379,000.0$ & $133,768.4$ \\
Land & Hectares & 5.0 & 67.8 & 399.5 & 50.3 \\
Labor & Hours/year & $1,080.0$ & $4,132.0$ & $41,990.0$ & $2,039.0$ \\
Feeding cost & $€$ & 4.6 & $28,540.0$ & $419,300.0$ & $33,818.3$ \\
Farm expenses & $€$ & 801.7 & $25,880.0$ & $676,000.0$ & $21,901.4$ \\
Capital & $€$ & 639.2 & $33,920.0$ & $372,000.0$ & $24,956.8$ \\
\hline
\end{tabular}

Source: Own calculation.

Table 4-1 Descriptive statistics of the variables in the production function.

\footnotetext{
${ }^{41}$ The Cobb-Douglas production function was also estimated. In all clusters the likelihood-ratio test favored the translog technology.

${ }^{42}$ All monetary values were deflated with 2000 as base year.
} 
As discussed before, agglomeration effects might be present in the frontier and in the efficiency term. The term $R_{k t}$ in Equation 4.4 is meant to capture the effects of agglomeration on the frontier and has the following form:

$$
\begin{aligned}
R_{k t}= & \theta_{1} \ln \text { Regional Prop }_{\cdot k t}+\theta_{2} \ln \text { Regional Prop }_{\cdot k t} * W_{k t}+\theta_{3} \ln \text { Regional Prop }_{\cdot k t} \\
& * \ln \text { Regional Prop }_{\cdot k t} * W_{k t}+\theta_{4} \text { Natural Conditions }_{k t}+\sum_{i=1}^{7} \varphi_{i} \text { Country dummies }
\end{aligned}
$$

Equation 4.5 introduces the previously described measures of local agglomeration to the frontier. $\theta_{3}$ is meant to capture the interaction of the local agglomeration and the agglomeration of the neighboring regions. Natural conditions are added to account for the possible effects of these conditions on the consolidation of the agglomeration of dairy activities. Country dummies are added to account for country heterogeneity.

The term $u_{i t}$ has a truncated normal distribution $u_{i t} \sim N^{+}\left(z_{i t} \delta, \sigma_{u}^{2}\right)$, and takes the following form:

$$
\begin{aligned}
u_{i t}=\delta_{0} & +\delta_{1} \ln \text { Regional Prop }_{k t}+\delta_{2} \ln \text { Regional Prop }_{\cdot k t} * W_{k t}+\delta_{3} \ln \text { Regional Prop }_{\cdot k t} \\
& * \ln \text { Regional Prop } \cdot k t * W_{k t}+\delta_{4} \text { Regional quota }_{k t}+\delta_{5} \text { Regional quota }_{k t}{ }^{2} \\
& +\delta_{4} \text { Natural Conditions }_{k t}+\delta_{5} \text { Subsidies }_{i t}
\end{aligned}
$$

The efficiency term also incorporates the same measures of local agglomeration used in the frontier. The term also incorporates the average local milk quota ${ }^{43}$ and milk quota squared. We also include subsidies as a proportion of the revenue into the efficiency term. This is to account for policy related structures in the different regions and countries. Since its reform in 2003, the Common Agricultural Policy (CAP) subsidies have been decoupled from production. Each member country is free to decide the time and form of application of the reform. On the other hand, subsidies might encourage farms to innovate and invest in new technologies that, in turn, decrease efficiency as noted by Harris and Trainor (2005). Notice that if the latter is true, subsidies might also encourage positive externalities derived from knowledge spillovers. Nevertheless, subsidies might also have a negative impact on efficiency. An additional income can reduce the effort of the farmers, as found by Berström (2000).

\footnotetext{
${ }^{43}$ Milk quota was not used in the frontier due to its high correlation with output and the possible endogeneity with the same variable.
} 


\subsection{Empirical results}

In this section, we present the results of the estimation of Equations 4.4, 4.5 and 4.6. Table 42 shows the result of the production function model ${ }^{44}$. The vast majority of the coefficients are statistically significant at the $1 \%$ level. Since the variables were normalized with respect to their means, they can be interpreted as partial production elasticities at the sample mean. That is, by how much the output would increase in percentage terms if any of the inputs are increased by $1 \%$. Among the 5 inputs, other farm expenses have the largest elasticity (0.329). On the other hand, labor has the lowest at 0.116 . The variable trend captures the technical progress, it has a positive and significant value of around 3,2\%. This means that there has been an expansion of the production possibilities in the dairy sector over the analysis period. In other words, the frontier has been shifting up.

\begin{tabular}{|c|c|c|c|c|c|}
\hline INPUT & Coeffici & ent & INPUT & Coeffici & ent \\
\hline INTERCEPT & 0,129 & $* * *$ & LABOR*FEED & $-0,007$ & \\
\hline LAND & 0,130 & $* * *$ & LABOR*FARM EXP & $-0,016$ & . \\
\hline LABOR & 0,116 & $* * *$ & LABOR*CAPITAL & 0,016 & $*$ \\
\hline FEED & 0,290 & $* * *$ & LABOR*TREND & $-0,010$ & $* * *$ \\
\hline OTHER EXPENSES & 0,329 & $* * *$ & FEED^2 & 0,081 & $* * *$ \\
\hline CAPITAL & 0,172 & $* * *$ & FEED*FARM EXP & $-0,027$ & $* * *$ \\
\hline TREND & 0,032 & $* * *$ & FEED*CAPITAL & $-0,030$ & $* * *$ \\
\hline LAND^2 & $-0,108$ & $* * *$ & FEED*TREND & 0,001 & \\
\hline LAND*LABOR & $-0,020$ & $* *$ & FARM EXP^2 & 0,087 & $* * *$ \\
\hline LAND*FEED & $-0,018$ & $* * *$ & FARM EXP*CAPITAL & $-0,065$ & $* * *$ \\
\hline LAND*FARM EXP & 0,066 & $* * *$ & FARM EXP*TREND & 0,009 & $* * *$ \\
\hline LAND*CAPITAL & 0,019 & $* *$ & CAPITAL^2 & 0,096 & $* * *$ \\
\hline LAND*TREND & 0,007 & $* * *$ & CAPITAL*TREND & $-0,010$ & $* * *$ \\
\hline LABOR^2 & $-0,051$ & $* * *$ & TREND^2 & 0,002 & $* *$ \\
\hline
\end{tabular}

Source: Own calculation

Table 4-2 Coefficients estimates of the production function.

Before continuing to deepen the core of this work, we would like to present some other results of the estimation of the stochastic frontier model. First of all, it is worth testing the hypothesis that data can be well represented by means of a production function. Put simply, we want to test the presence of inefficiency. In terms of Equation 4.4, this implies that $H_{0}: u_{i t}=0$ is not rejected. The model can then be efficiently estimated by an OLS estimator. This hypothesis was rejected with a likelihood-ratio test (LR) statistic equal to 2251.9. This value considerably

\footnotetext{
${ }^{44}$ All variables were normalized; this implies that estimated coefficients are elasticities at the sample mean.
} 
exceeds the upper one- percent point for the Chi-squared distribution with 11 degrees of freedom.

Now we turn to the primary focus of this work. First we tested the validity of our measures of agglomeration and their effects on both frontier and efficiency. We must then test the null hypothesis that the effects of the measures of local agglomeration (regional proportion of dairy farms in the region and proportion of dairy farms in neighboring regions) and size of the firm (measured by average quota in the region) are equal to zero. According to Equations 4.5 and 4.6, this implies that $H_{1}: \theta_{1}=\theta_{2}=\theta_{3}=\delta_{1}=\delta_{2}=\delta_{3}=\delta_{4}=\delta_{5}=0$. This hypothesis is rejected; the LR statistic is equal to 567.02. This considerably exceeds the upper onepercent point for the Chi-squared distribution with 8 degrees of freedom. The result of the test suggests that our measures of local agglomeration and farm size can explain, to some extent, both the frontier and the efficiency component.

One of the innovative contributions of this work is that it explicitly accounts for the local agglomeration of neighboring regions. We now test the validity of the influence of the agglomeration of neighboring regions. In terms of Equations 4.5 and 4.6, this implies that $H_{2}: \theta_{1}=\theta_{2}=\theta_{3}=\delta_{2}=\delta_{3}=0$. The hypothesis is rejected, the LR statistic is 193.21. Once again, this value considerably exceeds the upper one-percent point for the Chi-squared distribution with 4 degrees of freedom. The rejection of the hypothesis suggests that the effects of the proportion of dairy farms in neighboring regions are present in both the frontier and the efficiency term.

\subsubsection{Local agglomeration effects on the frontier}

Table 4-3 shows the results of the estimation of Equation 4.5. Fist, we have the effects of natural conditions on the frontier. As described before, the THI was converted into a dummy variable; the reference is the lowest tertile of the values of the THI. Both dummies are statistically significant and, as expected, carry a negative sign. The result is in line with theory which predicts that higher values of THI reduce the milk yield and in turn the total output of the farm. The proportion of grassland in the region has no significant impact on the frontier.

The effects of local agglomeration on the frontier are positive and statistically significant. The proportion of dairy farms in the region has a value of 0.021 . This implies that farms located in regions in which the concentration of dairy farms is high increase their total output. Since the variable is in logs, this implies that an increase of $1 \%$ in the local proportion represents an increase of $2.1 \%$ in the output. A similar result indicates that the proportion of dairy farms in 
neighboring regions takes on a value of 0.061 , and the integration of both is 0.028 . This shows that benefits from agglomeration are not only limited to the region where the farm is located. The output of farms also benefits from the agglomeration of dairy farming in neighboring regions. So far we have shown that agglomeration of dairy farming in the region in which the farm is located and in neighboring regions increases farms' output. Nevertheless, the exact mechanisms by which local agglomeration affects productivity are not easy to determine and cannot be explained in our proposed model. As hypothesized in this work, one of the main benefits that might come local agglomeration are knowledge spillovers. As found by Greunz (2003), this might not be limited and beneficial to just the "home" region, but also to neighboring regions. Knowledge might spread in different ways, for example, highly specialized workers who can move freely and settle in new regions may be agents of propagation of knowledge. Networks of farmers and regional associations may also be nodes that encourage the propagation of knowledge. However, as revealed previously, the externalities of local agglomeration are not limited to knowledge spillovers. Productivity may also benefit mainly from other externalities inherent to agglomeration. For example, the reduction of production costs, lower transaction costs and the attraction of more demand as noted by Diez-Vial (2011) might also be powerful explanations of the benefits of local agglomeration. Since natural conditions and country heterogeneity have been accounted for, the effects of the agglomeration can be interpreted as pure effects of the externalities derived from the process and not as convenient clustering of farms that are located in specific areas with ideal conditions for dairy farming.

\begin{tabular}{|c|c|c|}
\hline FRONTIER EFFECTS & Coeffic & ent \\
\hline DUMMY THI MEDIUM & $-0,066$ & $* * *$ \\
\hline DUMMYTHI HIGH & $-0,104$ & $* * *$ \\
\hline PROPORTION GRASSLAND & $-0,010$ & \\
\hline $\begin{array}{l}\text { PROPORTION DAIRY FARMS IN } \\
\text { THE REGION }(\theta 1)\end{array}$ & 0,021 & $* * *$ \\
\hline $\begin{array}{l}\text { PROPORTION DAIRY FARMS } \\
\text { NEIGHBOR REGIONS }(\theta 2)\end{array}$ & 0,061 & $* * *$ \\
\hline INTERACTION ( $\theta 3)$ & 0,028 & $* * *$ \\
\hline DUMMY BELGIUM & 0,218 & $* * *$ \\
\hline DUMMY DENMARK & 0,006 & \\
\hline DUMMY GERMANY & $-0,056$ & $* * *$ \\
\hline DUMMY SPAIN & 0,067 & $* *$ \\
\hline DUMMY FRANCE & 0,060 & $* * *$ \\
\hline DUMMY ITALY & 0,132 & $* * *$ \\
\hline DUMMY NETHERLANDS & 0,230 & $* * *$ \\
\hline
\end{tabular}

Table 4-3 Estimates of local agglomeration on the frontier. 


\subsubsection{Local agglomeration effects and farm size effects on efficiency}

Table 4-4 shows the estimates of the effects on efficiency ${ }^{45}$ in Equation 4.6. First of all, we analyze the effect of natural conditions on the efficiency. The THI dummies are both significant and negative. This means that farms located in regions with higher values of THI are less inefficient than those located in regions with the lowest values of THI. Our interpretation of this result is that farms located in adverse natural conditions might require extra effort to achieve better yields from the cows in comparison to those located in regions with lower values of THI. Farms located in these regions achieve lower yields and outputs, but in an effort to adapt to the adverse environment they could achieve higher efficiency scores.

The proportion of grassland has a positive sign. This means inefficiency increases as the proportion of grassland in the region is larger. Our interpretation of this result is that farms located in regions rich in grassland tend to feed less cows with concentrates. Cows fed on grassland need to move continuously, which implies extra energy consumption and a possible reduction of the efficiency.

\begin{tabular}{|c|c|c|}
\hline EFFICIENCY EEFECTS & Coeffici & ent \\
\hline INTERCEPT & 0,023 & \\
\hline DUMMY THI MEDIUM & $-0,158$ & $* * *$ \\
\hline DUMMYTHI HIGH & $-0,175$ & $* * *$ \\
\hline PROPORTION GRASSLAND & 0,142 & $* * *$ \\
\hline \multicolumn{3}{|l|}{ PROPORTION DAIRY FARMS IN } \\
\hline THE REGION ( $\delta 1)$ & $-0,051$ & $* * *$ \\
\hline \multicolumn{3}{|l|}{ PROPORTION DAIRY FARMS } \\
\hline $\begin{array}{l}\text { NEIGHBOR REGIONS }(\delta 2) \\
\text { INTERACTION }(\delta 3)\end{array}$ & $\begin{array}{l}-0,033 \\
-0,006\end{array}$ & \\
\hline REGIONAL FARM SIZE (QUOTA) & $-0,086$ & $* * *$ \\
\hline REGIONAL FARM SIZE (QUOTA)^2 & 0,033 & $* * *$ \\
\hline LOG SUBSIDIES & 0,177 & $* * *$ \\
\hline
\end{tabular}

Table 4-4 Estimates of efficiency effects.

Now we turn to the impact of the local agglomeration on efficiency. Only one out of our three measures of local agglomeration is statistically significant: the proportion of dairy farms in the region where the farm is located. Its negative sign implies that it reduces inefficiency. This result suggests that farms located in a region with a high proportion of dairy farms have a

\footnotetext{
${ }^{45}$ The average efficiency score over the period is $0.859, \gamma=0.436$.
} 
propensity to make fewer errors in the production process and achieve higher efficiency scores. As noticed by Tveteras and Battese (2006), farms located in regions with a high intensity of a common activity may receive the correct signals from environment where they operate. Moreover, they also suggest that the probability of making a wrong decision regarding the combination and use of inputs can be reduced in agglomerated environments. Such situations necessarily have a positive impact on efficiency.

Measures which are related to local agglomeration in neighboring regions are insignificant in the efficiency term. This implies that benefits to efficiency from local agglomeration mainly come from the region in which the farm is located. In spite of the fact that there is free movement of people, trade and capital in Europe, firms closely bounded in a specific area share a number of characteristics that encourage the presence of externalities which impact on efficiency. According to Harrison (1992), firms bounded closely in an area share a social and cultural identity facilitated by a common language, values and beliefs. On the other hand, as stated by Cevassus-Lozza and Galliano (2004), imitation is facilitated among neighboring farms which are located close to each other and have similar characteristics. In other words, proximity plays a role in the spread of knowledge. Furthermore, knowledge is more efficiently generated and propagated in environments in which agents share key features. This supports the findings of the previous section, stating that local agglomeration in the region and in neighboring regions seems to improve productivity via a reduction of costs and attraction of costumers (demand). Conversely, externalities derived from local agglomeration that impact efficiency seem to be more related to knowledge spillovers and bounded to the region where the farm is located.

The average size of a firm is measured by the average milk quota in the region. This is found to have a negative and statistically significant impact on inefficiency. Thus, the larger the average farm size, the lower the inefficiency. We interpret this result in two ways. First of all, larger farms tend to be associated with higher efficiency scores. Moreover, since quotas have been increasing over the analyzed period, this might be the result of a technological change in farm structure which traduces in higher efficiencies. Secondly, in terms of local agglomeration, as exposed before, larger farms tend to benefit more from the externalities of the local agglomeration while on the other hand they tend to produce more externalities. Thus, the result can also be interpreted as the benefits of the investment of large firms in fixed assets and in the training of specialized labor. Notice that the value of the estimated quota square parameter is positive; this shows that the average size of the farm decreases the inefficiency until a certain average farm size is reached. Our interpretation of this result is that large firms 
located in certain regions might experience heavy competition in the local final market which might be prejudicial for the performance of the farms. The competition might also be reflected in the input market, especially in the land and labor market. The competition in those markets might not only be reflected in a possible scarcity of the inputs, but also in their prices which would tend to rise. Biological congestion could be another outcome of the high concentration of large farms, not only affecting the productivity but also the efficiency.

Finally, the proportion of subsidies has a negative impact on efficiency. Similar findings have been reported by Giannakas et al. (2001), Iraizoz et al. (2005), Rezitis et al. (2003). The possible interpretation is the tradeoff between motivation or lack of effort and the additional income that the subsidy represents.

\subsection{Conclusion}

In this work we have estimated the effects of local agglomeration on the dairy sector in Europe. Apart from being the first work that examines agglomeration effects in the dairy sector by means of stochastic frontier analysis, it also innovates in the measure and scope of agglomeration. In particular, we have assumed that local agglomeration effects may not only come from the region in which the farm is located, but also from neighboring regions. We have found that by controlling for natural conditions, all our local agglomeration measures have a positive impact on the frontier, which in turn increases the output of the farms. Contrary to other studies, we did not find signs of congestion effects. Distinguishing exactly the channels by which local agglomeration benefits or is detrimental is still an issue to debate. So far, the main channel has been attributed to knowledge spillovers and there are substantial reasons to believe that this might be the main channel by which local agglomeration affects productivity. Nevertheless, as pointed out, other benefits of agglomeration can include market benefits. We believe that the benefits of local agglomeration on the frontier are more related to the latter than those achieved by knowledge spillovers.

Theoretically, when estimating effects of local agglomeration in stochastic frontier analysis, there are enough reasons to believe that its effects are not only present in the frontier, but also in the efficiency effects. If efficiency substantially depends on the skills and knowledge of the farmer, and knowledge spillovers are present in agglomerated areas, local agglomeration has an undeniable impact on the efficiency. The same measures of local agglomeration have been used as efficiency effects. We have found that only local agglomeration in the region in which the farm is located reduces inefficiency. The result suggests that only local externalities, presumably knowledge spillovers, have a positive impact on the allocation of the outputs of 
the farms from the frontier. The result might be interpreted as the geographical scope by which these externalities affect farms. It is reasonable to propose that knowledge and information are prone to propagate in places with homogeneous cultural, idiomatic, natural and political conditions.

We have also added a variable that measures the average size of the farm in the region. We found that the average size of the farm has a positive impact on efficiency. The interpretation of this result can be viewed from two different angles. First, larger farms tend to be associated with higher efficiency scores, thus our result supports this idea. Secondly, in terms of externalities derived from the local agglomeration. In spite of this, the measure does not capture the density of proportionality. The presence of larger farms might increase the likelihood of more externalities derived from agglomeration as explained in the previous section. Nevertheless, there seems to be a point at which the average farm size increases inefficiency. As discussed, this might be the result of congestion effects.

Several aspects of the results of this work are relevant for policy. First of all, the location of the dairy activity plays a key role in the determination of the productivity and efficiency. As demonstrated here, those effects go beyond the advantages of natural conditions. The results can serve as a guide for location of agricultural activities across Europe. Furthermore, policies that encourage better practices that improve productivity and efficiency might have a multiplier effect since farms may tend to imitate successful practices.

Finally, further research needs to be done on the exact channels by which externalities propagate in agglomerated areas. Models that use the exact location of the farms might help to fully understand the complex processes behind the propagation of externalities and their exact spatial scope. 


\section{CONCLUDING REMARKS}

This body of work addresses two important issues regarding efficiency and productivity analysis. Both issues stem from the geographical location in which production takes place. Firstly, Chapters 2 and 3 have addressed the importance of accounting for regional heterogeneity in the estimation of stochastic frontier models. This was done under the hypothesis that technologies are heterogeneous over space due to heterogeneous natural, political, socio-economic and cultural conditions. The aim in both chapters is to relax the assumption that all producers use the same technology. Secondly, this work explores an additional effect of location: the effects of local agglomeration on efficiency and productivity analysis in Chapter 4. To the author's knowledge, this is the first effort to explicitly address these issues in the dairy sector in spite of the long recognition of the implications of these issues in existing literature.

Ignoring regional heterogeneity has implications on policy makers' decisions. Assuming a common technology for all firms when analyzing efficiency and productivity at the transnational or transregional scale might lead to mistaken conclusions about farmers' performance. The findings of Chapters 2 and 3 suggest policy decisions should be based on smaller scales - on a regional level rather than national or continental.

The results which have been presented prove that, in some cases, accounting for such heterogeneity improved efficiency estimations as seen in Chapter 2. A Bayesian mixed model setup was used to take into account regional heterogeneity at the county level in sample dairy farms in the UK. This allowed us to show that, in all cases, models accounting for regional heterogeneity were preferred over those that ignored it. The results in Chapter 2 also show that efficiency scores improved, suggesting a subestimation of efficiency when regional heterogeneity is not accounted for. Furthermore, it was shown that the flexibility of the mixed model setup is such that, in principle, it is possible to obtain individual frontiers at the county level. As discussed in this Chapter, it is the authors' belief that the main gain of the setup used is the improvement in accuracy of the fixed effects of the frontier by accounting for regional heterogeneity.

Chapter 2 has also contributed to the abundant literature on the effects of subsidies on efficiency. It is worth noting that the existing literature on this topic has not reached a solid conclusion regarding the real impact of subsidies on efficiency. The nature of the effects and the magnitude of their impact varies considerably depending on how the subsidies are modeled, including factors such as the productive sector that is studied, the country, etc. 
Chapter 2 has considered subsidies only as determinants of inefficiency. The findings show that the impact of the subsidies on efficiency depends on their nature.

Chapter 3 uses variables of natural conditions (THI, altitude and LFA) and variables that might be seen as indicators of adaptation to natural conditions (cow per ha., feeding per cow, buildings per cow) to unveil different technologies in the dairy sector in Europe. The cluster analysis proposed in this chapter shows substantial differences in the technologies employed across Europe. This has the advantage that measuring farms' efficiency with adequate frontier could give a more realistic measure of efficiency since farmers are compared to those that face similar natural conditions and employ similar technologies. The results of the clusters in this chapter were contrasted with the results of the estimation of the complete panel, not taking into account the grouping of the observations by using LFA. When analyzing the clusters, the estimations provide additional information about the technology and the behavior of the TFP and its components. These individualities in efficiency scores and TFP behavior were completely omitted when the complete panel was analyzed. Therefore, the cluster analysis provides additional information about the performance of the farms.

In Chapter 4, it was shown that agglomeration effects have a positive impact on productivity and efficiency. Firstly, the findings proved that agglomeration effects are present in agricultural activities. Existing literature had suggested that industrial sectors of the economy benefit more from agglomeration economies. Furthermore, not only was it shown that these effects exist in an agricultural activity, but to the authors' knowledge it is the first attempt to estimate the effects of local agglomeration on productivity and efficiency in the dairy sector. The chapter introduces an innovative new concept on agglomeration economies not previously found in the existing literature by assuming that effects of agglomeration are not only limited to the region in which the farm is located. Instead, the model takes into account the effects of agglomeration of neighboring regions as well. This indicates that externalities produced in agglomerated areas have a wider spatial spread. These results are relevant for policy makers for several reasons. Firstly, the findings suggest differences in productivity and efficiency of farms located in agglomerated areas; this might serve as a guide for planning and stimulating the creation of clusters of different economic activities, in which knowledge spillovers would be encouraged.. Secondly, policies that encourage technical change and an increase in efficiency might have a multiplier effect since farmers would tend to imitate good farming practices. 
Finally, in line with the motivation of previous chapters, Chapter 4 also quantifies the impact of two key measures of natural conditions on productivity and efficiency: THI and the availability of grassland. The magnitude and significance of the estimators suggest that such factors should not be ignored when estimating productivity and efficiency. The results are relevant for policy because they can serve as a guide for focalization strategies of the policy to improve productivity. They show that there are differentials in the possibilities of the farms depending on their natural conditions. Again, this finding reinforces the idea that policies with national or continental scope might distort their aims if such conditions are ignored.

The scope of the analysis of the complex spatial processes that might affect the technology, efficiency and knowledge are certainly limited by the specificity of information on the location of the farms. This work has based its analysis on the smallest regional division available. Specific locations open the possibility to explore more complex spatial techniques at the smallest possible scale, the farm level.

The extent to which the results are driven by the simplicity of certain model specifications is open to question. Chapter 2 assumed a Cobb-Douglas production function with time-invariant efficiency. The flexibility of other technologies should be explored, e.g. translog. However, a more flexible technology implies an increasing number of parameters to estimate in the mixed model setup. Time-invariant efficiency might be seen as a very strong assumption on the farmers' skills. The results of Chapter 2 suggested a preference for the time-invariant specification by DIC. Nevertheless, further time-varying specifications need to be tested. In particular, given the described hierarchical structure of the data, efficiency trend parameters may also share this hierarchical structure and therefore be susceptible to being modeled with the corresponding random effects. This chapter also assumed that subsidies only influence efficiency scores. Modeling subsidies in stochastic frontier analysis has encouraged a considerable debate in literature. Nonetheless, it is the author's belief that subsidies may not only affect farmers' efficiency but also the input combinations. This would then imply that there is an effect on the technology as well as a technical change.

A two-step procedure was used in Chapter 3: in the first step, clusters are identified by means of LCA. Meanwhile, in the second step stochastic frontier, efficiencies and TFP are all estimated. It should be noted that estimating both steps in one single operation is possible and several publications have addressed the issue (see Alvarez and del Corral , 2010 and Orea and Kumbhakar 2004). However, the approach in this chapter uses variables to identify clusters that might be considered endogenous when the one-step procedure is performed. The two-step 
procedure allows us to use such variables in the analysis while avoiding possible endogeneity issues.

A surprising result of the LCA was the relatively large number of clusters that were found. The selection of the numbers of clusters was based on the methodology suggested by Collins and Lanza (2010). The chosen selection criterion primarily bases its decisions on the minimum possible value of AIC and/or BIC. These criteria have the advantage that they include a penalty term that increases with the number of estimated parameters. The final selection of the number of clusters also takes into account the properties of separability and homogeneity. Nevertheless, when selecting number of clusters other criteria may be used resulting in a different number of clusters. Another fact that can explain the number of clusters is the large number of farms present in the sample (21452 farms) alongside the sample's large heterogeneity.

Chapter 3 it was also assumed that prevalences (membership probabilities) are constant over time. Prevalences might be allowed to vary over time, imposing restrictions (invariability over time) on the item response parameters since the number of parameters to estimate would substantially increase. It is the author's opinion that time varying prevalences add little useful information to the cluster analysis performed in this chapter. This is primarily assumed because it is the THI variable which heavily drives the LCA estimation. THI is region specific, which somehow attaches the farm to the region in which it is located. Even more, THI has little variability over time but larger variability over space. On the other hand, the unbalanced nature of the panel data prevents an accurate estimation of prevalences over time.

The TFP decomposition deserves special attention. The measure of TFP presented in Chapter 3 is strongly driven by the selected model specification, Battese and Coelli (1992). This specification assumes the rate of growth of technical efficiency change is common to all producers in the same frontier (technology). Such assumption seems restrictive since farmers' skills and knowledge are clearly heterogeneous and therefore growth rates of efficiency are also heterogeneous. Furthermore, this specification ignores any statistical noise in the efficiency, which theoretically might be implausible. However, since the purpose of this chapter was to make a comparison among clusters, assuming a common trend for the efficiency in each group facilitates this comparison and makes it more consistent. Adding other sources of heterogeneity (e.g. farm heterogeneity) may cause difficulties when comparing different technologies given the large variability of the farms present in the sample. Finally, the TFP decomposition presented in Chapter 3 ignores one of the components 
of TFP: the allocative inefficiency. The estimation of this component requires information on the prices of inputs, which was not available.

The behavior of the TFP can also be explained by the structure of the data set. Annual TFP was estimated as the average of two consecutive years. Since the panel data used is highly unbalanced, this implies that the TFP estimation for a particular pair of years does not necessarily contain the same farms in the previous and following pair or years. As a result, more appropriate conclusions on the development of TFP over time may be obtained with a balanced panel data.

In Chapter 4, it was assumed that a common technology was used for all observations, an assumption which explains the low values of $\gamma^{46}$. The goal of the model presented in Chapter 4 was to identify and quantify the impacts of local agglomeration in the dairy sector. The measures of local agglomeration are also open to interpretation. In this chapter, the proportion of dairy farms per region was used as an appropriate measure. This measure is expected to capture the intensity or importance of the dairy sector in each region. Such a measure is based on the hypothesis that a higher proportion of dairy farms would encourage the diffusion of externalities (e.g. knowledge spillovers) and the creation of externalities themselves. The existing literature has a wide spectrum of measures of local agglomeration, measures which are certainly limited by the quality of the data. In general, census data are required to create such measures.

\subsection{Further research}

Further research should focus on the integration of spatial regression techniques with SFA when panel data is available. At present, the techniques developed are limited to crosssectional or balanced panel data. Considering the best case scenario, this limitation implies a loss of observations when the panel is balanced. The challenge then becomes the possibility of introducing changing distance matrices over time. This work has mainly studied the effects of regional heterogeneity and location in the frontier component, i.e. the technology employed by farmers. Nevertheless, these effects may also be present in the efficiency component as suggested in Chapter 4. This leads to the conclusion that attempts to incorporate spatial regression analysis into SFA should be flexible enough to incorporate the spatial effect in both the frontier and the efficiency component.

\footnotetext{
${ }^{46}$ The proportion of the variance that can be attributed to inefficiency.
} 
Further research is also needed to clarify the real impact of the subsidies on efficiency and technology. This suggests that the effects of subsidies in determining the technology and efficiency are more complex than effects tested so far in literature. Existing literature has not been able to accurately specify the mechanism by which subsidies affect productivity and efficiency. The latter issue is not trivial to solve as there are indications that subsidies might have an impact on every component of SFA. It is the author's belief that subsidies should not be treated as inputs in the production function, though they may influence the input combinations. Models like the one developed by McCloud and Kumbhakar (2008) in which subsidies are introduced as a function of inputs, technical change and technical efficiency can shed light on the direction in which subsidies can be properly modeled. Notice that the structure of such a model implicitly enables the researcher to incorporate the effects of subsidies into the measure of TPF.

Measuring the TFP clearly requires new estimation methods to analyze its decomposition and behavior over time. It is important to note that measuring TFP is very different from explaining it and little research has been done to tackle this issue. New estimators of TFP should search for the drivers of the behavior of TPF over time rather than merely measure it. Drivers like location, environment, policy and market structure should be accounted for when measuring TFP. Ignoring such drivers might lead to biased estimators and a biased measure of TFP. So far, some work has been done in this direction under strong assumptions concerning the econometrical estimation of the model (see O'Donnell, 2014a and 2014b).

Finally, more research should be done to identify the exact channels by which local agglomeration influences SFA. As described previously, effects of local agglomeration can be both negative and/or positive for the frontier and the efficiency component. This implies that it is essential to develop accurate measures of agglomeration. As exposed in Chapter 4, firms benefit from externalities derived from agglomeration and produce these externalities differently. For example, large firms are expected to generate more knowledge than small firms and are probably more prone to adopting newly generated knowledge. Measures of agglomeration that could incorporate the density and/or proportion of large farms derived from census data would allow researchers to understand the differentials in the generation and adaptation of knowledge spillovers. Another research line should consider knowledge spillovers and their propagation under the optic of social network analysis. This would allow researchers to understand the complexity of the mechanisms by which knowledge spillovers propagate. 


\section{REFERENCES}

Aigner D., Lovell C. and Schmidt P. (1977). Formulation and Estimation of Stochastic Frontier Production Function Models, J Econom 6: 21-37.

Alvarez A. and del Corral J. (2010). Identifying different technologies using latent class model: extensive versus intensive dairy farms. Europen Review of Agricultural Economics 37: 231-250.

Alvarez A., Amsler C., Orea L. and Schmidt P. (2006) Interpreting and testing the scaling property in models where inefficiency depends on firm characteristics, J Prod Anal 25: 201-212

Alvarez A., del Corral J., Solís D. and Pérez J. (2008) Does Intensification Improve the Economic Efficiency of Dairy Farms?. Journal of Dairy Science 91: 3693-3698.

Areal J., Balcome K. and Tiffin R. (2004) Integrating spatial dependence into stochastic frontier analysis, Aust J Agric Resour Econ 56: 521-541

Battese G. and Coelli T. (1992), Frontier Production Functions, Technical Efficiency and Panel Data: With Application to Paddy Farmers in India, the J Prod Anal 3: 153-169.

Battese G. and Coelli T. (1995), A Model for Technical Efficiency Effects in a Stochastic Frontier Production Function for Panel Data, Empirical Economics 20: 325-332.

Battese G., Rao P. and O'Donell C. (2004) A metafrontier production function for estimation of technical efficiencies and technology gaps for firms operating under different technologies. Journal of Productivity Analysis 21: 91-103.

Baun J.A. and Mezias S. (1992) Localized competition and organizational failure in the Manhattan hotel industry, 1898-1990. Administrative Science Quarterly 37: 580-604.

Beenson P. and Husted S. (1989) Patterns and determinants of productive efficiency in state manufacturing. Journal of Regional Science 29: 15-18.

Bergström F. (2000) Capital subsidies and the performance of firms. Small Business Economics 14(3): 183-193.

Bouraoui R., Lahmar M., Majdoud A., Djemali A. and Belyea. (2002). The relationship of temperature-humidity index with mik production of dairy cows in Mediterranean climate. Animal Research 54: 479-4941.

Brümmer B. and Loy J-P. (2000), The Technical Efficiency Impact of Farm Credit Programmes: A Case of Study of Northern Germany, J Agric. Econ 51: 405-418.

Brunello G. and Gambarotto F. (2004) Agglomeration effects on employer provided training: Evidence from the UK. Cesifo Working Paper No. 1150, Labor Markets.

Caballero R. and Lyons R. (1990) Internal versus external economies in European industry. European Economic Review 34: 805-830.

Caballero R. and Lyons R. (1992) External effects in the Unites States procyclical productivity. Journal of Monetary Economics 29: 209-225.

Caudill S. and Gropper D. (1995), Frontier Estimation and Firm-Specific Inefficiency Measures in the Presence of Heteroskedasticity, J Bus Econom Stat 13: 105-111. 
Chevassus-Lozza E. and Galliano D. (2004) Local spillovers, firm organization and export behavior: Evidence fron the French food industry. Regional Studies 37: 147-158.

Ciaian P., Kancs D., Swinnen J., Van Herck K. and Vranken L. (2012). Sales market regulation for agricultural land in the EU member states and candidate countries. Factor Markets Working Paper No. 14.

Collins L. and Lanza S. (2010). Latent class and latent transition analysis. Wiley.

Cornwell C., Schmidt P. and Sickles R. (1990)Production frontiers with cross-sectional and time series variation in efficiency levels. Journal of Econometrics 46: 185-200.

Data Source European Commission EU-FADN - DG AGRI.

Dei Ottati G. (2002) Social concentration and local development: The case of industrial districts. European Planning Studies 10: 449-466.

Demir N. and Mahmud S. (2002). Agro-climatic conditions and regional technical inefficiencies in agriculture. Canadian Journal of Agricultural Economics 50: 269-280.

Department for Environment, Food and Rural Affairs and National Assembly for Wales, Farm Business Survey, 2003-2004 . Colchester, Essex: UK Data Archive, August 2005. SN: 5228.

Department for Environment, Food and Rural Affairs and National Assembly for Wales, Farm Business Survey, 2004-2005 . Colchester, Essex: UK Data Archive August 2006. SN: 5447.

Department for Environment, Food and Rural Affairs and National Assembly for Wales, Farm Business Survey, 2005-2006. 3rd Edition. Colchester, Essex: UK Data Archive, May 2008. SN: 5662.

Department for Environment, Food and Rural Affairs and National Assembly for Wales, Farm Business Survey, 2006-2007. Colchester, Essex: UK Data Archive, May 2008. SN: 5838.

Department for Environment, Food and Rural Affairs and National Assembly for Wales, Farm Business Survey, 2007-2008. 3rd Edition. Colchester, Essex: UK Data Archive, August 2010. SN: 6144.

DairyCo. (2013) The Structure of the GB Dairy Farming Industry-What Drives the Change?. Summary report January 2013. Retrieved from: www.dairyco.org.uk/non_umbraco/download.aspx?media=14129 (Last accessed: February $\left.5^{\text {th }} 2015\right)$.

Diez-Vial I. (2011) Geographical cluster and performance: The case of Iberian ham. Food Policy 36: 517-525.

Diez-Vial I. and Alvarez-Suescun E. (2011) The impact of geographical proximity on vertical integration through specific assets: The case of the Spanish meat industry. Growth and Change 42:1-22.

Dries L. and Swinnen J. (2004) Foreign direct investment, vertical integration, and local suppliers: Evidence from the Polish dairy sector. World Development 32(9): 1525-1544. 
Druska V. and Horrace W. (2004) Generalized Moments Estimation for Spatial Panel Data: Indonesian Race Farming, Am J Agric Econ 86: 185-198.

Du Preez J.H., Giesecke W.H., and Hattinngh P.J.(1990). Heat stress in dairy cattle and other livestock under Souther African conditions. I. Temperature-humidity index mean values during the four main seasons. Journal of Veterinary Research 57: 77-86.

Du Preez J.H., Giesecke W.H., Hattinngh P.J and Eisenberg B.E. (1990b) Heat stress in dairy cattle and other livestock under Souther African conditions. III. Monthly temperaturehumidity index mean values and their significance on the performance of dairy cattle. Journal of Veterinary Research 57: 243-248.

Ehlers R. (2007), Comparing Bayesian Models for Production Efficiency. Departamento de Estatística, Universidade Federal do Paraná.

Ellison G. and Glaeser E. (1999) The geographic concentration of industry: Does natural advantage explain agglomeration?. The American Economic Review 89:311-316.

Foster A. and Rosenzweig M. (1995) Learning by doing and learning from others: Human capital and technical change in agriculture. Journal of Political Economy. 103(6) 11761209.

Galán, J.E., Veiga, H. y M.P. Wiper (2014). Bayesian Estimation of Inefficiency Heterogeneity in Stochastic Frontier Models, J Prod Anal 45:85-101.

Gelman A. and Hill J. (2007), Data Analysis Using Regression and Multilevel/Hierarchical Models. Cambridge University Press-New York.

Giannikas K., Schoney R. and Tzouvelekas V. (2001), Technical Efficiency, Technological Change and Output Growth of Wheat Farms in Saskatchewan, Canadian Journal Agricultural Econimics 49: 135-152.

Glass A., Kenjegalieva K. and Paez-Farrell J. (2013); Productivity Growth Decomposition Usin a Spatial Autoregressive Frontier Model, Econ Letters 119: 291-295.

Goldtsein H. and Silver R. (1989) Multilevel and Multivariate Models in Survey Analysis, in: CJ. Skinner D., Holt and Smith M. (Eds), Analysis of Complex Surveys (Chichester, Wiley)

Greene W. (2005). Reconsidering heterogeneity in panel data estimators of stochastic frontier model. Journal of Econometrics 126: 269-303.

Greunz L. (2003) Geographically and technologically mediated knowledge spillovers between European Regions. The Annals of Regional Science 97: 657-680.

Griffin J. and Steel M. (2007) Bayesian Stochastic Frontier Analysis Using WinBUGS, J Prod Anal 27: 163-172.

Hadley D. (2006), Patterns in Technical Efficiency and Technical Change at the Farm-level in England and Wales, 1982-2002, J Agric Econ 57: 81-100.

Hallam D. and Machado F. (1996). Efficiency analysis with panel data: A study of Portuguese dairy farms. European Review of Agricultural Economics. 23: 79-93. 
Harris R. and Trainor M. (2005) Capital subsidies and their impact on total factor productivity: Firm-level evidence from Northern Ireland. Journal of Regional Science 45(1): 49-74.

Harrison B. (1992) Industrial districts: Old wine in new bottles?. Regional Studies 26:469483.

Hoch I. (1962). Estimation of production function parameters combining time-series and cross-section data. Econometrica 30: 34-53.

Holloway G. and Tomberlin D. (2007) Bayesian Ranking and Selection of Fishing Boat Efficiencies, Mar Resour Econ 21: 415-432.

Holloway G., Tomberlin D. and Irz X. (2005), Hierarchical Analysis of Production Estimation, Applications of Simulation Methods in Environmental Resource Economics, Springer

Huang H. and Lui J. (1994), Estimation of Non-Neutral Stochastic Frontier Production Function, J Prod Anal 5: 171-180.

Ingraham R.H., Stanley R.W. and Wagner W.C. (1979) Seasonal effect of the tropical climate on shaded and no shaded cows as measured by rectal temperature, adrenal cortex hormones, thyroid hormone and milk production. America Journal of Veterinary Research 40: 1792-1797.

Institute for European Environmental Policy (2006). An evaluation of the less favoured area measure in the 25 member states of the European Union. Retrieved from: http://ec.europa.eu/agriculture/eval/reports/lfa/full_text_en.pdf (Last accessed on December $16^{\text {th }} 2014$ )

International Dairy Federation (2010). Environmental issues at the dairy farm level. Bulletin of the International Dairy Federation 443/2010. Retrieved from: www.filidf.org/Public/Download.php?media=28744 (Last accessed on December 16th 2014)

Johnson H., Ragsdale A., Berry L. and Shanklin M.D. (1962) Effects of various temperaturehumidity combinations on milk production of Holstein cattle. Missouri, Agr. Sta. Res. Bul. 791. Columbia

Johnson H.D. (1980). Evironmental management of cattle to minimize the stress of climate changes. International Journal of Biometeorology 24: 65-78.

Karagiannis G. and Sarris A. (2005), Measuring and Explaining Scale Efficiency with The Parametric Approach: The case of Greek Tabacco Growers, Agric Econ 33: 441-451.

Koening P. (2009) Agglomeration and the export decisions of French firms. Journal of Urban Economics 66: 186-195.

Koop G. and Steel M. (2004) Bayesian Analysis of Stochastic Frontier Models, Discussion Papers 19, Edinburgh School of Economics, University of Edinburgh.

Koop G., Osiewalski J. and Steel M. (1997) Bayesian Efficiency Analysis through Individual Effects: Hospital Cost Frontiers, J Econom 76: 77-105.

Kristensen T., Soegard K. and Kristensen I. (2005). Management of grasslands in intensive dairylivestock farming. Livestock Production Science 96: 61-73. 
Kumbhakar S. (1990) Production frontiers, panel data, and time-variant technical efficiency. Journal of Econometrics 46

Kumbhakar S., Tsionas E. and Sipiläinen T. (2009). Joint estimation of technology choice and technical efficiency: An application to orgabnic and concentional dairy farminf. Journal of Productivity Analysis 31:151-161.

Kumbhakar S. and Lovell C.A.K. (2000). Sthochastic Frontier Analysis. Cambridge: Cambridge University Press.

Kumbhakar S., Ghosh S. and McGuckin J. (1991), A Generalized Production Frontier Approach for Estimating Determinants of Inefficiency in the U.S. Dairy Farms, J Bus Econ Stat 9: 279-286.

Lakner S., von Cramon-Taubadel and Brümmer B. (2011) Technical efficiency of organic pasture farming in Germany: The role of location economics and specific knowledge. Renewvable Agriculture and Food Systems 27(3): 228-271.

Lall S., Shalizi Z. and Deichmann U. (2004) Agglomeration economies and productivity in Indian industry. Journal of Development Economics 73: 643-673.

Lansink A., Kyösti P. and Bäackman S. (2002). Efficiency and productivity of conventional and organic farms in Finalnd 1994-1997. European Review of Agricultural Economics 29: $51-65$.

Lee, Y.H. (2010) Group-specific sthochastic production frontier models with parametric specifications. European Journal of Operationla Research 200: 508-517.

Lewis D., Bradforf B. and Robinson B. (2011) Are there spatial spillovers in the adoption of clean technology? The case of organic dairy farming. Land Economics 87(2): 250-267.

Maudos J., Pastor J. and Pérez F. (2002). Competition and efficiency in the Spanish banking sector: the importance of specialization. Applied Financial Economics 12: 505-516.

McCloud N. and Kumbhakar S. (2008) Does Subsidy Drive Productivity? A Cross-Country Analysis of Nordic Dairy Farms, Adv Econom 23: 245-274

Meeusen W. and van den Broeck J. (1977), Efficiency Estimation from Cobb-Douglas Production Functions with Composed Errors, Int Econ Review 8: 435-444.

Mitra A. (1999) Agglomeration economies as manifested in technical efficiency at the firm level. Journal of Urban Economics 45: 490-500.

Morrison Paul C. and Siegel D. (1999) Scale economies and industry agglomeration externalities: A dynamic cost function approach. American Economic Review 89: 272-290.

Nakamura R. (2012) Contributions of local agglomeration to productivity: Stochastic frontier estimations from Japanese manufacturing firm data. Papers in regional Science 91: 569597.

Newman C. and Matthews A. (2006). The productivity performance of Irish dairy farms 1984-2000: a multiple output distance function approach. Journal of Productivity Analysis 26: 191-205. 
O'Donell C. (2014a) An economic approach to identifying the drivers of productivity change in the market sectors of the Australian economy. Centre for Efficiency and Productivity Analysis. Working paper Series No. WP02/2014.

O’Donell C. (2014b) Technologies, markets and behavior: Some implications for estimating efficiency and productivity change. Centre for Efficiency and Productivity Analysis. Working paper.

Orea L. and Kumbhakar S. (2004). Efficiency measurement using latent class stochastic frontier model. Empirical Economics 29: 169-183.

Patterson L. and Goldstein H. (1991), New Statistical Methods for Analyzing Social Structures: An Introduction to Multilevel Models, Br Educ Research J 17: 387-393.

Peeters A. (2008). Challenges for grassland-based systems and their production potential in Europe. Grassland Science in Europe 13: 9-24.

Pitt M. and Lee L. (1981), The Measurement and Sources of Technical Inefficiency in the Indonesian Weaving Industry, J Dev Econ 9: 43-64.

Porter M. (1990) The competitive advantage of nations: Free Press. New York.

Puig-Junoy D. (2001) Technical efficiency and public capital in the US states: A stochastic frontier approach. Journal of Regional Science 41: 75-96.

Reinhard S., Lovell K. and Thijssen. (1999). Econometric estimation of technical and environmental efficiency: An application to Dutch dairy farms. American Journal of Agricultural Economics 81: 44-60.

Rezitis A., Tsiboukas and Tsoukalas S. (2003), Investigation of Factors Influencing the Technical Efficiency of Agricultural Producers Participating in Farm Credit Programs: The Case of Greece, J Agric Appl Econ 35/3: 529-541.

Schimmelpfennig D. and Thirtle C. (1999) The internationalization of agricultural technology: Paterns, R\&D spillovers, and their effects on productivity in the European Union and United States. Contemporary Economic Policy 17(4) 457-468.

Schmidt A., Moreira A., Helfand S. and Foseca T. (2009), Spatial Stochastic Frontiers: Accounting for Unobserved Local Determinants of Efficiency, J Prod Anal 31: 101-112.

Schmidt P. and Sickles R. (1984), Production Frontiers and Panel Data, J Bus Econ Stat 2, 367-374.

Simpson J.R. and Conrad J.H. (1993). Intensification of cattle production systems in Central America: Why and when. Journal of Dairy Science 76:1744-1752.

Stypinski P. (2011) The effect of grassland-based forages on milk quality and quantity. Agronomy Research 9:479-488.

Swinnen J. (2009) Compensation payments in EU agriculture. Working paper Centre for Institutions and Economic Performance and Department of Economics University of Leuven and Centre for European Policies.

Tsionas E. (2002). Sthochastic frontier models with random coefficients. Journal of Applied Econometrics 17: 127-247. 
Tveteras R. and Battese G. (2006) Agglomeration externalities, productivity, and technical efficiency. Journal of Regional Science 46(4): 605-625.

Van den Broeck J., Koop G., Osiewalski J. and Steel M. (1994) Stochastic Frontier Models. A Bayesian Perspective, J Econom 61, 273-303.

Wang H. (2002), Heteroscedasticity and non-monotonic efficiency effects of a stochastic frontier model, J Prod Anal 18, 241-253.

Wang H. and Schmidt P. (2002), One Step and Two Step Estimation of the Effects of Exogenous Variables on Technical Efficiency Levels, J Prod Anal 18, 129-144.

West J.W. (2003). Effects of heat-stress on Production in dairy cattle. Journal of Dairy Science 86: 2131-2144. 


\section{APPENDIX 1.}

Appendix one shows Markov Chain Monte Carlo (MCMC) of models 1, 2 and 3.

\section{Model 1.}

Iterations of elasticities and inefficiency effects.
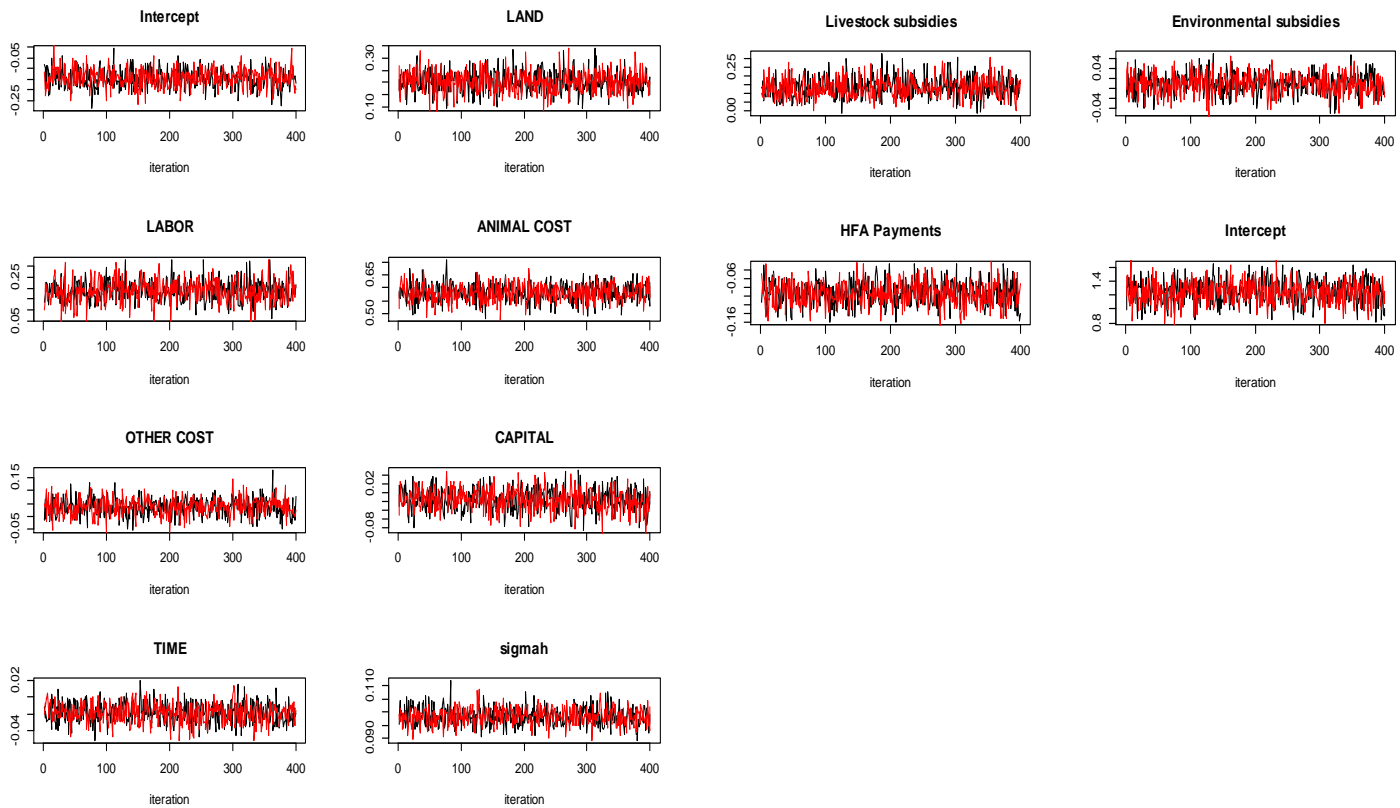

Correlograms of MCMC of elasticities, inefficiency effects and variances of random intercepts.
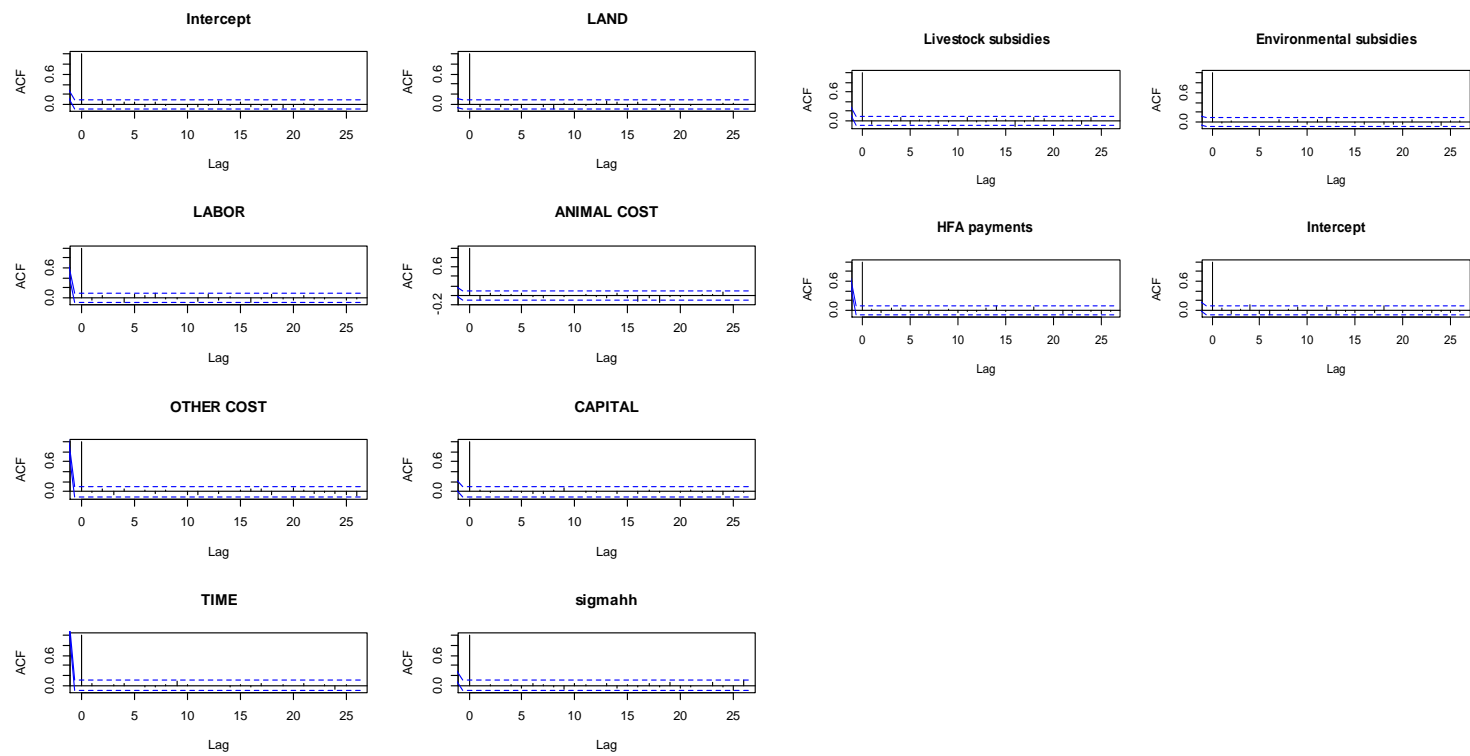


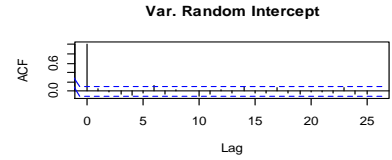

Var. Random LABOR

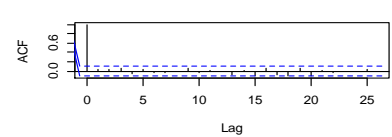

Var. Random OTHER COST

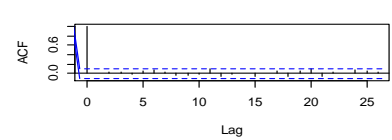

Var. Random TIME

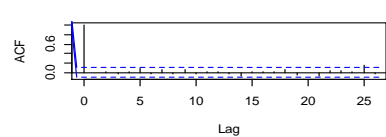

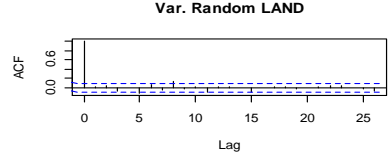

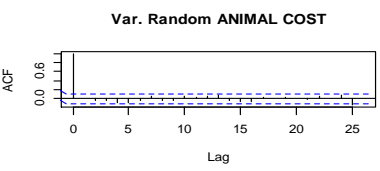

Var. Random CAPITAL

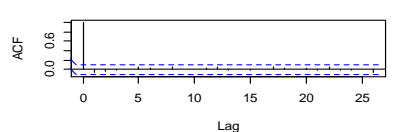

\section{Model 2.}

Iterations of elasticities and inefficiency effects.
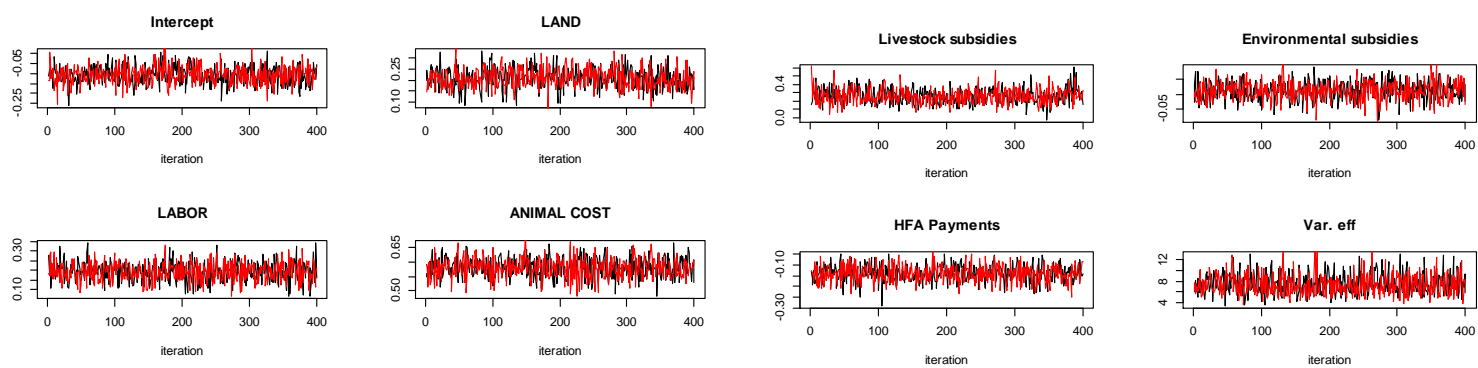

HFA Payments

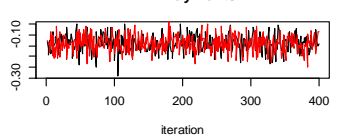

Var. eff

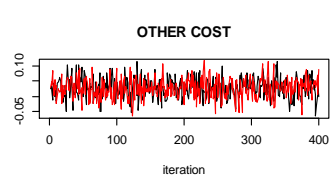

CAPITAL
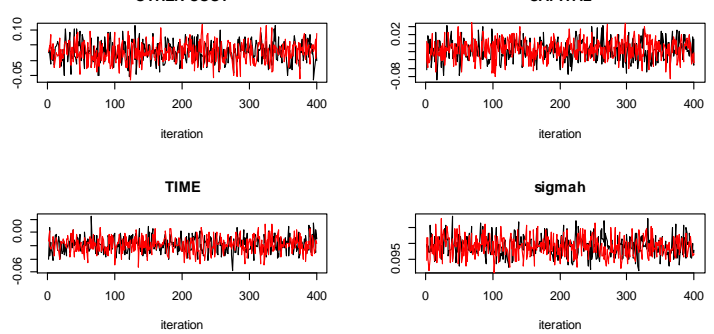

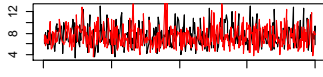
iteration 
Correlograms of MCMC of elasticities, inefficiency effects and variances of random intercepts.
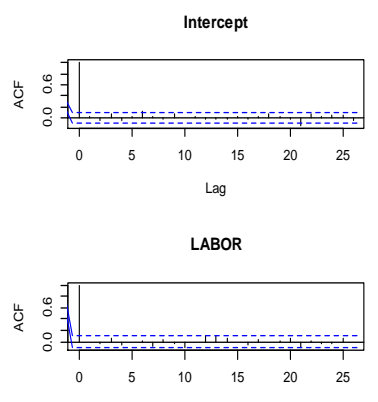

Lag

OTHER COST

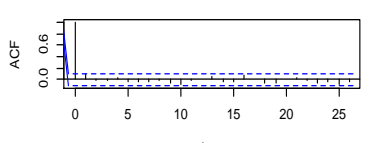

Lag

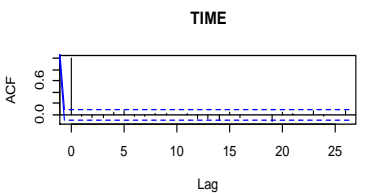

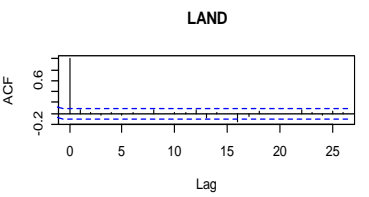

ANIMAL COST

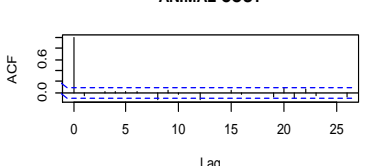

CAPITAL

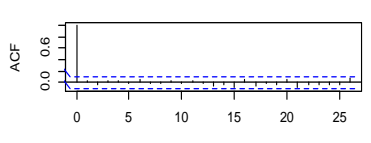

Lag

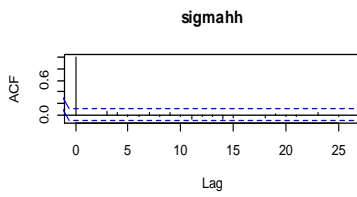

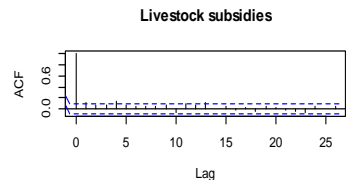

HFA Payments

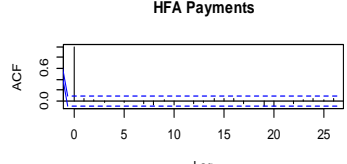

Lag

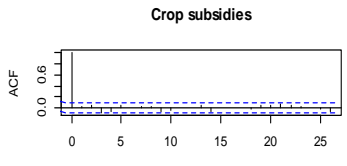

Lag

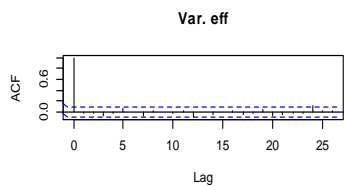

\section{Model 3.}

Iterations of elasticities and inefficiency effects.
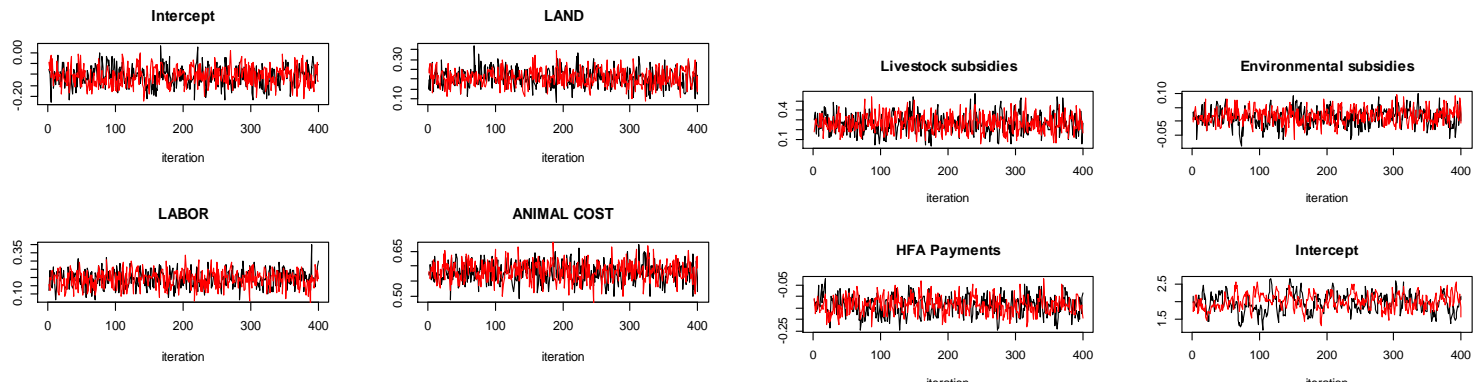

OTHER COST

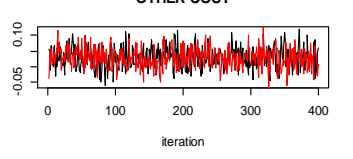

CAPITAL
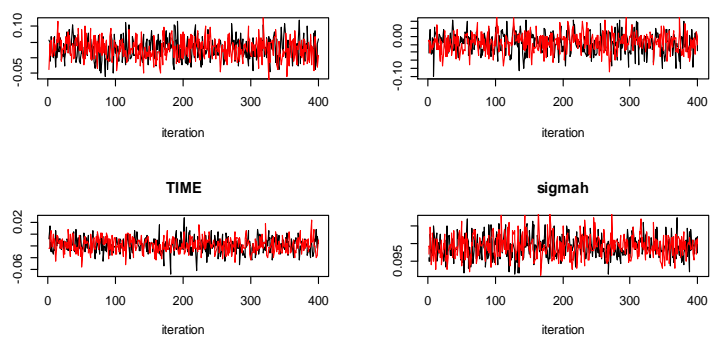
Correlograms of MCMC of elasticities, inefficiency effects and variances of random intercepts.
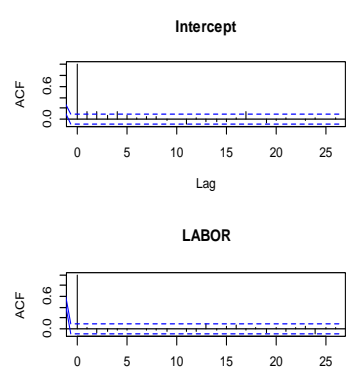

Lag

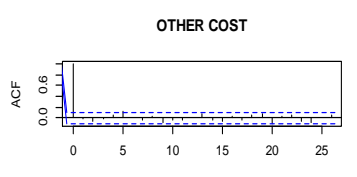

Lag

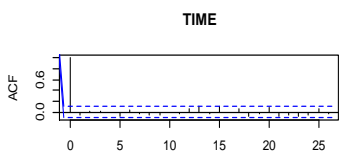

Lag
LAND

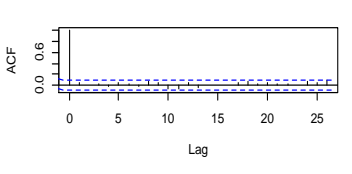

ANIMAL COST

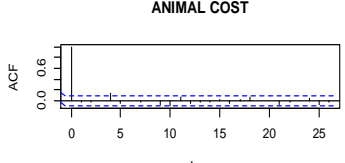

Lag
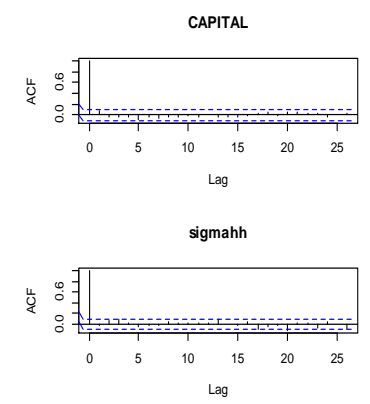
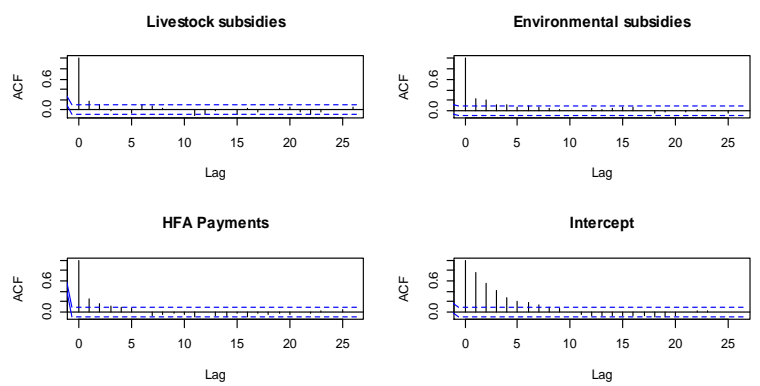

$(2+2$
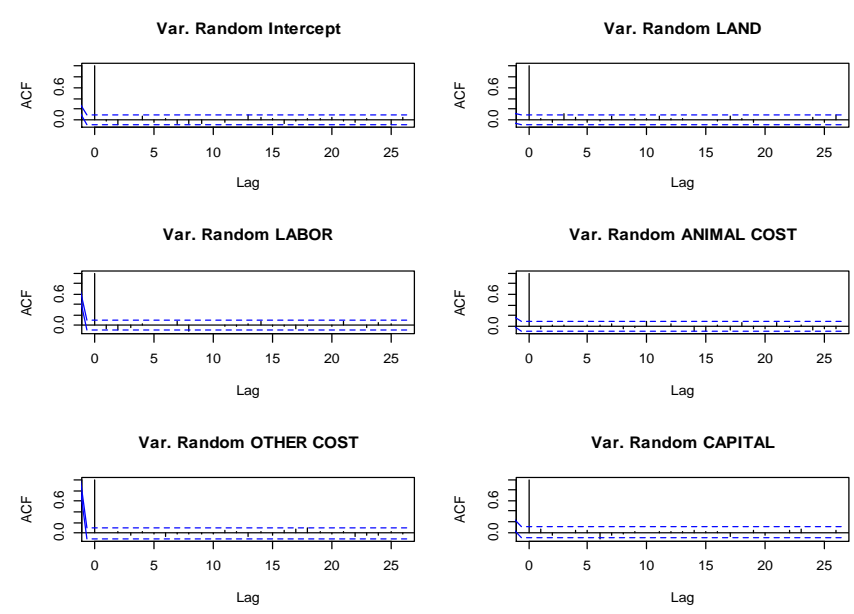

Var. Random CAPITAL

Var. Random TIME
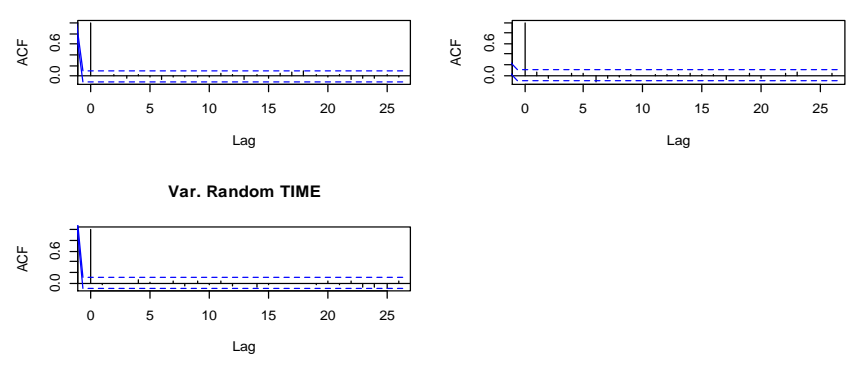


\section{APPENDIX 2.}

Results of Model 4 are presented. This model does not have a random coefficient in the production function. The prior distribution for the inefficiency term is the same as in Mode2.

\begin{tabular}{lc}
\hline \hline \multicolumn{1}{c}{ INPUT } & Model 4 \\
\hline Intercept & -0.017 \\
& $(0.032)$ \\
LAND & 0.173 \\
& $(0.028)$ \\
LABOR & 0.198 \\
& $(0.030)$ \\
LIVESTOCK COSTS & 0.590 \\
& $(0.024)$ \\
OTHER COSTS & 0.023 \\
& $(0.022)$ \\
CAPITAL & 0.005 \\
& $(0.014)$ \\
TREND & -0.017 \\
& $(0.003)$ \\
Precision* & 81.840 \\
& $(4.715)$ \\
\hline \multicolumn{2}{c}{ Inefficiency effects } \\
\hline Precision* & 5.142 \\
Iterations & -1.156 \\
Livestock sub. & 0.238 \\
Environmental sub. & $(0.091)$ \\
HFA payments & $(0.001$ \\
MiC & -0.081 \\
& $(0.035)$ \\
& 0.713 \\
& -1233.0 \\
& 920 \\
&
\end{tabular}

* Precision is the inverse of the variance. 


\section{Model 4.}

Iterations of elasticities and inefficiency effects.
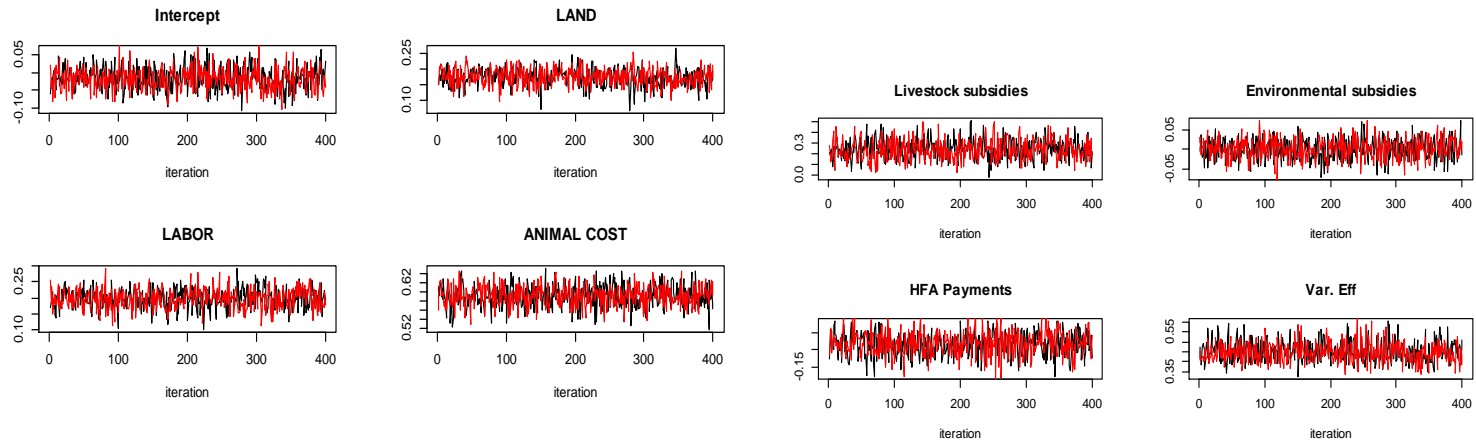

OTHER COST

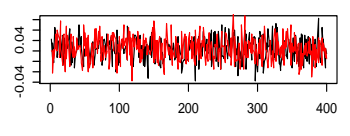

CAPITAL

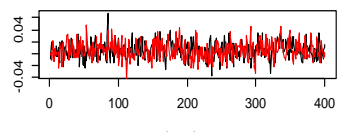

iteration

iteration

TIME

sigmah
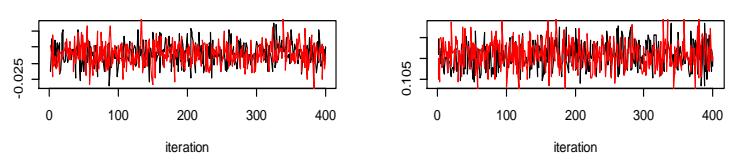

Correlograms of MCMC of elasticities and inefficiency effects.
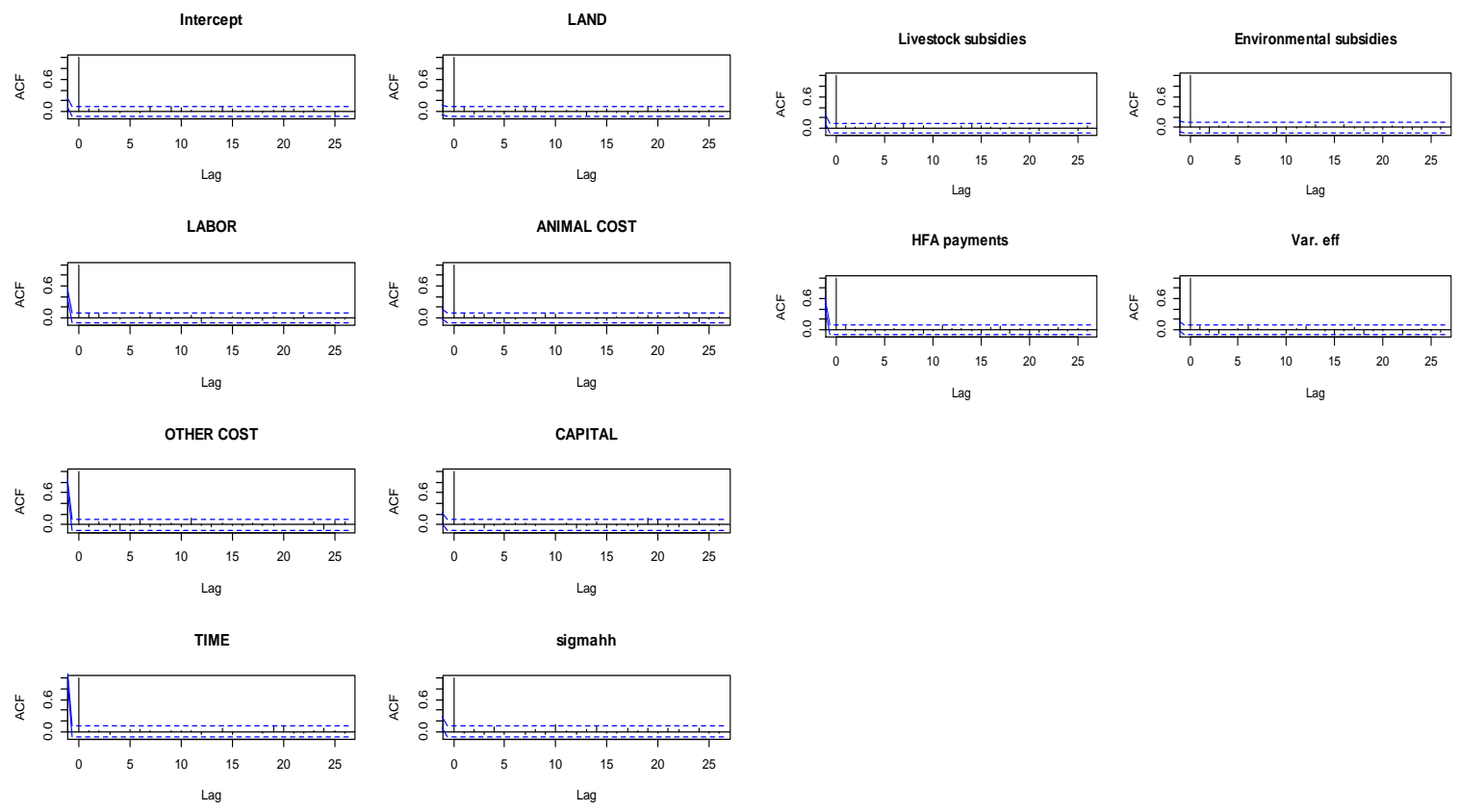
APPENDIX 3. Descriptive statistics per cluster.

\begin{tabular}{|c|c|c|c|c|c|c|}
\hline Variable & Unit & Cluster & Minimum & Mean & Maximum & $\begin{array}{c}\text { Standard } \\
\text { Deviation }\end{array}$ \\
\hline \multirow{16}{*}{ Output } & \multirow{16}{*}{$€$} & 1 & $9,761.0$ & $252,800.0$ & $5,953,000.0$ & $283,710.7$ \\
\hline & & 2 & 308.3 & $128,800.0$ & $1,793,000.0$ & $118,275.3$ \\
\hline & & 3 & 771.9 & $63,860.0$ & $918,700.0$ & $60,815.0$ \\
\hline & & 4 & $17,590.0$ & $359,500.0$ & $4,100,000.0$ & $297,369.6$ \\
\hline & & 5 & $19,150.0$ & $288,300.0$ & $7,640,000.0$ & $548,470.8$ \\
\hline & & 6 & 2,089.0 & $90,480.0$ & $5,869,000.0$ & $242,631.2$ \\
\hline & & 7 & $22,320.0$ & $212,400.0$ & $2,542,000.0$ & $132,580.1$ \\
\hline & & 8 & $1,970.0$ & $96,260.0$ & $2,573,000.0$ & $61,152.5$ \\
\hline & & 9 & 218.8 & $63,860.0$ & $1,100,000.0$ & $62,339.4$ \\
\hline & & 10 & $4,404.0$ & $129,600.0$ & $1,383,000.0$ & $86,800.9$ \\
\hline & & 11 & $7,817.0$ & $96,230.0$ & $6,020,000.0$ & $149,614.8$ \\
\hline & & 12 & $8,587.0$ & $53,310.0$ & $393,400.0$ & $32,430.1$ \\
\hline & & 13 & $9,536.0$ & $185,200.0$ & $5,903,000.0$ & $234,136.0$ \\
\hline & & 14 & $9,198.0$ & $81,950.0$ & $2,066,000.0$ & $72,253.1$ \\
\hline & & 15 & $4,902.0$ & $72,810.0$ & $494,200.0$ & $43,476.3$ \\
\hline & & 16 & $13,420.0$ & $172,900.0$ & $8,135,000.0$ & $427,007.1$ \\
\hline \multirow{16}{*}{ Land } & \multirow{16}{*}{ Hectares } & 1 & 5.1 & 35.5 & $2,186.0$ & 45.3 \\
\hline & & 2 & 5.0 & 26.2 & 383.0 & 25.4 \\
\hline & & 3 & 5.0 & 66.4 & $2,838.0$ & 120.8 \\
\hline & & 4 & 6.1 & 104.4 & 802.8 & 70.4 \\
\hline & & 5 & 6.9 & 120.3 & $3,016.0$ & 202.0 \\
\hline & & 6 & 5.0 & 21.0 & 902.0 & 32.2 \\
\hline & & 7 & 5.3 & 48.3 & 265.0 & 28.9 \\
\hline & & 8 & 5.3 & 70.0 & $1,385.0$ & 44.6 \\
\hline & & 9 & 5.0 & 22.5 & 705.3 & 25.6 \\
\hline & & 10 & 7.0 & 61.5 & 623.4 & 38.9 \\
\hline & & 11 & 5.8 & 53.9 & $1,767.0$ & 80.9 \\
\hline & & 12 & 5.2 & 38.3 & 795.5 & 36.7 \\
\hline & & 13 & 5.6 & 65.3 & $2,137.0$ & 81.5 \\
\hline & & 14 & 5.1 & 25.2 & 583.7 & 39.5 \\
\hline & & 15 & 5.0 & 27.5 & 187.2 & 16.5 \\
\hline & & 16 & 6.3 & 83.1 & $4,235.0$ & 208.0 \\
\hline
\end{tabular}




\begin{tabular}{|c|c|c|c|c|c|c|}
\hline Variable & Unit & Cluster & Minimum & Mean & Maximum & $\begin{array}{c}\text { Standard } \\
\text { Deviation }\end{array}$ \\
\hline \multirow{16}{*}{ Labor } & \multirow{16}{*}{ Hours/year } & 1 & $1,050.0$ & $6,376.0$ & $65,670.0$ & $3,625.6$ \\
\hline & & 2 & 720.0 & $4,462.0$ & $43,680.0$ & $2,452.8$ \\
\hline & & 3 & 560.0 & $4,959.0$ & $21,350.0$ & $2,618.4$ \\
\hline & & 4 & $1,050.0$ & $4,976.0$ & $59,670.0$ & $3,699.9$ \\
\hline & & 5 & $1,100.0$ & $6,978.0$ & $291,700.0$ & $15,247.9$ \\
\hline & & 6 & 940.0 & $4,069.0$ & $138,900.0$ & $4,034.3$ \\
\hline & & 7 & 756.0 & $4,347.0$ & $65,050.0$ & $1,965.9$ \\
\hline & & 8 & $1,025.0$ & $3,679.0$ & $135,900.0$ & $2,442.6$ \\
\hline & & 9 & 747.0 & $3,801.0$ & $36,030.0$ & $1,912.4$ \\
\hline & & 10 & $1,051.0$ & $3,803.0$ & $26,520.0$ & $1,892.7$ \\
\hline & & 11 & $1,000.0$ & $4,074.0$ & $347,000.0$ & $6,961.1$ \\
\hline & & 12 & 981.0 & $4,288.0$ & $31,910.0$ & $1,561.6$ \\
\hline & & 13 & $1,000.0$ & $4,397.0$ & $232,000.0$ & $7,555.5$ \\
\hline & & 14 & 936.0 & $4,440.0$ & $29,700.0$ & $1,912.9$ \\
\hline & & 15 & $1,114.0$ & $3,783.0$ & $12,550.0$ & $1,257.2$ \\
\hline & & 16 & 960.0 & $5,923.0$ & $374,400.0$ & $15,047.8$ \\
\hline \multirow{16}{*}{ Feed cost } & \multirow{16}{*}{$€$} & 1 & $3,130.0$ & $86,070.0$ & $1,832,000.0$ & $101,407.8$ \\
\hline & & 2 & 468.3 & $53,880.0$ & $861,800.0$ & $49,810.6$ \\
\hline & & 3 & $1,604.0$ & $21,960.0$ & $249,600.0$ & $19,078.9$ \\
\hline & & 4 & $4,238.0$ & $88,480.0$ & $1,665,000.0$ & $86,679.1$ \\
\hline & & 5 & 3.5 & $54,290.0$ & $1,754,000.0$ & $120,328.6$ \\
\hline & & 6 & 115.4 & $26,190.0$ & $2,693,000.0$ & $81,351.4$ \\
\hline & & 7 & $1,354.0$ & $33,260.0$ & $378,600.0$ & $22,377.0$ \\
\hline & & 8 & 326.2 & $15,530.0$ & $600,800.0$ & $12,354.7$ \\
\hline & & 9 & 671.7 & $22,290.0$ & $589,800.0$ & $22,546.9$ \\
\hline & & 10 & 0.9 & $17,050.0$ & $162,500.0$ & $12,537.5$ \\
\hline & & 11 & 4.5 & $13,680.0$ & $649,600.0$ & $22,090.9$ \\
\hline & & 12 & 7.6 & $5,870.0$ & $61,690.0$ & $4,985.5$ \\
\hline & & 13 & 7.7 & $38,060.0$ & $1,145,000.0$ & $49,423.7$ \\
\hline & & 14 & $2,543.0$ & $30,510.0$ & $349,400.0$ & $24,006.9$ \\
\hline & & 15 & 157.2 & $9,576.0$ & $64,170.0$ & $7,280.0$ \\
\hline & & 16 & $1,279.0$ & $33,660.0$ & $1,442,000.0$ & $89,104.1$ \\
\hline
\end{tabular}




\begin{tabular}{|c|c|c|c|c|c|c|}
\hline Variable & Unit & Cluster & Minimum & Mean & Maximum & $\begin{array}{l}\text { Standard } \\
\text { Deviation }\end{array}$ \\
\hline \multirow{16}{*}{ Farm expenses } & \multirow{16}{*}{$€$} & 1 & $1,512.0$ & $48,090.0$ & $1,672,000.0$ & $62,174.9$ \\
\hline & & 2 & 464.0 & $24,630.0$ & $358,600.0$ & $25,306.9$ \\
\hline & & 3 & 258.6 & $16,690.0$ & $403,400.0$ & $19,900.4$ \\
\hline & & 4 & $5,405.0$ & $80,820.0$ & $926,700.0$ & $59,752.9$ \\
\hline & & 5 & $3,163.0$ & $89,080.0$ & $3,024,000.0$ & $163,242.8$ \\
\hline & & 6 & 760.4 & $15,880.0$ & $2,162,000.0$ & $46,264.3$ \\
\hline & & 7 & $6,036.0$ & $59,520.0$ & $668,700.0$ & $34,978.2$ \\
\hline & & 8 & 687.7 & $33,900.0$ & $997,700.0$ & $23,654.7$ \\
\hline & & 9 & 257.3 & $10,900.0$ & $288,300.0$ & $12,467.8$ \\
\hline & & 10 & $2,369.0$ & $40,780.0$ & $522,400.0$ & $30,991.2$ \\
\hline & & 11 & $4,514.0$ & $38,320.0$ & $3,089,000.0$ & $63,172.7$ \\
\hline & & 12 & $3,935.0$ & $23,690.0$ & $159,000.0$ & $13,848.5$ \\
\hline & & 13 & $3,532.0$ & $51,030.0$ & $2,024,000.0$ & $71,544.3$ \\
\hline & & 14 & $1,590.0$ & $20,350.0$ & $296,200.0$ & $16,061.7$ \\
\hline & & 15 & $5,212.0$ & $29,420.0$ & $139,500.0$ & $16,500.4$ \\
\hline & & 16 & $4,233.0$ & $65,030.0$ & $2,710,000.0$ & $147,035.5$ \\
\hline \multirow{16}{*}{ Cows } & \multirow{16}{*}{ Number of cows } & 1 & 3.8 & 72.1 & $1,427.0$ & 74.7 \\
\hline & & 2 & 4.0 & 48.2 & 527.0 & 35.7 \\
\hline & & 3 & 2.7 & 24.9 & 200.0 & 19.7 \\
\hline & & 4 & 5.5 & 100.9 & 996.0 & 69.3 \\
\hline & & 5 & 4.0 & 86.6 & $1,842.0$ & 142.1 \\
\hline & & 6 & 3.0 & 40.1 & $2,165.0$ & 84.4 \\
\hline & & 7 & 7.8 & 67.0 & 619.0 & 40.2 \\
\hline & & 8 & 4.0 & 42.9 & 692.1 & 22.5 \\
\hline & & 9 & 3.0 & 30.8 & 608.0 & 27.3 \\
\hline & & 10 & 6.8 & 49.3 & 345.5 & 28.8 \\
\hline & & 11 & 5.1 & 38.4 & $1,555.0$ & 52.2 \\
\hline & & 12 & 4.0 & 17.9 & 130.0 & 10.6 \\
\hline & & 13 & 4.2 & 64.4 & $1,256.0$ & 61.5 \\
\hline & & 14 & 2.0 & 25.4 & 288.3 & 18.7 \\
\hline & & 15 & 6.2 & 27.8 & 157.1 & 15.9 \\
\hline & & 16 & 4.5 & 50.6 & $2,100.0$ & 98.4 \\
\hline
\end{tabular}

Source: Own calculation. 